\title{
Polyprotic Acids and Beyond-An Algebraic Approach
}

\author{
Harald Kalka
}

check for

updates

Citation: Kalka, H. Polyprotic Acids and Beyond-An Algebraic Approach. Chemistry 2021, 3, 454-508. https: / / doi.org/10.3390/chemistry3020034

Academic Editor: Edwin

Charles Constable

Received: 3 March 2021

Accepted: 19 March 2021

Published: 7 April 2021

Publisher's Note: MDPI stays neutral with regard to jurisdictional claims in published maps and institutional affiliations.

Copyright: (C) 2021 by the author. Licensee MDPI, Basel, Switzerland. This article is an open access article distributed under the terms and conditions of the Creative Commons Attribution (CC BY) license (https:/ / creativecommons.org/licenses/by/ $4.0 /)$.
Umwelt- und Ingenieurtechnik GmbH Dresden (UIT), Zum Windkanal 21, 01109 Dresden, Germany; h.kalka@uit-gmbh.de

\begin{abstract}
For an N-protic acid-base system, the set of nonlinear equations (i.e., mass action and balance laws) provides a simple analytical solution/formula for any integer $\mathrm{N} \geq 1$. The approach is applicable for the general case of zwitterionic acids $\mathrm{H}_{\mathrm{N}} \mathrm{A}^{+\mathrm{Z}}$ (e.g., amino acids, NTA, and EDTA), which includes (i) the "ordinary acids" as a special case $(Z=0)$ and (ii) surface complexation. Examples are presented for $\mathrm{N}=1$ to 6 . The high-N perspective allows the classification of equivalence points (including isoionic and isoelectric points). Principally, there are two main approaches to N-protic acids: one from hydrochemistry and one "outside inorganic hydrochemistry". They differ in many ways: the choice of the reference state (either $\mathrm{H}_{\mathrm{N}} \mathrm{A}$ or $\mathrm{A}^{-\mathrm{N}}$ ), the reaction type (dissociation or association), the type/nature of the acidity constants, and the structure of the formulas. Once the (nonlinear) conversion between the two approaches is established, we obtain a systematics of acidity constants (macroscopic, microscopic, cumulative, and Simms). Finally, from the viewpoint of statistical mechanics (canonical isothermal-isobaric ensemble), buffer capacities, buffer intensities, and higher $\mathrm{pH}$ derivatives are actually fluctuations in the form of variance, skewness, and kurtosis.
\end{abstract}

Keywords: polyprotic acids; acid-base equilibria; titration; buffer capacity; equivalence points; zwitterions; alkalinity; amino acids; surface complexation

\section{Introduction \\ 1.1. State of the Art}

The subject of acid-base equilibria is covered in an extensive bibliography, usually focusing on mono- and diprotic acids, which is the entry point to understanding chemical equilibrium reactions per se. The list of classical textbooks and monographies is long and stems from various subfields, such as hydrochemistry [1-3] as well as general and analytical chemistry [4-7]. This is accompanied with several modeling approaches, e.g., [8-10].

For the general case of aquatic systems (as mixtures of any number of acids and bases plus solid and gaseous phases), there are two prototypes of numerical approaches: (i) models that are based on the law of mass action (e.g., PhreeqC [11] and many others) and (ii) models that are based on Gibbs energy minimization (GEM) [12,13].

The mathematical description of polyprotic acids (with $\mathrm{N} \geq 3$ ) is a special topic that extends the traditional view on acid-base reactions. Algebraic equations are presented in [14-20]; their application to titration and buffer capacities can be found in [21-24] and in [25-30]. Many of the developments come from areas outside conventional hydrochemistry (e.g., org/bio/med chemistry), which is the playground of proton-binding macromolecules such as nucleic acids and fulvic/humic acids. This also encourages a statistical description [31-34].

There are two principal ways of mathematical description: (i) the hydrochemical approach (based on dissociation reactions with reference state $\mathrm{H}_{\mathrm{N}} \mathrm{A}$ ) and (ii) the approach employed in organic and biochemistry (based on association reactions with reference state $\left.A^{-N}\right)$. The present review follows the first approach; the interrelation with the second approach is established in Section 2.5. The latter provides an overview of different types of equilibrium constants (macroscopic, cumulative, microscopic) used today in acid-base theory-see Section 2.5.7. 
The question whether a polyprotic acid $\mathrm{H}_{\mathrm{N}} \mathrm{A}$ can be represented as a sum of $\mathrm{N}$ monoprotic acids is answered in Sections 2.5.5 and 2.5.6 by factorizing the partition function of the canonical isothermal-isobaric ensemble. This is equivalent to the "quasiparticle-like" concept of $\mathrm{N}$ noninteracting proton-binding sites, known as decoupled sites representation (DSR) [33,34].

Titration and buffer capacities are summarized in an excellent review article by Asuero and Michałowski [26]. This and other papers [24-30] rely on association reactions (with reference state $\left.A^{-N}\right)$, so one has to be careful when comparing the formulas with the present approach. Additionally, most of these papers take the dilution during titration into account by explicitly using the volume of the titrant. This effect is ignored in this review to keep the formulas simple.

\subsection{Motivation}

Today, computers solve nonlinear systems numerically in the shortest time with high quality, which is a great help in dealing with complex real-world tasks (and we are grateful for that). However, by delegating everything to computers, we sometimes lose the overview of the underlying principles and functional relationships (digital data are too incomplete/imprecise to understand the deeper aspects of reality).

Starting from the laws of mass action and mass/charge balance, a mathematical solution is provided in the form of simple and smooth analytical formulas for acid-base reactions. This is performed for the general case of $\mathrm{N}$-protic acids, where $\mathrm{N}$ can be any integer $(N \geq 1)$. The approach applies to the broad class of zwitterionic acids $\mathrm{H}_{\mathrm{N}} \mathrm{A}^{+\mathrm{Z}}$ (amino acids, NTA, EDTA, etc.), which embeds all "ordinary acids" as a special subclass characterized by $\mathrm{Z}=0$.

There are at least five questions:

1. Why do we need equations/formulas for $\mathrm{N}>3$ ?

2. Is the approach mathematically strict/rigorous?

3. What is the difference to standard approaches celebrated in textbooks?

4. What does it mean to be a simple and smooth analytical formula?

5. This report contains more than 100 formulas. What is the central formula?

Answer 1. Usually (and this is the first that comes to mind) $\mathrm{N}$ is a small number: 1, 2 or 3 for monoprotic, diprotic and triprotic acids. However, in reality, there are compounds with more protons (e.g., EDTA with $\mathrm{N}=6$ in Section 4.1.6 or other macromolecules in biochemistry and/or mixtures thereof). Moreover, when treating $\mathrm{N}$ as a variable integer, the equations tell us things that might otherwise be non-obvious (e.g., classification of equivalence points in Section 2.3).

Answer 2. The mathematical derivation is strict/rigorous. For this purpose, it is assumed that the activities (that enter the mass action laws) are replaced by molar concentrations, which is justified either for dilute systems or for non-dilute systems using conditional equilibrium constants (c.f. seawater example in Section 3.3.5). Deviations in the analytical model from numerical activity-based calculations are discussed in Section 3.3.6.

Answer 3. In standard textbooks [1-6], an algebraic solution of the acid-base problem is usually provided for diprotic acids $(\mathrm{N}=2)$ in implicit form, namely as a polynomial of degree 4 in $x=10^{-\mathrm{pH}}$ (quartic equation!)—see, e.g., [1] (p. 107) or Equation (46) below. That is the common way to handle the acid-base problem. In the general case of N-protic acids, this procedure leads to polynomials of order $\mathrm{N}+2$, where, for $\mathrm{N}>4$, there is principally no algebraic solution (according to the Abel-Ruffini theorem). This dilemma will be avoided in the present approach. However, before we start, let us explain this in another way.

In titration, a titrant (strong base of amount $\mathrm{C}_{\mathrm{B}}$ ) is added to the analyte (N-protic acid with amount $\mathrm{C}_{\mathrm{T}}$ ), resulting in a certain $\mathrm{pH}$ value. So, one is tempted to write the $\mathrm{pH}$ as a function of $\mathrm{C}_{\mathrm{T}}$ and $\mathrm{C}_{\mathrm{B}}$ (or $\left.\mathrm{n}=\mathrm{C}_{\mathrm{B}} / \mathrm{C}_{\mathrm{T}}\right)$, that is: $\mathrm{pH}=\mathrm{pH}$ (analyte, titrant) $=\mathrm{pH}\left(\mathrm{C}_{\mathrm{T}}, \mathrm{C}_{\mathrm{B}}\right)$ or $\mathrm{pH}=\mathrm{pH}\left(\mathrm{C}_{\mathrm{T}}, \mathrm{n}\right)$. However, as mentioned above, these relations cannot be expressed in the form of an explicit function; they only exist implicitly in the form of polynomials of degree $\mathrm{N}$ +2 (see Equation (44)). So we put the whole thing "from head to toe" by providing a strict 
algebraic solution in the form of the explicit function $n=n\left(C_{T}, p H\right)$, or shorter $n=n(x)$. The polynomials are then considered as the inverse task in Section 2.2.3.

Answer 4. "Simple" means that the analytical formula(s) is (are) easy to handle in a Lego-like manner from plain constructs, as summarized in Section 5 at the end of this report. There is no need for programming or root-solving methods. All results/diagrams in this report were created with Excel, and anyone can easily reproduce them.

"Smooth" means that the analytical formula $\mathrm{n}=\mathrm{n}(\mathrm{x})$ - as well as its building blocksare infinitely derivable functions that offer calculus in the form of $\mathrm{pH}$ derivatives and integrals (a feature that is not possible for numerical solutions/data). The $\mathrm{pH}$ derivatives convert buffer capacities to buffer intensities; $\mathrm{pH}$ derivatives are also used to identify equivalence points (EPs) as local minima/maxima and/or inflection points.

Answer 5. The central formula is the equivalent fraction $\mathrm{n}=\mathrm{Y}_{1}+\mathrm{w} / \mathrm{C}_{\mathrm{T}}$ (symbols are explained in the text), which contains all information about the acid-base system in condensed form. As sketched in Figure 1, depending on whether $\mathrm{n}$ is a specific discrete number or a real function, different aspects appear: the equivalence points (as special/exceptional equilibrium states) or buffer capacities as "distances" between two equilibrium states. In this report, the function $\mathrm{n}(\mathrm{x})$ appears under several names: equivalence fraction, titration function/curve, and normalized buffer capacity (because it measures the distance to $\mathrm{EP}_{0}$ ).

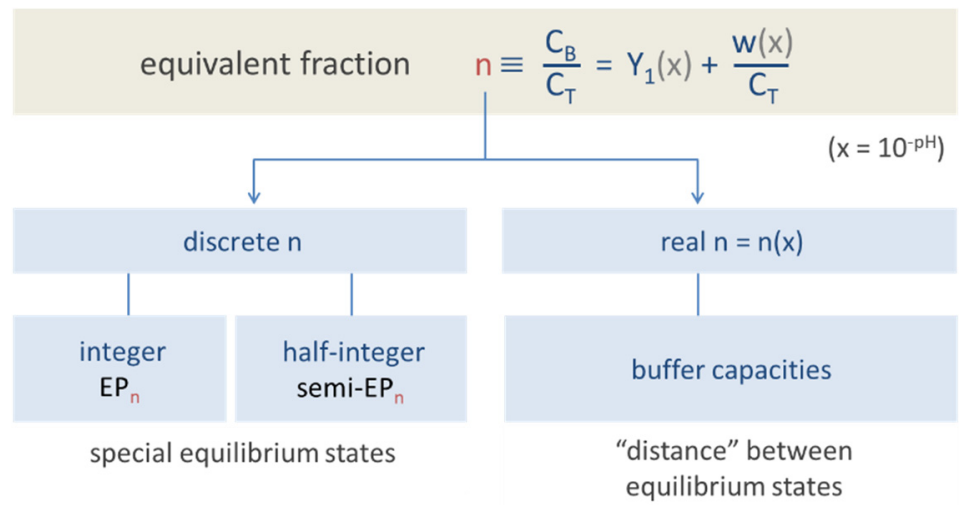

Figure 1. Equivalent fraction as the central quantity from which all other formulas follow.

\subsection{Structure of this Report}

The report consists of three main parts/sections: (i) the mathematical framework (see also Figure 2), (ii) its application (including the discussion of alternative concepts and common approximations), and (iii) the extension of the approach to zwitterions and surface complexation.

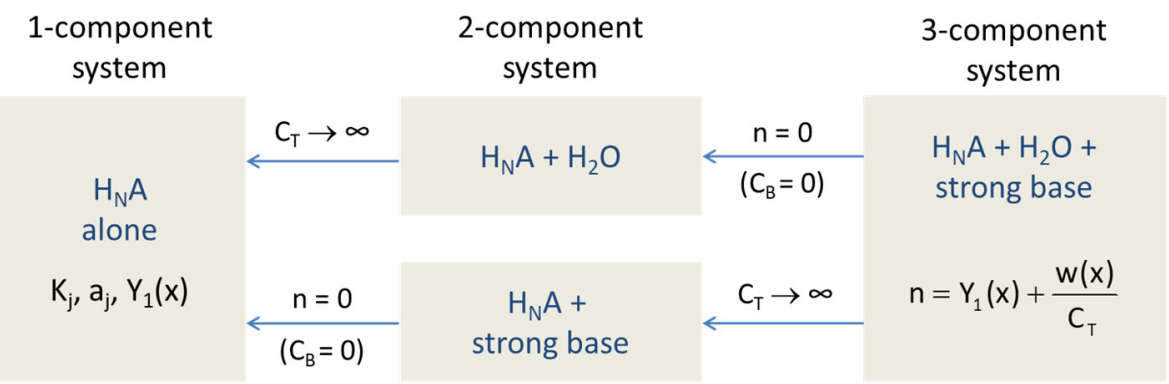

Figure 2. Relationships between 1-, 2-, and 3-component systems.

The goal of Section 2 is to bundle a set of $\mathrm{N}+3$ nonlinear equations into an analytical formula. We start with the 1-component system in Section 2.1, i.e., the $\mathrm{N}$-protic acid itself, which is fully determined by $\mathrm{N}$ acidity constants $\mathrm{K}_{1}$ to $\mathrm{K}_{\mathrm{N}}$. In Section 2.2, the 1-component system is extended to a 3-component acid-base system, which opens the door to the description of acid-base titrations. After discussion/classification of equivalence 
points in Section 2.3, buffer capacities and buffer intensities are introduced in Section 2.4. Regarding the connection between the three subsystems in Figure 2, the numbers $1 / C_{T}$ and $C_{B} / C_{T}$ act as "coupling constants" of the acid to the water (autoprotolysis) and to the base. Section 2.5 embeds the present mathematical approach into alternative concepts "outside" traditional hydrochemistry.

In Sections 2 and 3, example calculations are performed for four common acids listed in Table 1. In fact, the beauty and elegance of the acid-base behavior/equations is best illustrated in diagrams, and this is used extensively in this report. In Section 4, the mathematical description is applied beyond the realm of ordinary acids to zwitterions and surface complexation.

Table 1. $\mathrm{pK}$ values for four $\mathrm{N}$-protic acids at $25^{\circ} \mathrm{C}$. (The composite carbonic acid is the sum of the unionized species $\mathrm{CO}_{2}(\mathrm{aq})$ and the pure acid: $\mathrm{H}_{2} \mathrm{CO}_{3}{ }^{*}=\mathrm{CO}_{2}(\mathrm{aq})+\mathrm{H}_{2} \mathrm{CO}_{3}$; to simplify the notation, we omit the asterisk ${ }^{*}$ ) on $\mathrm{H}_{2} \mathrm{CO}_{3}{ }^{*}$ throughout the paper).

\begin{tabular}{llcccccc}
\hline $\mathbf{N}$ & Acid & Formula & Type & $\mathbf{p K}_{\mathbf{1}}$ & $\mathbf{p K}_{\mathbf{2}}$ & $\mathbf{p K}_{\mathbf{3}}$ & Ref. \\
\hline 1 & acetic acid & $\mathrm{CH}_{3} \mathrm{COOH}$ & $\mathrm{HA}$ & 4.76 & & & {$[35]$} \\
2 & (composite) carbonic acid & $\mathrm{H}_{2} \mathrm{CO}_{3}$ & $\mathrm{H}_{2} \mathrm{~A}$ & 6.35 & 10.33 & {$[36]$} \\
3 & phosphoric acid & $\mathrm{H}_{3} \mathrm{PO}_{4}$ & $\mathrm{H}_{3} \mathrm{~A}$ & 2.15 & 7.12 & 12.35 & {$[35]$} \\
3 & citric acid & $\mathrm{C}_{6} \mathrm{H}_{8} \mathrm{O}_{7}$ & $\mathrm{H}_{3} \mathrm{~A}$ & 3.13 & 4.76 & 6.4 & {$[35]$} \\
\hline
\end{tabular}

\section{Mathematical Framework}

\subsection{The 1-Component System: $N$-Protic Acid $\left(H_{N} A\right)$}

\subsubsection{Notation}

An acid is a proton donor; it releases $\mathrm{H}^{+}$ions (more precisely: $\mathrm{H}_{3} \mathrm{O}^{+}$) when dissolved in water:

$$
\mathrm{HA}=\mathrm{H}^{+}+\mathrm{A}^{-}
$$

which is a shorthand for $\mathrm{HA}(\mathrm{aq})+\mathrm{H}_{2} \mathrm{O}(\mathrm{l})=\mathrm{H}_{3} \mathrm{O}^{+}(\mathrm{aq})+\mathrm{A}^{-}(\mathrm{aq})$. An N-protic acid $\mathrm{H}_{\mathrm{N}} \mathrm{A}$ dissolves into $\mathrm{N}+1$ species:

1 undissociated species: $\quad \mathrm{H}_{\mathrm{N}} \mathrm{A}^{0}$

$\mathrm{N}$ dissociated species: $\quad \mathrm{H}_{\mathrm{N}-1} \mathrm{~A}^{-1}, \ldots, \mathrm{HA}^{-(\mathrm{N}-1)}, \mathrm{A}^{-\mathrm{N}}$

(uncharged)

(anions)

To simplify the notation, we abbreviate the molar concentrations of the $\mathrm{N}+1$ acid species with:

$$
[\mathrm{j}] \equiv\left[\mathrm{H}_{\mathrm{N}-\mathrm{j}} \mathrm{A}^{-\mathrm{j}}\right] \quad \text { for } \quad \mathrm{j}=0,1,2, \ldots \mathrm{N}
$$

The integer $j$ also labels the electric charge of the species $\left(z_{j}=0-j\right)$. Thus, the neutral, undissociated species $\mathrm{H}_{\mathrm{N}} \mathrm{A}^{0}$ is abbreviated with [0]. Henceforth we skip the superscript 0 in $\mathrm{H}_{\mathrm{N}} \mathrm{A}^{0}$.

In each successive dissociation step, $\mathrm{j}$ is enhanced by 1 (due to the release of one $\mathrm{H}^{+}$):

$$
\text { jth dissociation step: } \quad[j-1] \rightarrow[j]
$$

The corresponding conjugate acid-base pair is composed of

$$
\left.\begin{array}{lc}
\text { acid : } & {[j-1]} \\
\text { ugate base : } & {[j]}
\end{array}\right\} \text { of } j \text { th dissociation step }
$$

The sum of all species is the acid's total amount $\mathrm{C}_{\mathrm{T}}$ :

$$
\mathrm{C}_{\mathrm{T}} \equiv\left[\mathrm{H}_{\mathrm{N}} \mathrm{A}\right]_{\mathrm{T}}=\sum_{\mathrm{j}=0}^{\mathrm{N}}[\mathrm{j}]=[0]+[1]+\ldots+[\mathrm{N}] \text { (mass balance) }
$$

Note: The total concentration $\mathrm{C}_{\mathrm{T}}=\left[\mathrm{H}_{\mathrm{N}} \mathrm{A}\right]_{\mathrm{T}}$ should not be confused with the molar concentration of the undissociated species $\left[\mathrm{H}_{\mathrm{N}} \mathrm{A}\right]$. 
In chemical thermodynamics, one has to distinguish between molar concentrations and activities:

concentrations: denoted by square brackets [j]

activities denoted by curly braces

As discussed in Appendix B, activities are "effective concentrations" calculated from the molar concentrations using semi-empirical activity corrections $\gamma_{\mathrm{j}}$ :

$$
\{j\}=\gamma_{j}[j]
$$

The activity corrections $\gamma_{\mathrm{j}}$ increase with the ionic strength $I$ of the solution. In ideal or nearly-ideal solutions (i.e., diluted systems), we have $I \approx 0$ and $\gamma_{\mathrm{j}} \approx 1$, so the activities and concentrations become equal.

The activity of $\mathrm{H}^{+}$is abbreviated with $\mathrm{x}$; it is linked to the $\mathrm{pH}$ value via:

$$
\mathrm{x} \equiv\left\{\mathrm{H}^{+}\right\}=10^{-\mathrm{pH}} \quad \Leftrightarrow \quad \mathrm{pH}=-\lg \mathrm{x}
$$

Using $\mathrm{x}$ instead of $\mathrm{pH}$ simplifies the formulas considerably. For the sake of simplicity, we speak about $p H$ dependence when a function or quantity depends on $\mathrm{x}, \mathrm{f}=\mathrm{f}(\mathrm{x})$.

The self-ionization of water (autoprotolysis) is defined by

$$
\mathrm{H}_{2} \mathrm{O}=\mathrm{H}^{+}+\mathrm{OH}^{-} \quad \text { with } \quad \mathrm{K}_{\mathrm{w}}=\left\{\mathrm{H}^{+}\right\}\left\{\mathrm{OH}^{-}\right\}
$$

and $\mathrm{K}_{\mathrm{w}}=1.0 \times 10^{-14}$ at $25^{\circ} \mathrm{C}$. This yields $\left[\mathrm{OH}^{-}\right] \approx\left\{\mathrm{OH}^{-}\right\}=\mathrm{K}_{\mathrm{w}} / \mathrm{x}$.

In this context, we introduce the quantity $\mathrm{w}(\mathrm{x})$ (in combination with the approximation $\left.\gamma_{\mathrm{H}} \approx 1\right):$

$$
\mathrm{w}(\mathrm{x}) \equiv\left[\mathrm{OH}^{-}\right]-\left[\mathrm{H}^{+}\right]=\frac{\mathrm{K}_{\mathrm{w}}}{\mathrm{x}}-\frac{\mathrm{x}}{\gamma_{\mathrm{H}}} \approx \frac{\mathrm{K}_{\mathrm{w}}}{\mathrm{x}}-\mathrm{x}
$$

For pure water, we have $\mathrm{w}=0$. As we will see later, the quotient $\mathrm{w} / \mathrm{C}_{\mathrm{T}}$ is the term which couples the polyprotic acid to $\mathrm{H}_{2} \mathrm{O}$. This term vanishes in the so-called

$$
\text { high- } \mathrm{C}_{\mathrm{T}} \text { limit: } \mathrm{C}_{\mathrm{T}} \gg \mathrm{w}(\mathrm{x})\left(\text { or } \mathrm{C}_{\mathrm{T}} \rightarrow \infty\right)
$$

and removes the component " $\mathrm{H}_{2} \mathrm{O}$ " from the 3-component acid-base system, as shown in Figure 2. A list of all abbreviations and symbols is given in Appendix A.

\subsubsection{Acidity Constants and Dissociation Reactions}

The equilibrium constant of reaction (1) is called acidity constant; it exists in (at least) two modifications:

$$
\begin{array}{rll}
\text { (thermodynamic) acidity constant : } & \mathrm{K}_{\mathrm{a}}=\frac{\left\{\mathrm{H}^{+}\right\}\left\{\mathrm{A}^{-}\right\}}{\{\mathrm{HA}\}} & \text { (based on activities) } \\
\text { conditional acidity constant (of mixed type) : } & { }^{c} \mathrm{~K}_{\mathrm{a}}=\frac{\left\{\mathrm{H}^{+}\right\}\left[\mathrm{A}^{-}\right]}{[\mathrm{HA}]} \quad \text { (based on concentrations) }
\end{array}
$$

Both equations represent the law of mass action. The value of $K_{a}$ signifies the strength of the acid (strong acids: $\mathrm{K}_{\mathrm{a}}$ large; weak acids: $\mathrm{K}_{\mathrm{a}}$ small). The negative decadic logarithm of $\mathrm{K}_{\mathrm{a}}$ is abbreviated by:

$$
\mathrm{pK}_{\mathrm{a}}=-\lg \mathrm{K}_{\mathrm{a}}
$$

The smaller the $\mathrm{pK}_{\mathrm{a}}$, the stronger the acid—quite the opposite to a $\mathrm{K}_{\mathrm{a}}$-based ranking.

A monoprotic acid HA is characterized by one acidity constant $\mathrm{K}_{1}\left(=\mathrm{K}_{\mathrm{a}}\right)$, a diprotic acid $\mathrm{H}_{2} \mathrm{~A}$ by two acidity constants $\left(\mathrm{K}_{1}, \mathrm{~K}_{2}\right)$, and a triprotic acid by three acidity constants $\left(\mathrm{K}_{1}, \mathrm{~K}_{2}, \mathrm{~K}_{3}\right)$ :

1st dissociation step:

2nd dissociation step:

3rd dissociation step:
$\mathrm{H}_{3} \mathrm{~A}=\mathrm{H}^{+}+\mathrm{H}_{2} \mathrm{~A}^{-}$
$\mathrm{H}_{2} \mathrm{~A}^{-}=\mathrm{H}^{+}+\mathrm{HA}^{-2}$
$\mathrm{HA}^{-2}=\mathrm{H}^{+}+\mathrm{A}^{-3}$

$$
\begin{aligned}
\mathrm{K}_{1} & =\left\{\mathrm{H}^{+}\right\}\left\{\mathrm{H}_{2} \mathrm{~A}^{-}\right\} /\left\{\mathrm{H}_{3} \mathrm{~A}\right\} \\
\mathrm{K}_{2} & =\left\{\mathrm{H}^{+}\right\}\left\{\mathrm{HA}^{-2}\right\} /\left\{\mathrm{H}_{2} \mathrm{~A}^{-}\right\} \\
\mathrm{K}_{3} & =\left\{\mathrm{H}^{+}\right\}\left\{\mathrm{A}^{-3}\right\} /\left\{\mathrm{HA}^{-2}\right\}
\end{aligned}
$$


The dissociation reactions can also be written as:

$$
\begin{array}{ll}
\mathrm{H}_{3} \mathrm{~A}=\mathrm{H}^{+}+\mathrm{H}_{2} \mathrm{~A}^{-} & \mathrm{k}_{1}=\mathrm{K}_{1} \\
\mathrm{H}_{3} \mathrm{~A}=2 \mathrm{H}^{+}+\mathrm{HA}^{-2} & \mathrm{k}_{2}=\mathrm{K}_{1} \mathrm{~K}_{2} \\
\mathrm{H}_{3} \mathrm{~A}=3 \mathrm{H}^{+}+\mathrm{A}^{-3} & \mathrm{k}_{3}=\mathrm{K}_{1} \mathrm{~K}_{2} \mathrm{~K}_{3}
\end{array}
$$

The first representation describes the step-by-step release of one $\mathrm{H}^{+}$in each dissociation step (it is the way nature works); the second representation, by contrast, relates each dissociated species to the undissociated acid by a cumulative $\mathrm{H}^{+}$release. Extending it from 3- to N-protic acids, we obtain a general formula for the cumulative acidity constants:

$$
k_{j}=\left\{\begin{array}{cc}
1 & \text { for } j=0 \\
K_{1} K_{2} \cdots K_{j}=\left\{H^{+}\right\}^{j}\left\{H_{N-j} A^{-j}\right\} /\left\{H_{N} A\right\} & \text { for } 1 \leq j \leq N
\end{array}\right.
$$

For values of $\mathrm{j}$ outside this range (i.e., either for negative $\mathrm{j}$ or for $\mathrm{j}>\mathrm{N}$ ), we set $\mathrm{k}_{\mathrm{j}}=0$. Equation (13) also includes the trivial case of the undissociated acid $(\mathrm{j}=0)$, which is $\mathrm{k}_{0}=1$. In our shortened notation, the last line is $k_{j}=x^{j}\{j\} /\{0\}$.

Equation (13) together with the mass balance (4) provides the set of $\mathrm{N}+1$ equations for the description of $\mathrm{N}$-protic acids. In shorthand notation (and ignoring the trivial case $\mathrm{j}=0$ ), this set becomes:

$$
\begin{array}{ll}
\text { N dissociation reactions }(j=1 \text { to } N): & \{j\}=\left(\frac{k_{j}}{x^{j}}\right)\{0\} \\
\text { mass balance : } & C_{T}=\sum_{j=0}^{N}[j]=[0] \sum_{j=0}^{N} \frac{k_{j}}{x^{j}}
\end{array}
$$

In the next Section, using the approximation $\{\mathrm{j}\} \approx[\mathrm{j}]$, these equations are converted into analytical formulas for ionization fractions.

\subsubsection{Ionization Fractions (Degree of Dissociation)}

The $\mathrm{N}$-protic acid $\mathrm{H}_{\mathrm{N}} \mathrm{A}$ dissolves into $\mathrm{N}+1$ acid species denoted by [j], where $\mathrm{j}$ runs from 0 to $\mathrm{N}$. Instead of the molar concentrations [j], it is convenient to use unitless or intensive quantities, known as ionization fractions:

$$
a_{j} \equiv \frac{[j]}{C_{T}} \quad \text { for } j=0,1,2, \ldots N
$$

The $\mathrm{pH}$ dependence of $\mathrm{a}_{\mathrm{j}}$ as a function of $\mathrm{x}\left(=10^{-\mathrm{pH}}\right)$ follows directly from Equations (14) and (15). Dividing them by $C_{T}$ and using the approximation $\{j\} \approx[j]$ yields:

$$
a_{j}=\left(\frac{k_{j}}{x^{j}}\right) a_{0} \quad \text { with } a_{0}=\left(1+\frac{k_{1}}{x}+\frac{k_{2}}{x^{2}}+\ldots+\frac{k_{N}}{x^{N}}\right)^{-1}=\left(\sum_{j=0}^{N} \frac{k_{j}}{x^{j}}\right)^{-1}
$$

The ionization fractions are completely specified by the $\mathrm{N}$ acidity constants $\mathrm{K}_{1}, \mathrm{~K}_{2}$, $\ldots \mathrm{K}_{\mathrm{N}}$, which are encapsulated in the cumulative equilibrium constants (as products of $\mathrm{K}_{\mathrm{j}}$-values):

$$
\mathrm{k}_{0}=1, \quad \mathrm{k}_{1}=\mathrm{K}_{1}, \quad \mathrm{k}_{2}=\mathrm{K}_{1} \mathrm{~K}_{2}, \quad \ldots \quad \mathrm{k}_{\mathrm{N}}=\mathrm{K}_{1} \mathrm{~K}_{2} \ldots \mathrm{K}_{\mathrm{N}}
$$

Figure 3 displays the ionization fractions as a function of $\mathrm{pH}$ for four acids. For any chosen value of $\mathrm{x}($ or $\mathrm{pH})$, the sum of all ionization fractions equals 1 :

$$
1=\mathrm{a}_{0}+\mathrm{a}_{1}+\ldots+\mathrm{a}_{\mathrm{N}}=\sum_{\mathrm{j}=0}^{\mathrm{N}} \mathrm{a}_{\mathrm{j}}(\mathrm{x}) \quad \text { (mass balance) }
$$



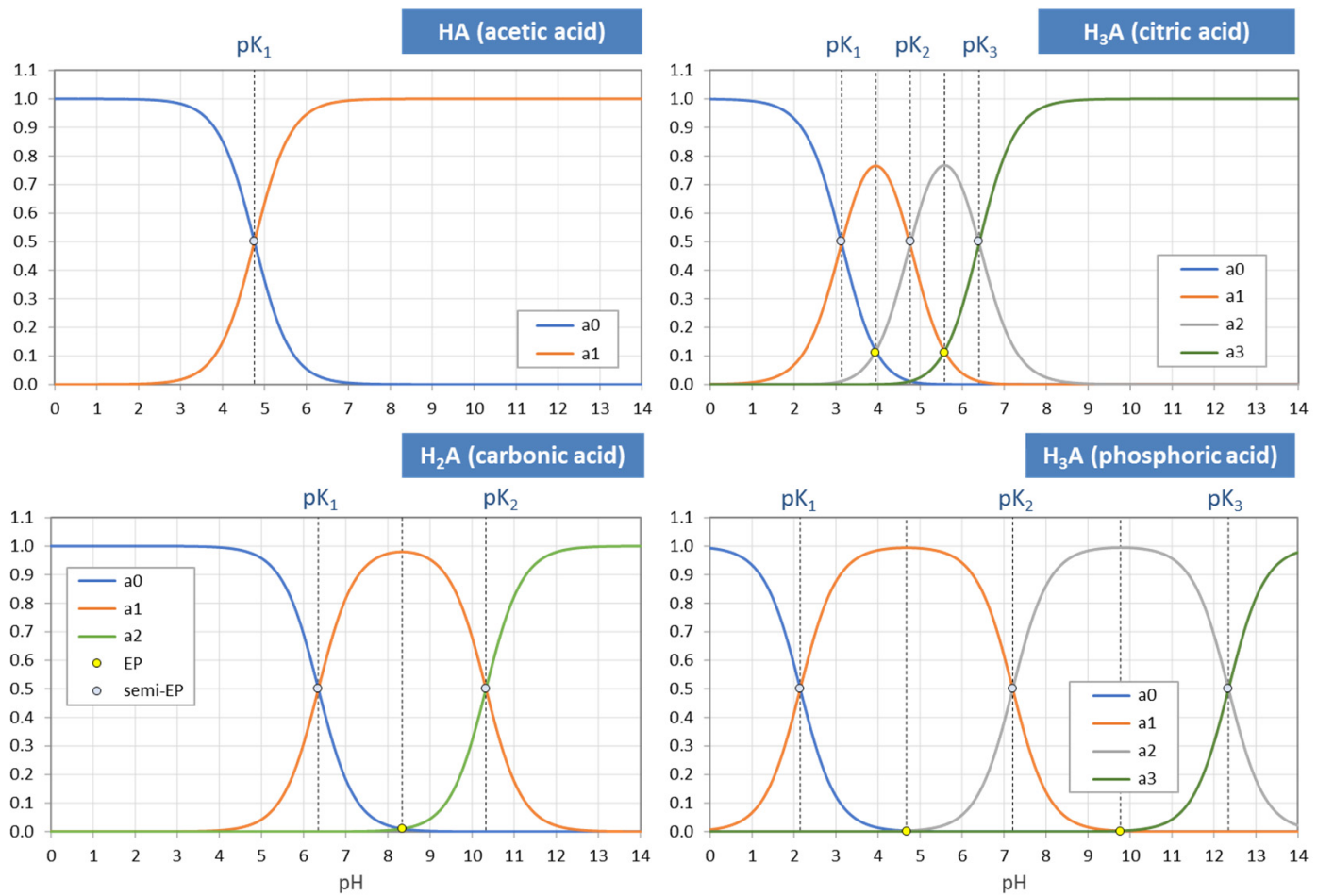

Figure 3. $\mathrm{pH}$ dependence of ionization fractions for four acids (small circles mark equivalence points).

Ionization fractions are smooth, infinitely differentiable functions of $\mathrm{x}$ or $\mathrm{pH}$ with values between 0 and 1: $0<a_{j}<1$. The latter makes them excellent candidates for probabilities (as will be discussed later in Section 2.5.3).

The points where two curves intersect (marked with small circles in Figure 3) are special equilibrium states called equivalence points (EP)—cf. Section 2.3. The actual values at these points are:

$$
\begin{array}{llll}
\text { semi-Eps } & \text { (blue circles): } & \mathrm{a}_{\mathrm{j}}=\mathrm{a}_{\mathrm{j}-1} \approx \frac{1}{2} & \text { (inflection points of } \mathrm{a}_{\mathrm{j}} \text { ) } \\
\text { EPs } & \text { (yellow circles): } & \mathrm{a}_{\mathrm{j}}=1-2 \mathrm{a}_{\mathrm{j}-1}(\approx 1) & \left(\text { maximum of } \mathrm{a}_{\mathrm{j}}\right)
\end{array}
$$

Universality. Ionization fractions have the nice feature that they are independent of the acid's total amount $C_{T}$; they are intensive (non-extensive) variables. Regardless of the assumed $\mathrm{C}_{\mathrm{T}}$ (either constant or $\mathrm{pH}$ dependent, such as in open systems), the curves/shapes of the ionization fractions remain the same (as in Figure 3). Examples for this "universality" are given in Section 3.3.3 $\left(\mathrm{H}_{2} \mathrm{~A}\right.$ as titrant vs. $\mathrm{H}_{2} \mathrm{~A}$ as analyte) and Section 3.3.4 (open vs. closed $\mathrm{CO}_{2}$ system).

\subsubsection{Two Types of Ionization Fractions: S Shaped vs. Bell Shaped}

The acidity constants in the form of $\mathrm{pK}_{\mathrm{j}}$ values subdivide the entire $\mathrm{pH}$ domain into $\mathrm{N}+1$ distinct intervals, as shown in Figure 4. The jth interval is the subdomain in which the ionization fraction $a_{j}$ exercises its full dominance-see right diagrams in Figure 4. As indicated by colors, there are two types of curves: (i) S-shaped curves (sigmoid curves) in the 0th and the Nth interval at the opposite ends of the $\mathrm{pH}$ scale (red color) and (ii) bell-shaped curves in all other intervals (blue color), with their maxima in the middle of the interval. [Note 1: For $\mathrm{N}=1, \mathrm{a}_{0}$ and $\mathrm{a}_{1}$ represent prominent functions: logistic functions or the Fermi-Dirac distribution-see Section 2.5.3. Note 2: The S-shaped curves appear as the two halves of a bell-shaped curve when the opposite ends are glued together at $\pm \infty$.] 

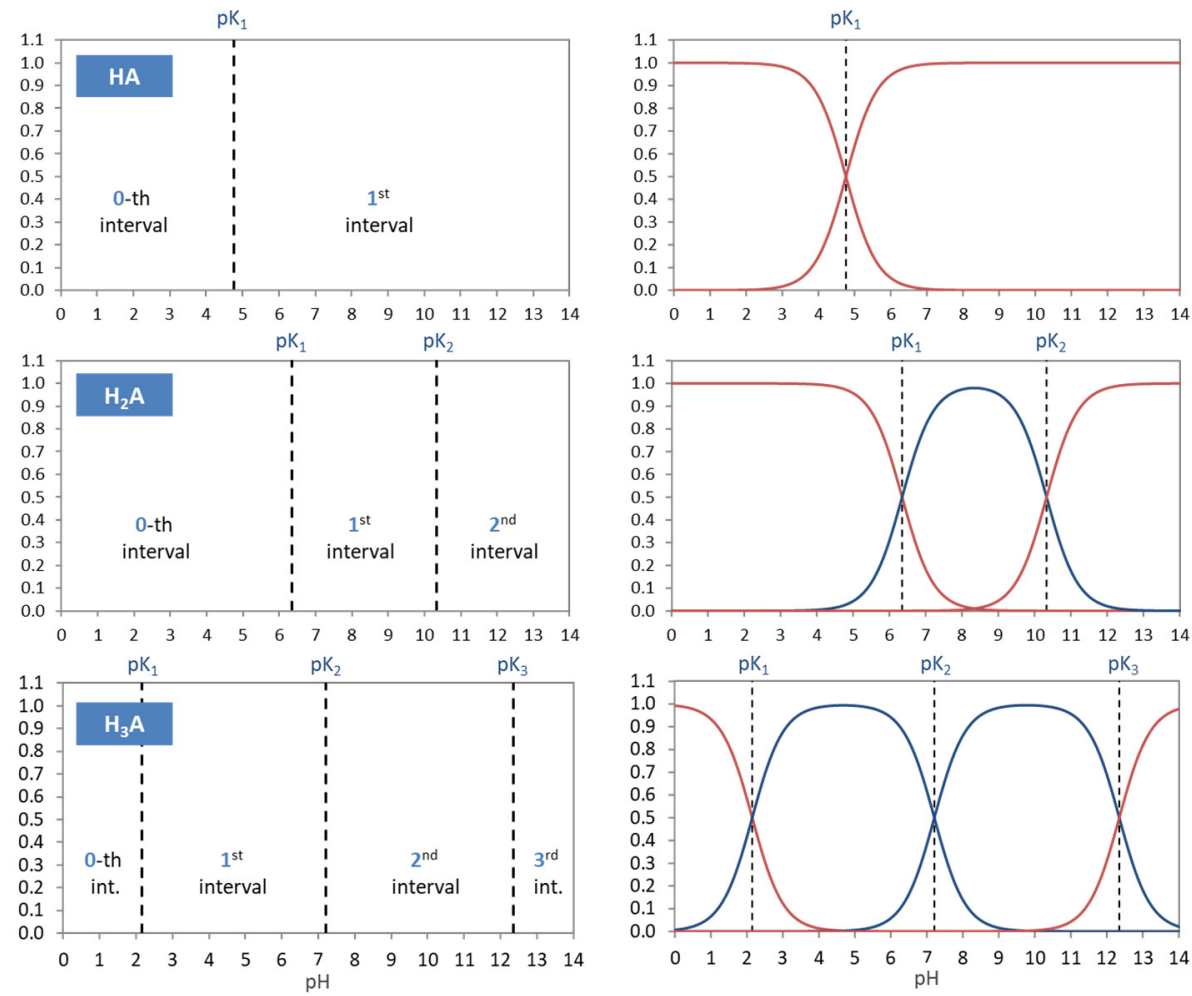

Figure 4. Each ionization fraction $\mathrm{a}_{\mathrm{j}}$ has its own domain in the $\mathrm{pH}$ interval between two adjacent $\mathrm{pK}_{\mathrm{j}}$ values. (HA-acetic acid, $\mathrm{H}_{2} \mathrm{~A}$ - carbonic acid, $\mathrm{H}_{3} \mathrm{~A}$ - phosphoric acid).

Table 2 contrasts the two types of ionization fractions. Their otherness implies the distinction between external (outer) and internal (inner) equivalence points in Section 2.3.

Table 2. Two types of ionization fractions.

\begin{tabular}{|c|c|c|}
\hline & Type 1 (S Shaped) & Type 2 (Bell Shaped) \\
\hline ionization fraction & $\mathrm{a}_{0}$ and $\mathrm{a}_{\mathrm{N}}$ & $\begin{array}{c}\mathrm{a}_{1}, \mathrm{a}_{2}, \ldots \mathrm{a}_{\mathrm{N}-1} \\
\text { (does not exist for 1-protic acids) }\end{array}$ \\
\hline domain ( $\mathrm{pH}$ interval) & $\begin{array}{c}\mathrm{pH}<\mathrm{pK}_{1}\left(\text { for } \mathrm{a}_{0}\right) \\
\mathrm{pH}>\mathrm{pK}_{\mathrm{N}}\left(\text { for } \mathrm{a}_{\mathrm{N}}\right)\end{array}$ & $\mathrm{pK}_{\mathrm{j}}<\mathrm{pH}<\mathrm{pK}_{\mathrm{j}+1}$ \\
\hline maximum at $\mathrm{pH}$ & $\begin{array}{l}-\infty\left(\text { for } \mathrm{a}_{0}\right) \\
+\infty\left(\text { for } \mathrm{a}_{\mathrm{N}}\right)\end{array}$ & $\frac{1}{2}\left(p K_{j}+p K_{j+1}\right)$ \\
\hline $\begin{array}{c}\text { strongly acidic }(\mathrm{pH} \rightarrow 0) \\
\text { strongly alkaline }(\mathrm{pH} \rightarrow 14)\end{array}$ & $\begin{array}{l}a_{0}=1, a_{N}=0 \\
a_{0}=0, a_{N}=1\end{array}$ & $\begin{array}{l}a_{j}=0 \\
a_{j}=0\end{array}$ \\
\hline integral (area below curve) & infinite & finite \\
\hline $\begin{array}{l}\text { statistical meaning } \\
\text { (see Section 2.5.3) }\end{array}$ & $\begin{array}{l}\text { cumulative distribution } \\
\text { function }\end{array}$ & - \\
\hline $\begin{array}{c}\text { associated } \\
\text { equivalence points }\end{array}$ & $\begin{array}{l}\text { two external EPs: } \\
\mathrm{EP}_{0} \text { and } \mathrm{EP}_{\mathrm{N}}\end{array}$ & $\begin{array}{l}\mathrm{N}-1 \text { internal } \mathrm{EPs}: \\
\mathrm{EP}_{1}, \mathrm{EP}_{2}, \ldots \mathrm{EP}_{\mathrm{N}-1}\end{array}$ \\
\hline
\end{tabular}

At the opposite ends of the $\mathrm{pH}$ scale, the two ionization fractions $\mathrm{a}_{0}$ and $\mathrm{a}_{\mathrm{N}}$ attain the maximum value 1 :

$\begin{array}{llll}\text { strongly acidic: } & \mathrm{pH}<0 & (\text { or } \mathrm{x} \rightarrow \infty): & \mathrm{a}_{0}=1, \quad \text { all other } \mathrm{a}_{\mathrm{j}}=0\end{array}$

strongly alkaline: $\quad \mathrm{pH}>14 \quad($ or $\mathrm{x} \rightarrow 0): \quad \mathrm{a}_{\mathrm{N}}=1, \quad$ all other $\mathrm{a}_{\mathrm{j}}=0$

This behavior is an important fact to identify them as cumulative distribution functions in Section 2.5.3. [Note: The $\mathrm{pH}$ scale does not end at 0 or 14 , but also extends to $\mathrm{pH}<0$ and $\mathrm{pH}>14$ (in theory, even up to $-\infty$ and to $+\infty$ ).] 


\subsubsection{Moments $\mathrm{Y}_{\mathrm{L}}$}

The simplest constructs we can build from ionization fractions are so-called moments. The Lth moment $Y_{L}$ is defined as the weighting sum over $a_{j}$ :

$$
\mathrm{Y}_{\mathrm{L}} \equiv \sum_{\mathrm{j}=0}^{\mathrm{N}} \mathrm{j}^{\mathrm{L}} \mathrm{a}_{\mathrm{j}}
$$

In the next Sections, the moments become the building blocks of several relevant quantities (while their statistical significance is discussed in Section 2.5.4):

$$
\begin{array}{lll}
Y_{0}=a_{0}+a_{1}+\ldots+a_{N}=1 & \Rightarrow \text { mass balance } & \\
Y_{1}=a_{1}+2 a_{2}+\ldots+N a_{N} & \Rightarrow \text { enters buffer capacity } & \text { in Eq. (68) } \\
Y_{2}=a_{1}+4 a_{2}+\ldots+N^{2} a_{N} & \Rightarrow \text { enters buffer intensity } \beta & \text { in Eq. (69) } \\
Y_{3}=a_{1}+8 a_{2}+\ldots+N^{3} a_{N} & \Rightarrow \text { enters 1st derivative of } \beta & \text { in Eq. (70) }
\end{array}
$$

The example in Figure 5 demonstrates how the "titration curve"-like $Y_{1}$ is built up from the ionization fractions $\mathrm{a}_{\mathrm{j}}$ (of the triprotic phosphoric acid). Figure 6 displays the $\mathrm{pH}$ dependence of $Y_{1}$ to $Y_{4}$ for four acids. Note that in the trivial case of monoprotic acids (top-left diagram), all moments are equal, i.e., the four $\mathrm{Y}_{\mathrm{L}}$ curves cover each other.
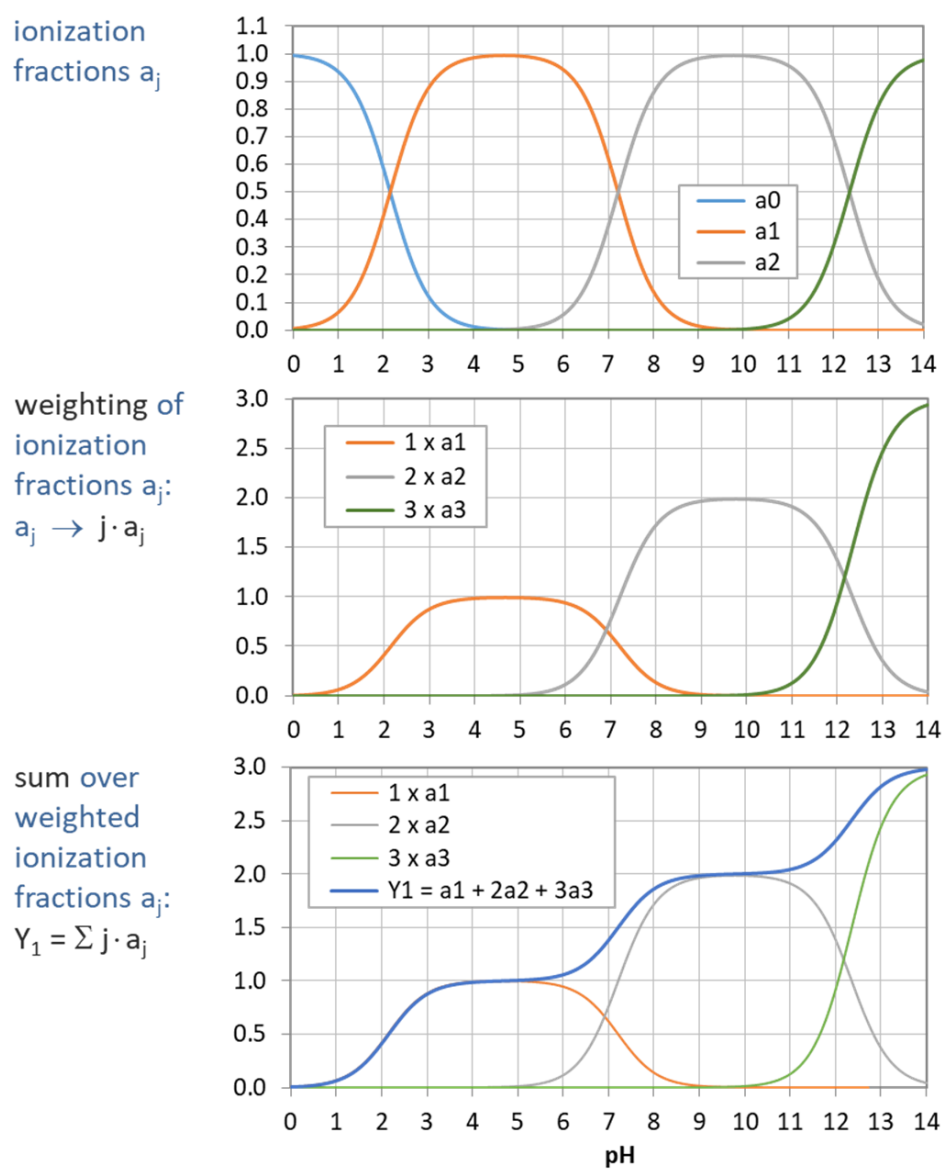

Figure 5. Construction of $Y_{1}$ (blue curve in bottom diagram) from summation over weighted ionization fraction $\mathrm{a}_{\mathrm{j}}$. (Example: phosphoric acid as a triprotic acid). 

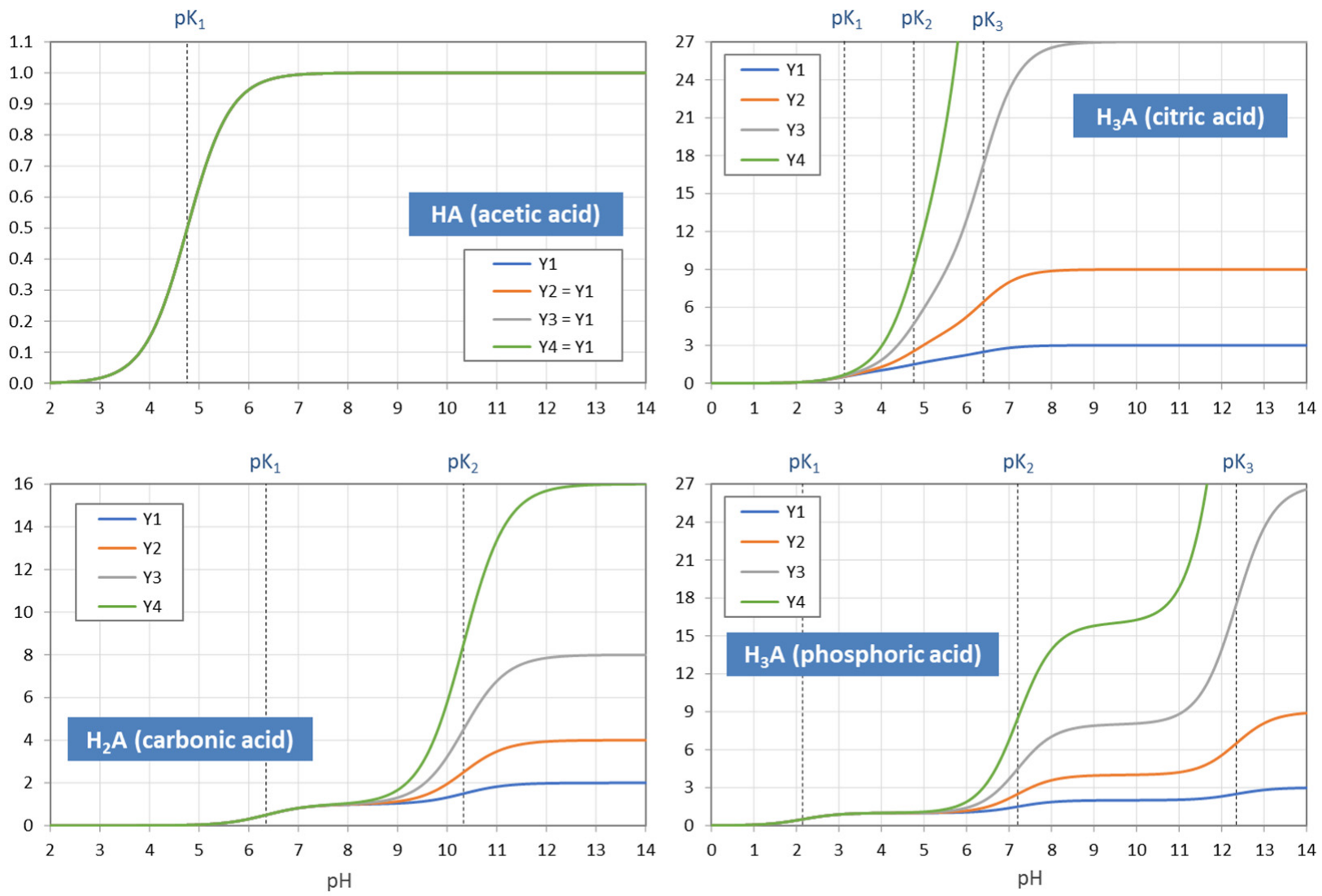

Figure 6. $\mathrm{pH}$ dependence of the moments $\mathrm{Y}_{1}$ to $\mathrm{Y}_{4}$ for four acids. In the case of monoprotic acids (top-left diagram), all $\mathrm{Y}_{\mathrm{L}}$ are equal, i.e., the four curves cover each other.

The moments $Y_{L}$ are positive, monotonic (increasing) functions, living in the range $0<\mathrm{Y}_{\mathrm{L}} \leq \mathrm{N}^{\mathrm{L}}$ (where the equal sign applies only for $\mathrm{Y}_{0}$ ). Their asymptotic behavior results from Equations (20) and (21):

$$
\begin{array}{lll}
\mathrm{Y}_{\mathrm{L}}(\mathrm{pH} \rightarrow-\infty)=0 & \text { or } & \mathrm{Y}_{\mathrm{L}}(\mathrm{x} \rightarrow+\infty)=0 \\
\mathrm{Y}_{\mathrm{L}}(\mathrm{pH} \rightarrow+\infty)=\mathrm{N}^{\mathrm{L}} & \text { or } & \mathrm{Y}_{\mathrm{L}}(\mathrm{x} \rightarrow 0)=\mathrm{N}^{\mathrm{L}}
\end{array}
$$

Note: The introduction of moments is not a new idea. Similar constructs can be found in ligand theory [32]. The formulas, however, differ due to differently chosen reference states (dissociation vs. association reactions).

\subsection{The 3-Component Acid-Base System}

\subsubsection{Basic Set of Equations}

The acid-base system is made up of three components:

- pure water $\mathrm{H}_{2} \mathrm{O}$

- N-protic acid $\mathrm{H}_{\mathrm{N}} \mathrm{A}$ (with amount $\mathrm{C}_{\mathrm{T}}=\left[\mathrm{H}_{\mathrm{N}} \mathrm{A}\right]_{\mathrm{T}}$ )

- strong base $\mathrm{BOH}$ (with amount $\mathrm{C}_{\mathrm{B}}=[\mathrm{BOH}]_{\mathrm{T}}$ )

The term strong means that the base dissociates completely: $\mathrm{BOH}=\mathrm{B}^{+}+\mathrm{OH}^{-}$. This implies two things: first, $\left[\mathrm{B}^{+}\right]=\mathrm{C}_{\mathrm{B}}$; second, no extra equilibrium constant is needed for the dissociation of the base. Here, $\mathrm{BOH}$, for example, stands for $\mathrm{NaOH}$ or $\mathrm{KOH}$ (i.e., $\mathrm{B}^{+}=\mathrm{Na}^{+}$ or $\mathrm{K}^{+}$). 
The 3-component system is characterized by

$$
\mathrm{N}+4 \text { species (variables): } \mathrm{H}^{+}, \mathrm{OH}^{-}, \underbrace{\mathrm{H}_{\mathrm{N}} \mathrm{A}, \mathrm{H}_{\mathrm{N}-1} \mathrm{~A}^{-}, \ldots, \mathrm{A}^{-\mathrm{N}}}_{\mathrm{N}+1 \text { acid species }}, \mathrm{B}^{+}
$$

For the mathematical description, we use a set of $\mathrm{N}+3$ equations:

$$
\begin{array}{ll}
\mathrm{K}_{\mathrm{W}}=\left\{\mathrm{H}^{+}\right\}\left\{\mathrm{OH}^{-}\right\} & \text {(self-ionization of } \mathrm{H}_{2} \mathrm{O} \text { ) } \\
\mathrm{K}_{1}=\left\{\mathrm{H}^{+}\right\}\left\{\mathrm{H}_{\mathrm{N}-1} \mathrm{~A}^{-}\right\} /\left\{\mathrm{H}_{\mathrm{N}} \mathrm{A}\right\} & \text { (1st diss. step) } \\
\mathrm{K}_{2}=\left\{\mathrm{H}^{+}\right\}\left\{\mathrm{H}_{\mathrm{N}-2} \mathrm{~A}^{-2}\right\} /\left\{\mathrm{H}_{\mathrm{N}-1} \mathrm{~A}^{-}\right\} & \text {(2nd diss. step) } \\
\vdots & \\
\mathrm{K}_{\mathrm{N}}=\left\{\mathrm{H}^{+}\right\}\left\{\mathrm{A}^{-\mathrm{N}}\right\} /\left\{\mathrm{HA}^{-(\mathrm{N}-1)}\right\} & \text { (Nth diss. step) } \\
\mathrm{C}_{\mathrm{T}}=\left[\mathrm{H}_{\mathrm{N}} \mathrm{A}\right]+\left[\mathrm{H}_{\mathrm{N}-1} \mathrm{~A}^{-}\right]+\ldots+\left[\mathrm{A}^{-\mathrm{N}}\right] & \text { (mass balance) }
\end{array}
$$

It is worth noting that this set of equations comprises two types of laws: mass-action laws (first $\mathrm{N}+1$ equations) and balance laws for mass and charge (last two equations). This embodies a kind of asymmetry: while the mass-action laws are based on activities, the mass balance and charge balance rely on molar concentrations.

Since we have $\mathrm{N}+4$ variables, but only $\mathrm{N}+3$ equations, the description is given one degree of freedom. Thus, we can vary the parameter $\mathrm{C}_{\mathrm{B}}$ (amount of base) to change the $\mathrm{pH}$ (known as titration).

Instead of $C_{B}$, we prefer the normalized or unitless quantity

$$
\text { equivalent fraction : } \mathrm{n}=\frac{\mathrm{C}_{\mathrm{B}}}{\mathrm{C}_{\mathrm{T}}}(\mathrm{n} \geq 0)
$$

If $\mathrm{n}=0$, the 3-component system collapses to the 2-component system " $\mathrm{H}_{\mathrm{N}} \mathrm{A}+\mathrm{H}_{2} \mathrm{O}^{\prime}$ (see Figure 2). Plotting $\mathrm{n}=\mathrm{n}(\mathrm{pH})$ as a function of $\mathrm{pH}$ yields the titration curve. The corresponding formula, $\mathrm{n}=\mathrm{n}(\mathrm{x})$, will be derived in the next Section.

The concept even works when the strong base is replaced by a strong monoprotic acid $\mathrm{HX}$ with amount $\mathrm{C}_{\mathrm{A}}=[\mathrm{HX}]_{\mathrm{T}}$ (for example $\mathrm{HCl}$, whereby $\mathrm{X}^{-}=\mathrm{Cl}^{-}$). In this way, we are able to generalize Equation (33):

$$
\text { equivalent fraction : } \mathrm{n}=\frac{\mathrm{C}_{\mathrm{B}}-\mathrm{C}_{\mathrm{A}}}{\mathrm{C}_{\mathrm{T}}}(\text { for any real } \mathrm{n} \text { ) }
$$

where either $C_{A}$ or $C_{B}$ is zero. For $\mathrm{n}>0$, it describes the alkalimetric titration (with a strong base); for $\mathrm{n}<0$, it describes the acidimetric titration (with a strong monoprotic acid). The integer and half-integer values of $\mathrm{n}$ are especially interesting because they constitute equivalence points (cf. Section 2.3).

The principle is explained in Figure 7, where a carbonate system with $C_{T}=100 \mathrm{mM}$ is titrated. The special state $\mathrm{n}=0$ represents the $\mathrm{pH}$ of the base-free 2-component system. Starting from this point, the $\mathrm{pH}$ increases by adding $\mathrm{NaOH}(\mathrm{n}>0)$ and decreases by adding $\mathrm{HCl}(\mathrm{n}<0)$. The small circles at $\mathrm{n}=0,1$, and 2 mark three equivalence points. Alternatively, taking $100 \mathrm{mM} \mathrm{NaHCO}_{3}\left(\right.$ or $\left.\mathrm{Na}_{2} \mathrm{CO}_{3}\right)$, the titration will start at $\mathrm{n}=1$ (or $\left.\mathrm{n}=2\right)$.

The titration curve from Figure 7 is shown in Figure 8 (blue color) together with curves for $\mathrm{C}_{\mathrm{T}}=1 \mathrm{mM}$ and $10 \mathrm{mM}$. The only difference between the left and right diagram is that the $x$ and $y$ axis are interchanged; left: $n=n(p H)$, right: $\mathrm{pH}=\mathrm{pH}(\mathrm{n})$. All curves are calculated using Equation (41) below. 


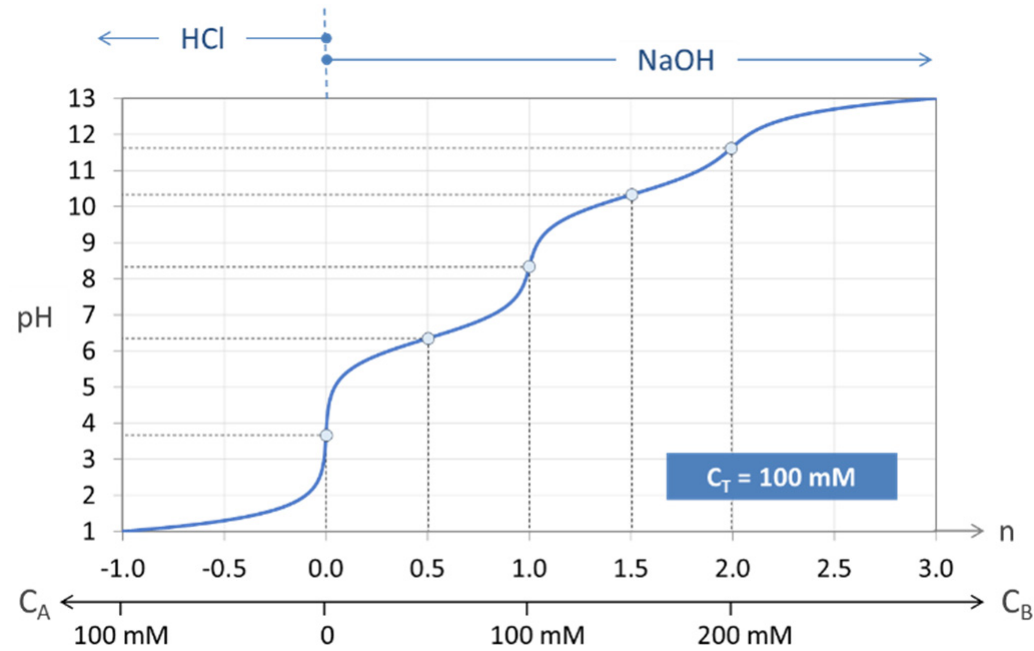

Figure 7. Titration curve $\mathrm{n}=\mathrm{n}(\mathrm{pH})$ of the "closed" carbonate system $\left(100 \mathrm{mM} \mathrm{H}_{2} \mathrm{CO}_{3}\right)$.
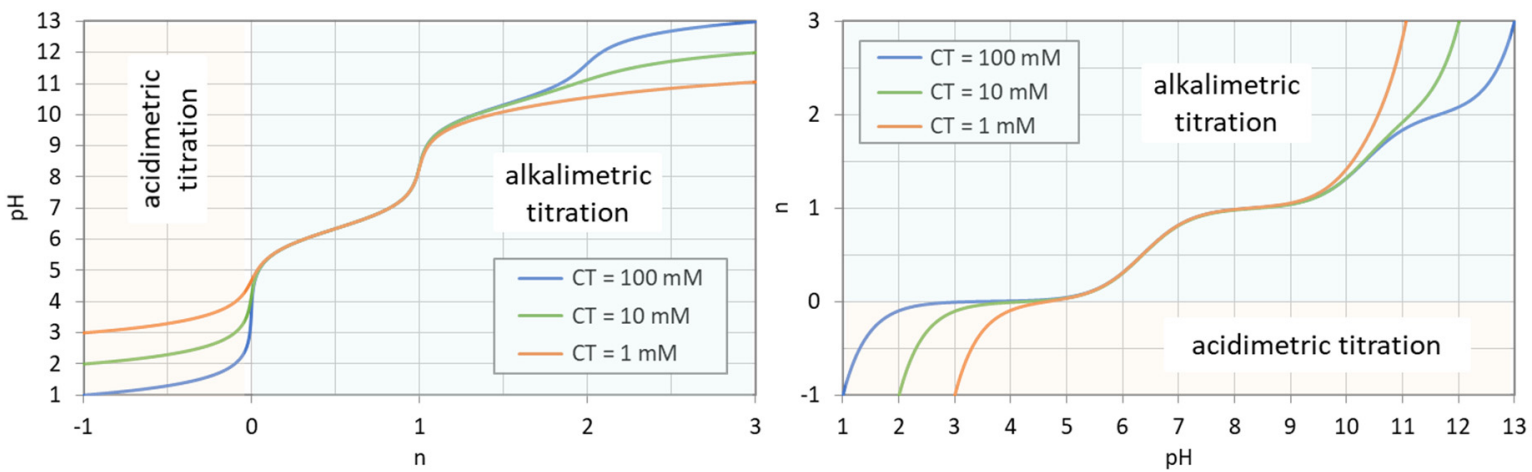

Figure 8. Titration curves for 1,10 , and $100 \mathrm{mM} \mathrm{H}_{2} \mathrm{CO}_{3}$. (Left): $\mathrm{n}=\mathrm{n}(\mathrm{pH})$; (right): $\mathrm{pH}=\mathrm{pH}(\mathrm{n})$.

\subsubsection{Analytical Formula (Titration Curves)}

The starting point is the set of nonlinear Equations (27)-(32). Its algebraic solution leads to a simple analytical formula when the following procedure is applied:

- $\quad$ replace activities by concentrations: $\{\mathrm{j}\} \Rightarrow[\mathrm{j}]$ in Equations (28)-(30);

- $\quad$ replace acid species by ionization fractions: $[j] \Rightarrow a_{j}$ in Equations (28)-(32);

- $\quad$ replace $\left\{\mathrm{H}^{+}\right\}$by $\mathrm{x}$ and use $\mathrm{w}(\mathrm{x})$ defined in Equation (8);

- $\quad$ use $Y_{1}$ for summation over $\mathrm{j} \mathrm{a}_{\mathrm{j}}$ defined in Equation (24);

- $\quad$ divide Equations (31) and (32) by $\mathrm{C}_{\mathrm{T}}$.

In this way, the set of $\mathrm{N}+3$ Equations (27)-(32) becomes:

$$
\begin{aligned}
& \mathrm{w}=\mathrm{K}_{\mathrm{w}} / \mathrm{x}-\mathrm{x} \quad \text { (self-ionization of } \mathrm{H}_{2} \mathrm{O} \text { ) } \\
& \mathrm{a}_{1}=\left(\mathrm{k}_{1} / \mathrm{x}\right) \mathrm{a}_{0} \quad \text { (1st diss. step) } \\
& \mathrm{a}_{2}=\left(\mathrm{k}_{2} / \mathrm{x}^{2}\right) \mathrm{a}_{0} \quad \text { (2nd diss. step) } \\
& \mathrm{a}_{\mathrm{N}}=\left(\mathrm{k}_{\mathrm{N}} / \mathrm{x}^{\mathrm{N}}\right) \mathrm{a}_{0} \\
& 1=\mathrm{a}_{0}+\mathrm{a}_{1}+\ldots+\mathrm{a}_{\mathrm{N}} \\
& \mathrm{n}=\mathrm{Y}_{1}+\mathrm{w} / \mathrm{C}_{\mathrm{T}} \\
& \text { (Nth diss. step) } \\
& \text { (mass balance) } \\
& \text { (charge balance) }
\end{aligned}
$$

The essence of the entire set is now bundled in a single analytical formula (taken from the last line):

$$
\mathrm{n}(\mathrm{x})=\mathrm{Y}_{1}(\mathrm{x})+\frac{\mathrm{w}(\mathrm{x})}{\mathrm{C}_{\mathrm{T}}}
$$


This formula encapsulates the information contained in all other equations, i.e., Equations (27)-(31). Each term in Equation (41) represents one of the three components/subsystems: $\mathrm{n}$-the strong base, $\mathrm{w} / \mathrm{C}_{\mathrm{T}}$ - the effect of water, and $\mathrm{Y}_{1}$-the pure acid. Figure 9 illustrates how the three components are cemented together via one equation: the charge-balance equation. In the high- $C_{T}$ limit, the last term in Equation (41) vanishes and the formula simplifies to $\mathrm{n}=\mathrm{Y}_{1}(\mathrm{x})$. [Note: Instead of the charge balance, one can also use an alternative concept known as proton balance, which is the balance between the species that have excess protons versus those that are deficient in protons. Both concepts lead to the same results].

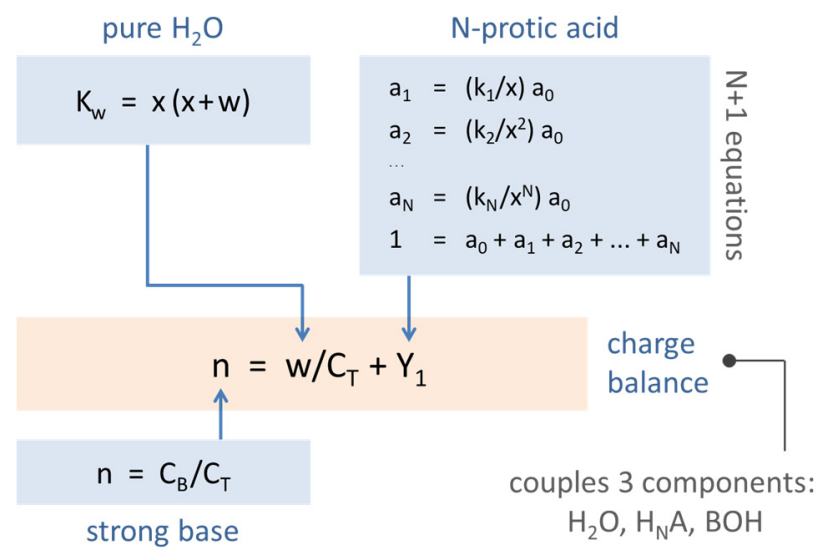

Figure 9. Set of equations describing the 3-component acid-base system $\left(\mathrm{H}_{2} \mathrm{O}, \mathrm{H}_{\mathrm{N}} \mathrm{A}\right.$, strong base). The three components are coupled via the charge-balance equation.

Using Equation (41), titration curves for four acids with different $C_{T}$ values are plotted in Figure 10. The diagrams also include the high- $C_{T}$ limit, $n=Y_{1}$ (as dark-blue curves).
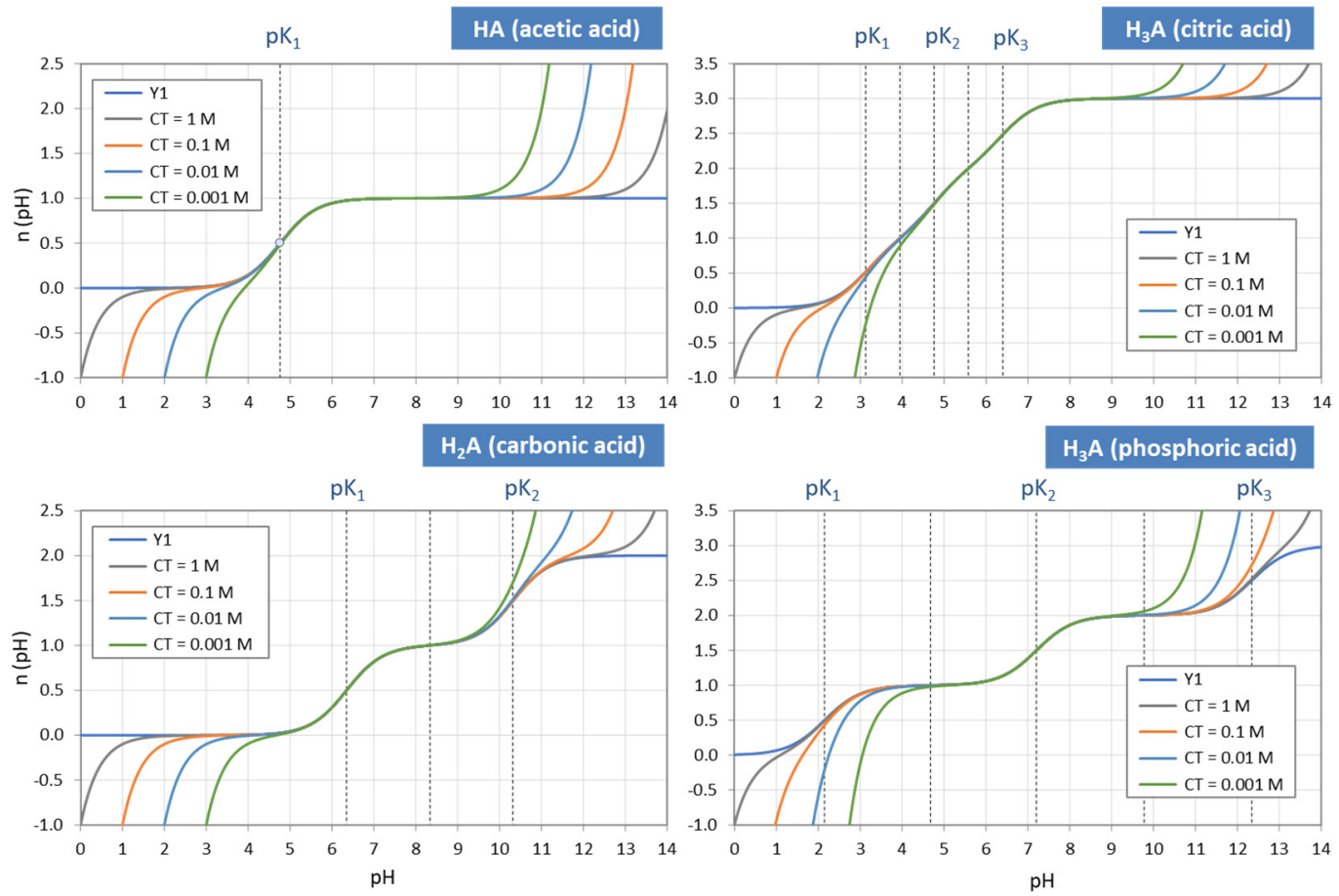

Figure 10. Titration curves (i.e., buffer capacities) for four acids with different amounts of $C_{T}$ (including the high- $C_{T}$ limit $\left.\mathrm{n}(\mathrm{pH})=\mathrm{Y}_{1}\right)$. Plots are based on Equation (41). 


\subsubsection{Forward and Inverse Task (Polynomials for $\mathrm{x}=10^{-\mathrm{pH}}$ )}

The 3-component system is controlled by three "master variables": $\mathrm{pH}, \mathrm{C}_{\mathrm{T}}$, and $\mathrm{n}$ (or $C_{B}$ ), but only two of them can be chosen freely. From the viewpoint of Equation (41), the following tasks emerge:

- forward task 1: given $\mathrm{pH}$ and $\mathrm{C}_{\mathrm{T}} \quad \Rightarrow$ calculate $\mathrm{n}$ (or $\mathrm{C}_{\mathrm{B}}$ )

- forward task 2: given $\mathrm{pH}$ and $\mathrm{n}\left(\right.$ or $\mathrm{C}_{\mathrm{B}}$ ) $\Rightarrow$ calculate $\mathrm{C}_{\mathrm{T}}$

- inverse task: given $\mathrm{C}_{\mathrm{T}}$ and $\mathrm{n}\left(\right.$ or $\mathrm{C}_{\mathrm{B}}$ ) $\Rightarrow$ calculate $\mathrm{pH}$

Using the shorthand $\mathrm{x}=10^{-\mathrm{pH}}$, the two forward tasks are easily obtained from Equation (41):

forward task 1: $\mathrm{n}=\mathrm{Y}_{1}(\mathrm{x})+\frac{\mathrm{w}(\mathrm{x})}{\mathrm{C}_{\mathrm{T}}}$ or $\mathrm{C}_{\mathrm{B}}=\mathrm{Y}_{1}(\mathrm{x}) \mathrm{C}_{\mathrm{T}}+\mathrm{w}(\mathrm{x})$

forward task 2: $C_{T}=\frac{w(x)}{n-Y_{1}(x)} \quad$ or $\quad C_{T}=\frac{C_{B}-w(x)}{Y_{1}(x)}$

These are explicit functions.

The inverse task to calculate the $\mathrm{pH}$ for a given $\mathrm{C}_{\mathrm{T}}$ and $\mathrm{C}_{\mathrm{B}}$ is intricate because an explicit function, such as $\mathrm{pH}=\mathrm{f}\left(\mathrm{C}_{\mathrm{T}}, \mathrm{C}_{\mathrm{B}}\right)$, does not exist for $\mathrm{N}>1$. The only thing we can offer is an implicit function in the form of polynomials of degree $\mathrm{N}+2$ in $\mathrm{x}$ :

$$
0=\sum_{j=0}^{N}\left\{x^{2}+(n-j) C_{T} x-K_{w}\right\} k_{j} x^{N-j}
$$

Example $N=1$. The monoprotic acid represents the simplest case, where the sum runs over two terms only: $\mathrm{j}=0$ and 1 . With $\mathrm{k}_{0}=1$ and $\mathrm{k}_{1}=\mathrm{K}_{1}$ we get a cubic equation:

$$
0=\mathrm{x}^{3}+\left\{\mathrm{K}_{1}+\mathrm{nC}_{\mathrm{T}}\right\} \mathrm{x}^{2}-\left\{(\mathrm{n}-1)\left(\mathrm{C}_{\mathrm{T}} \mathrm{K}_{1}+\mathrm{K}_{\mathrm{w}}\right)\right\} \mathrm{x}-\mathrm{K}_{1} \mathrm{~K}_{\mathrm{w}}
$$

Example $N=2$. For a diprotic acid with $\mathrm{k}_{0}=1, \mathrm{k}_{1}=\mathrm{K}_{1}$, and $\mathrm{k}_{2}=\mathrm{K}_{1} \mathrm{~K}_{2}$ we obtain a quartic equation:

$$
0=x^{4}+\left\{K_{1}+n C_{T}\right\} x^{3}+\left\{K_{1} K_{2}+(n-1) C_{T} K_{1}-K_{w}\right\} x^{2}+K_{1}\left\{(n-2) C_{T} K_{2}-K_{w}\right\} x-K_{1} K_{2} K_{w}
$$

Setting $K_{2}=0$, this equation falls back to Equation (45). Setting $n=0$, one obtains the formula for diprotic acids given in textbooks (e.g., [1] (p. 107)). Setting $n=C_{B} / C_{T}$ yields an alternative form of the quartic equation:

$$
0=x^{4}+\left\{K_{1}+C_{B}\right\} x^{3}+\left\{K_{1} K_{2}+\left(C_{B}-C_{T}\right) K_{1}-K_{w}\right\} x^{2}+K_{1}\left\{\left(C_{B}-2 C_{T}\right) K_{2}-K_{w}\right\} x-K_{1} K_{2} K_{w}
$$

Theoretically, the polynomial (44) can be used to calculate $\mathrm{x}$ or $\mathrm{pH}$ for any N. However, in practice, it is not quite easy. For polynomials of order $\mathrm{N}>4$, there is principally no algebraic solution, no matter how hard we try (due to the Abel-Ruffini theorem). Thus, numerical root-finding methods should be applied. However, this effort is not necessary if you want to plot titration curves with $\mathrm{pH}$ on the abscissa, because you can take the forward approach and then swap the axes.

An example is given in Figure 11 for the case $\mathrm{n}=0$ (i.e., the 2-component system $\mathrm{H}_{\mathrm{N}} \mathrm{A}+\mathrm{H}_{2} \mathrm{O}$ ). The left diagram represents the forward task $\mathrm{pH} \Rightarrow \mathrm{C}_{\mathrm{T}}$ based on Equation (43); the right diagram represents the inverse task $\mathrm{C}_{\mathrm{T}} \Rightarrow \mathrm{pH}$ based on the polynomial (44) using root-finding methods. Alternatively, the right diagram can be created from the left diagram by interchanging the axes (as a cost-free by-product of the first calculation). 

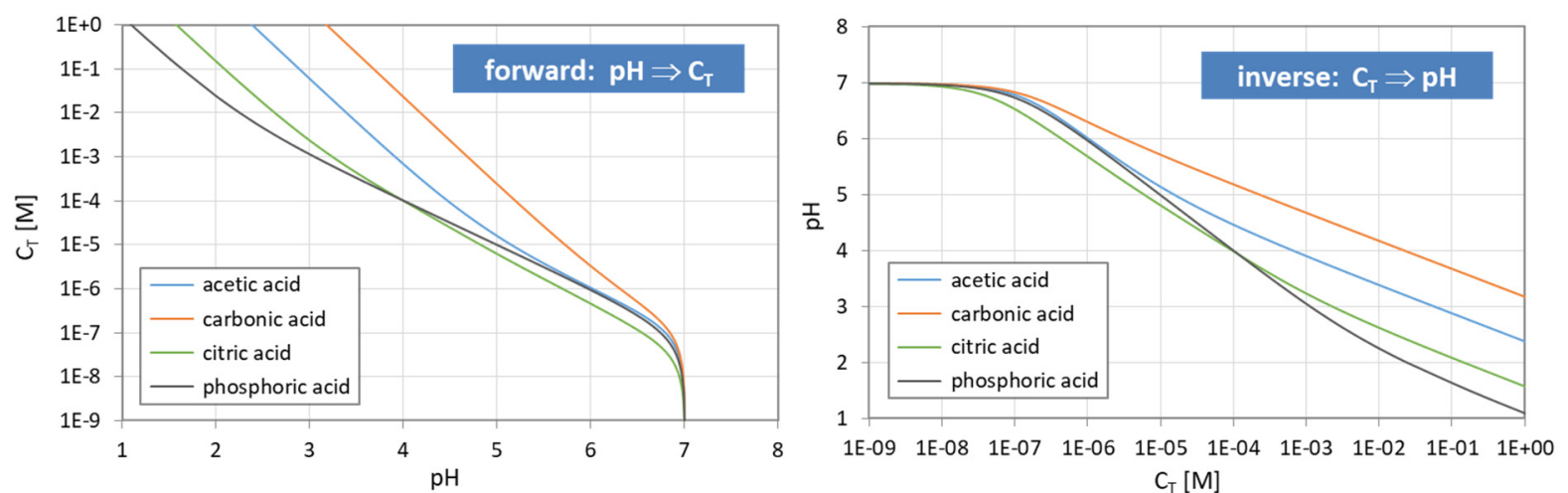

Figure 11. Functional relationship between $\mathrm{pH}$ and $\mathrm{C}_{\mathrm{T}}$ for four acids (and $\mathrm{n}=0$ ). (Left): calculation based on Equation (43); (right): calculation based on the polynomial (44).

Remark. To show that the main polynomial is indeed of degree $\mathrm{N}+2$, you can transform Equation (44) into the following form:

$$
0=\sum_{j=0}^{N+2} h_{j} x^{N+2-j} \quad \text { with } \quad h_{j}=k_{j}+k_{j-1}(n+1-j) C_{T}-k_{j-2} K_{w}
$$

The first and the last coefficients of this polynomial are: $h_{0}=1$ and $h_{N+2}=-K_{w} K_{1} K_{2} \ldots K_{N}$. [Note: $k_{j}$ is per definition zero for negative values of $j$ and for $j>N$ ].

\subsection{Equivalence Points}

An equivalence point (EP) is a special equilibrium state at which chemically equivalent quantities of an acid and a base have been mixed:

$$
\text { equivalence point: } \quad[\text { acid }]=[\text { base }]
$$

In titration, it is the point where all of the acid/base has been neutralized. In the next Sections, we will extend this perspective/definition. Equivalence points can be introduced in two ways: (i) within the 1-component system " $\mathrm{H}_{\mathrm{N}} \mathrm{A}$ ", which leads to a widely used approach with simple formulas, and (ii) within the 3-component acid-base system, which provides a strict and more general definition of EPs (including the first definition as an approximation).

\subsubsection{EPs of the 1-Component System $\left(\mathrm{H}_{\mathrm{N}} \mathrm{A}\right)$}

Even though the 1-component system does not involve a strong base, the concept in Equation (49) can still be applied, but in a modified form. For this purpose, recall that a polyprotic acid dissociates in successive steps, whereby each dissociation step (by releasing one $\mathrm{H}^{+}$) relates an acid species to its conjugate base-see Equation (3). In this context, Equation (49) relates conjugate acid-base pairs:

$$
\text { equivalence point: [acid }]=[\text { conjugate base }]
$$

This gives rise to a whole series of equivalence points, as defined by

$$
\begin{array}{llll}
\text { EP: } & {[j-1]=[j+1]} & \Rightarrow & \\
\text { semi-EP: } & {[j-1]=[j]} & \Rightarrow & a_{j-1}(x)=a_{j+1}(x) \\
& & & a_{j-1}(x)=a_{j}(x)
\end{array}
$$

They are easily recognizable as intersection points of two curves in the ionizationfraction diagrams of Figure 3 (where semi-EPs are marked as small blue circles and EPs as small yellow circles).

An N-protic acid has $\mathrm{N}+1$ integer-valued EPs (the same number as the number of acid species) plus $\mathrm{N}$ semi-EPs. In total, there are $2 \mathrm{~N}+1$ equivalence points, henceforth 
symbolized by $\mathrm{EP}_{\mathrm{n}}$, where $\mathrm{n}$ runs over all integer and half-integer values: $\mathrm{n}=0, \frac{1}{2}, 1, \ldots, \mathrm{N}$ $-\frac{1}{2}, \mathrm{~N}$. The idea behind the index conversion from $\mathrm{j}$ to $\mathrm{n}$ becomes clear in the next Section where all equivalence points are related to the equivalent fraction $\mathrm{n}$ in Equation (33). To recall: In contrast to $n, j$ is an integer (never a half-integer); $j$ indicates the acid species [ $j]$, the acidity constants $K_{j}$, and the ionization fraction $a_{j}$. In the new notation, Equations (51) and (52) become:

$$
\begin{array}{lll}
\mathrm{EP}_{\mathrm{n}}: & {[\mathrm{n}-1]=[\mathrm{n}+1]} & (\text { for integer } \mathrm{n}=0,1, \ldots \mathrm{N}) \\
\text { semi-EP } \mathrm{n}: & {\left[\mathrm{n}-\frac{1}{2}\right]=\left[\mathrm{n}+\frac{1}{2}\right]} & \left(\text { for half-integer } \mathrm{n}=\frac{1}{2}, 3 / 2, \ldots \mathrm{N}-\frac{1}{2}\right)
\end{array}
$$

where the simple transformation rule is applied: $n=j$ for EPs and $n=j-\frac{1}{2}$ for semi-EPs-see Appendix C.1).

Example for Equation (53): In carbonate systems, $\mathrm{EP}_{1}$ is often introduced as the equilibrium state for which $\left[\mathrm{CO}_{2}\right]=\left[\mathrm{CO}_{3}{ }^{-2}\right]$ applies. Another example is the triprotic acid $(\mathrm{N}=3)$ in Figure 12, which dissolves into $3+1$ species: $\mathrm{H}_{3} \mathrm{~A}, \mathrm{H}_{2} \mathrm{~A}^{-1}, \mathrm{HA}^{-2}$, and $\mathrm{A}^{-3}$. There are $2 \times 3+1$ equivalence points $\mathrm{EP}_{\mathrm{n}}$ with $\mathrm{n}=0, \frac{1}{2}, 1, \ldots 3$.

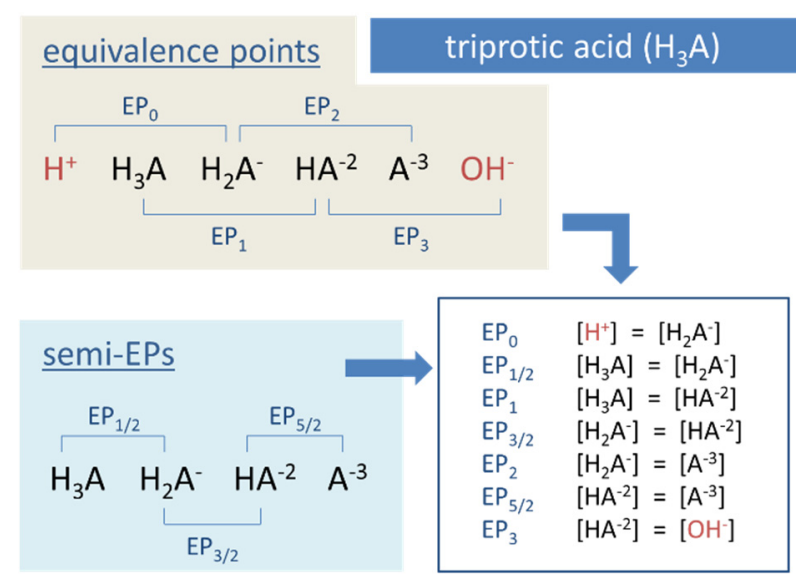

Figure 12. Equivalence points of a triprotic acid—the common approach.

As already indicated in Section 2.1.4 and Table 2 (last row), there is another important subdivision that differentiates between so-called external and internal EPs:

$$
\begin{aligned}
& \text { external (or outer) equivalence points } \quad \mathrm{EP}_{0} \text { and } \mathrm{EP}_{\mathrm{N}} \quad \text { (only two!) } \\
& \text { internal (or inner) equivalence points all other } \mathrm{EP}_{\mathrm{n}} \quad\left(\text { for } \frac{1}{2} \leq \mathrm{n} \leq \mathrm{N}-\frac{1}{2}\right. \text { ) }
\end{aligned}
$$

The two external EPs are special, because they are linked to non-acid species $\mathrm{H}^{+}$ and $\mathrm{OH}^{-}$, as highlighted in red in Figure 12. In $\mathrm{pH}$ diagrams, they are positioned at the opposite ends of the entire $\mathrm{EP}_{\mathrm{n}}$ sequence (see Figures 13-15).

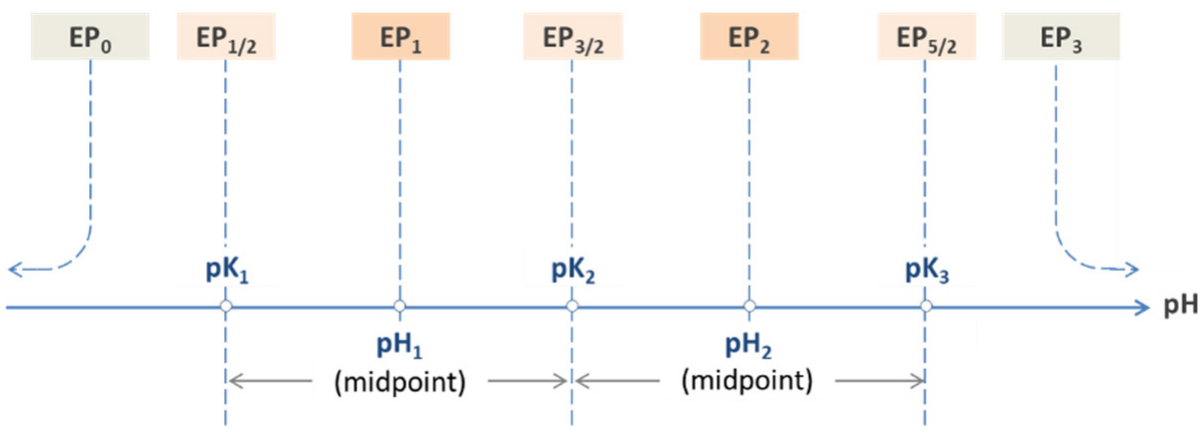

Figure 13. Equivalence points of a triprotic acid $\mathrm{H}_{3} \mathrm{~A}$ arranged on the $\mathrm{pH}$ scale. 


\section{$\mathrm{H}_{2} \mathrm{~A}$ (carbonic acid)}

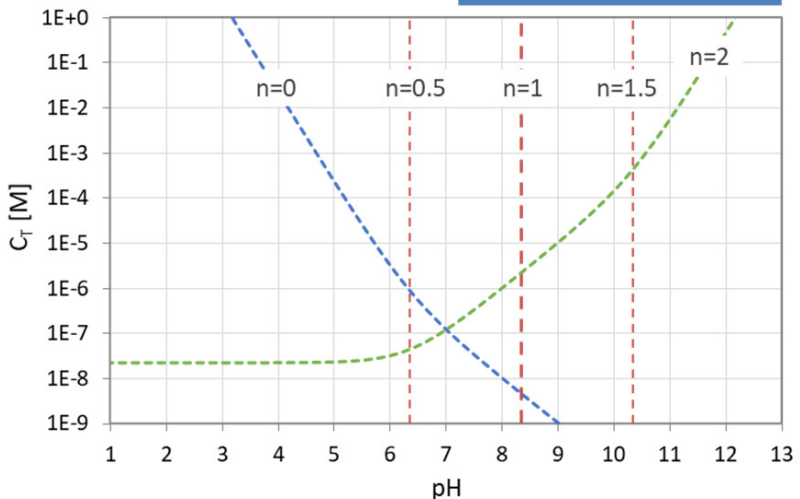

\section{$\mathrm{H}_{3} \mathrm{~A}$ (phosphoric acid)}

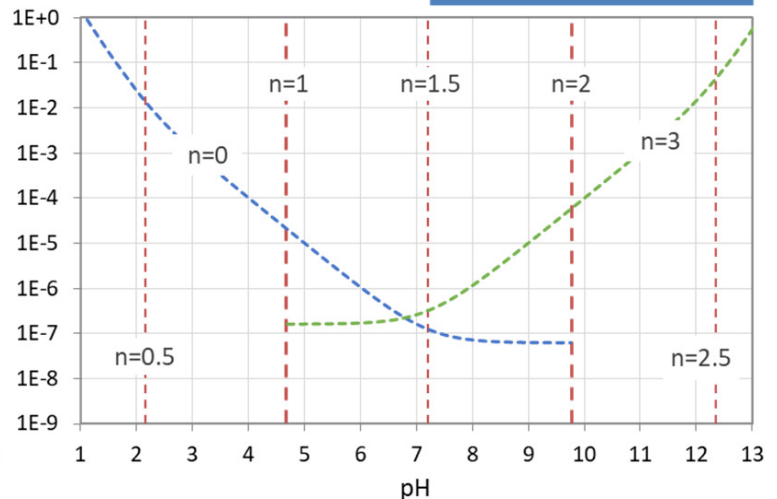

Figure 14. $\mathrm{pH}-\mathrm{C}_{\mathrm{T}}$ diagrams for a diprotic and triprotic acid-the common approach.

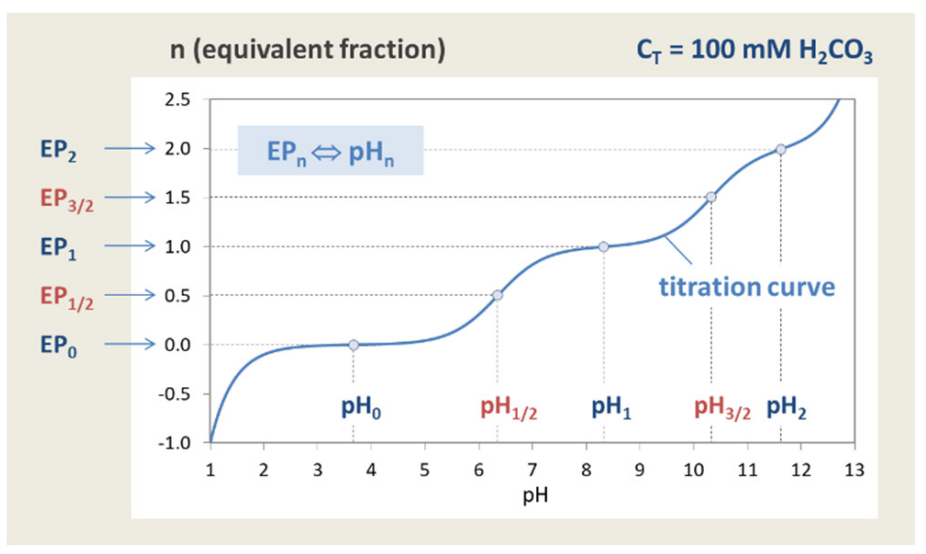

Figure 15. Relationship $\mathrm{EP}_{\mathrm{n}} \Leftrightarrow \mathrm{pH}_{\mathrm{n}}$. EPs and semi-EPs are located at integer and half-integer values of $\mathrm{n}$ on the titration curve. Calculation for $100 \mathrm{mM} \mathrm{H}_{2} \mathrm{CO}_{3}$.

Each $\mathrm{EP}_{\mathrm{n}}$ is characterized by a specific $\mathrm{pH}$ value called $\mathrm{pH}_{\mathrm{n}}$. The $2 \mathrm{~N}-1$ internal $\mathrm{EPs}$ provide particularly simple formulas that establish a direct link to the acidity constants:

$$
\mathrm{pH}_{\mathrm{n}}=\left\{\begin{array}{cccc}
\frac{1}{2}\left(\mathrm{pK}_{\mathrm{n}}+\mathrm{pK}_{\mathrm{n}+1}\right) & \Leftrightarrow & \mathrm{EP}_{\mathrm{n}} & \text { (for integer } \mathrm{n} \text {, except } 0 \text { and } \mathrm{N} \text { ) } \\
\mathrm{pK}_{\mathrm{n}+1 / 2} & \Leftrightarrow & \text { semi-EP } & \text { (for half-integer } \mathrm{n} \text { ) }
\end{array}\right.
$$

This is obtained from Equations (51) and (52) by inserting Equation (17) into $a_{j-1}=a_{j+1}$ and $a_{j-1}=a_{j}$ (then use the transformation rule: $n=j$ for EPs, $n=j-\frac{1}{2}$ for semi-EPs).

Table 3 lists the internal equivalence points of four acids calculated with Equation (55). As shown on the $\mathrm{pH}$ scale in Figure 13, each $\mathrm{EP}_{\mathrm{n}}$ is the midpoint between two adjacent semi-EPs.

Table 3. Internal equivalence points (based on pK values in Table 1).

\begin{tabular}{llccccc}
\hline $\mathbf{N}$ & Acid & $\mathbf{p H}_{\mathbf{1 / 2}}$ & $\mathbf{p H}_{\mathbf{1}}$ & $\mathbf{p H}_{\mathbf{3} / \mathbf{2}}$ & $\mathbf{p H}_{\mathbf{2}}$ & $\mathbf{p H}_{\mathbf{5} / \mathbf{2}}$ \\
\hline 1 & acetic acid & 4.76 & & & & \\
2 & (composite) carbonic acid & 6.35 & 8.34 & 10.33 & & \\
3 & phosphoric acid & 2.15 & 4.68 & 7.21 & 9.78 & 12.35 \\
3 & citric acid & 3.13 & 3.94 & 4.76 & 5.58 & 6.4 \\
\hline
\end{tabular}


For the two external EPs, such simple formulas do not exist. In contrast, $\mathrm{pH}_{0}$ and $\mathrm{pH}_{\mathrm{N}}$ depend sensitively on $\mathrm{C}_{\mathrm{T}}$. This relationship can only be expressed in implicit form:

$$
\begin{array}{lclll}
\mathrm{EP}_{0}: & {\left[\mathrm{H}^{+}\right]=[1] \quad} & \Rightarrow & \mathrm{x}=\mathrm{C}_{\mathrm{T}} \mathrm{a}_{1} \quad \Rightarrow & \mathrm{C}_{\mathrm{T}}=\frac{\mathrm{x}^{2}}{\mathrm{~K}_{1}} \cdot \frac{1}{\mathrm{a}_{0}(\mathrm{x})} \\
\mathrm{EP}_{\mathrm{N}}: & {[\mathrm{N}-1]=\left[\mathrm{OH}^{-}\right]} & \Rightarrow & \mathrm{C}_{\mathrm{T}} \mathrm{a}_{\mathrm{N}-1}=\frac{\mathrm{K}_{\mathrm{W}}}{\mathrm{x}} \quad \Rightarrow \quad \mathrm{C}_{\mathrm{T}}=\frac{\mathrm{K}_{\mathrm{W}} \mathrm{K}_{\mathrm{N}}}{\mathrm{x}^{2}} \cdot \frac{1}{\mathrm{a}_{\mathrm{N}}(\mathrm{x})}
\end{array}
$$

The scheme in Figure 13 illustrates how the $2 \times 3+1$ equivalence points of a triprotic acid are marshalled in ascending order on the $\mathrm{pH}$ scale, with $\mathrm{EP}_{0}$ and $\mathrm{EP}_{3}$ at the extreme left and right positions. For $\mathrm{C}_{\mathrm{T}} \rightarrow \infty$ the two external EPs drift apart: $\mathrm{pH}_{0} \rightarrow 0$ and $\mathrm{pH}_{3} \rightarrow 14$, while all internal EPs remain fixed at the position dictated by the $\mathrm{pK}$ values in Equation (55).

The same behavior is displayed in Figure 14, where the equivalence points of the carbonic acid (left) and the phosphoric acid (right) are plotted in $\mathrm{pH}-\mathrm{C}_{\mathrm{T}}$ diagrams. Again, the internal equivalence points (red color) are independent of $\mathrm{C}_{\mathrm{T}}$, and therefore straight vertical lines, whereas the two external EPs (blue and green) are not. The representation of the curves as dashed instead of solid lines is to remind us that these are approximations, valid for the 1-component system only. The general case will be discussed later and is shown in Figure 27.

\subsubsection{EPs of the 3-Component Acid-Base System}

In the most general sense, equivalence points are equilibrium states in which the equivalent fraction $\mathrm{n}=\mathrm{C}_{\mathrm{B}} / \mathrm{C}_{\mathrm{T}}$ becomes an integer or half-integer value:

$$
\begin{array}{llll}
\mathrm{EP}_{\mathrm{n}} & \Leftrightarrow & \mathrm{C}_{\mathrm{B}} / \mathrm{C}_{\mathrm{T}}=\mathrm{n} & \text { for } \mathrm{n}=0,1, \ldots \mathrm{N} \\
\text { semi-EP } & \Leftrightarrow & \mathrm{C}_{\mathrm{B}} / \mathrm{C}_{\mathrm{T}}=\mathrm{n} & \text { for } \mathrm{n}=\frac{1}{2}, 3 / 2, \ldots \mathrm{N}-\frac{1}{2}
\end{array}
$$

An $\mathrm{N}$-protic acid has a total of $2 \mathrm{~N}+1$ equivalence points (i.e., the same number as in the 1-component system). In this context, the original idea in Equation (49) represents only one special case, namely $\mathrm{EP}_{1}$ with $\mathrm{n}=1$. The particular case $\mathrm{n}=0$ (or $\mathrm{EP}_{0}$ ) refers to the base-free 2-component system with $\mathrm{pH}_{0}$ as the equilibrium $\mathrm{pH}$ of the acid with amount $\mathrm{C}_{\mathrm{T}}$ dissolved in pure water.

The algebraic relation between $\mathrm{EP}_{\mathrm{n}}$ and $\mathrm{pH}_{\mathrm{n}}$ is dictated by Equation (41), that is:

$$
\mathrm{EP}_{\mathrm{n}} \Leftrightarrow \mathrm{pH}_{\mathrm{n}}: \quad \mathrm{n}=\mathrm{Y}_{1}\left(\mathrm{pH}_{\mathrm{n}}\right)+\frac{\mathrm{w}\left(\mathrm{pH}_{\mathrm{n}}\right)}{\mathrm{C}_{\mathrm{T}}} \text { for } \mathrm{n}=0, \frac{1}{2}, 1, \ldots \mathrm{N}
$$

Figure 15 shows all five equivalence points of the diprotic acid $\mathrm{H}_{2} \mathrm{CO}_{3}$ with integer and half-integer values of $n$ on the titration curve $n=n(p H)$. More examples are given in Section 3.2. proach:

For $C_{T} \gg w$, the last term in Equation (60) vanishes, leading to the 1-component ap-

$$
\mathrm{Y}_{1}\left(\mathrm{pH}_{\mathrm{n}}\right)-\mathrm{n}=0
$$

This approximation works for $\mathrm{C}_{\mathrm{T}}>10^{-3} \mathrm{M}$, but fails miserably for very dilute acids when the autoprotolysis of water becomes dominant—cf. Figure 28. [Note: Equations (61) and (55) are equivalent for $\mathrm{N} \leq 2$, but deviate for higher $\mathrm{N}$, though the deviation is very small].

The scheme in Figure 16 contrasts the 1-component approach based on Equation (61) with the general and strict approach based on Equation (60). While the first approach relies on the equality of species concentrations, the second relies on the equality of two real chemical components (the acid $\mathrm{H}_{\mathrm{N}} \mathrm{A}$ and the strong base). As $\mathrm{C}_{\mathrm{T}}$ increases, the two approaches become more and more similar. 


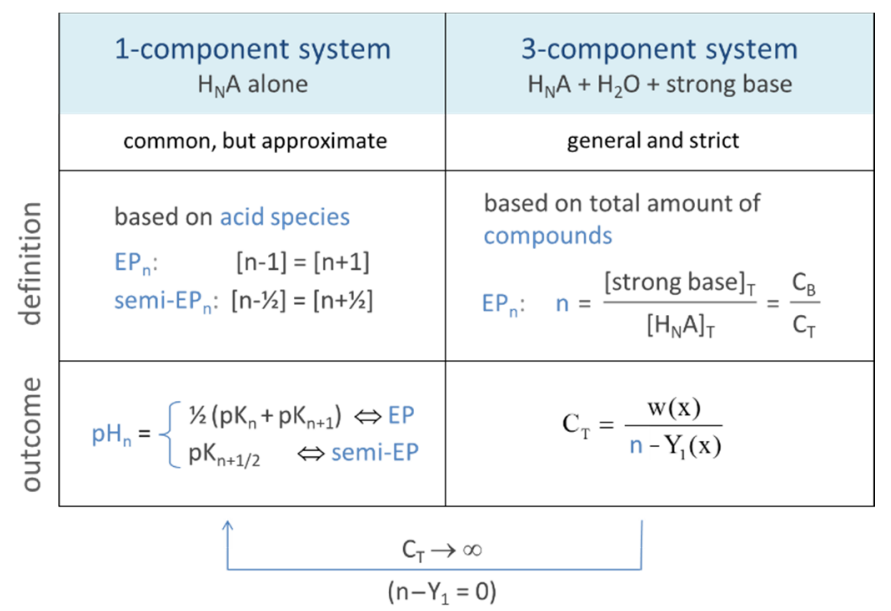

Figure 16. Two approaches to equivalence points.

\subsection{Buffer Capacities}

\subsubsection{ANC and BNC}

An equilibrium state of the acid-base system with a given amount of $C_{T}$ is fully specified by the parameter $C_{B}$ or $n=C_{B} / C_{T}$. Buffer capacities are "distances" between two equilibrium states, expressed as the difference/deviation from a reference point:

$$
\Delta \mathrm{n}=\mathrm{n}-\mathrm{n}_{\mathrm{ref}} \quad \text { or } \quad \Delta \mathrm{C}_{\mathrm{B}}=\mathrm{C}_{\mathrm{B}}-\mathrm{n}_{\mathrm{ref}} \mathrm{C}_{\mathrm{T}}
$$

The reference point is usually an equivalence point $\mathrm{EP}_{\mathrm{n}=\mathrm{j}}$ (with integer $\mathrm{j}$ ), that is $\mathrm{n}_{\mathrm{ref}}=\mathrm{j}$, yielding:

$$
\Delta \mathrm{n}=\mathrm{n}(\mathrm{x})-\mathrm{j} \quad \text { or } \quad \Delta \mathrm{C}_{\mathrm{B}}=\mathrm{C}_{\mathrm{B}}(\mathrm{x})-\mathrm{j} \cdot \mathrm{C}_{\mathrm{T}} \quad(\text { with } \mathrm{j}=0,1, \ldots)
$$

If $\mathrm{n}_{\text {ref }}=0$, these equations collapse to $\Delta \mathrm{n}=\mathrm{n}$ and $\Delta \mathrm{C}_{\mathrm{B}}=\mathrm{C}_{\mathrm{B}}$. This legitimizes calling $\mathrm{n}$ and $\mathrm{C}_{\mathrm{B}}$ buffer capacities; they measure the distance to $\mathrm{EP}_{0}$.

Two types of buffer capacities are in common use: the acid-neutralizing capacity (ANC) and the base-neutralizing capacity (BNC). The ANC is the amount of basicity of the system that can be titrated with a strong acid to a chosen equivalence point $\mathrm{EP}_{\mathrm{j}}\left(\right.$ at $\left.\mathrm{pH}_{\mathrm{j}}\right)$ :

$$
[\mathrm{ANC}]_{\mathrm{n}=\mathrm{j}}=\mathrm{C}_{\mathrm{B}}(\mathrm{pH})-\mathrm{j} \cdot \mathrm{C}_{\mathrm{T}}
$$

The small subscript $\mathrm{n}$ in the symbol [ANC] $\mathrm{n}$ refers to the chosen reference point, usually $\mathrm{EP}_{\mathrm{n}}$ (with an integer $\mathrm{n}$ ). In the special case of $\mathrm{n}=0$, which corresponds to the base-free 2-component system, the last term vanishes, and the ANC becomes

$$
[\mathrm{ANC}]_{0}=\mathrm{C}_{\mathrm{B}}(\mathrm{pH})
$$

The BNC is the exact opposite of ANC:

$$
[\mathrm{BNC}]_{\mathrm{n}}=-[\mathrm{ANC}]_{\mathrm{n}}
$$

The definition in Equation (64) leads to a simple formula for ANC. Using Equation (41) for $\mathrm{C}_{\mathrm{B}}(\mathrm{pH})=\mathrm{n}_{\mathrm{T}}$ yields:

$$
[A N C]_{n=j}=\left\{Y_{1}(x)-j\right\} C_{T}+w(x)
$$

For example, the amount of strong acid (say $\mathrm{HCl}$ ) required to neutralize the system from startpoint $\mathrm{x}\left(=10^{-\mathrm{pH}}\right)$ to a particular $\mathrm{EP}_{\mathrm{n}}$ (titration endpoint) is: 


$$
\begin{aligned}
& {[A N C]_{0}=\left\{Y_{1}(x)-0\right\} C_{T}+w(x)=\left\{Y_{1}(x) C_{T}+w(x)\right\}-0 \cdot C_{T}} \\
& {[A N C]_{1}=\left\{Y_{1}(x)-1\right\} C_{T}+w(x)=\left\{Y_{1}(x) C_{T}+w(x)\right\}-1 \cdot C_{T}} \\
& {[A N C]_{2}=\left\{Y_{1}(x)-2\right\} C_{T}+w(x)=\left\{Y_{1}(x) C_{T}+w(x)\right\}-2 \cdot C_{T}}
\end{aligned}
$$

The three ANC curves are shown in the top diagram of Figure 17 for carbonic acid $\left(\mathrm{C}_{\mathrm{T}}=10 \mathrm{mM}\right)$. The small circles at $\mathrm{pH}_{0}=4.2, \mathrm{pH}_{1}=8.2$, and $\mathrm{pH}_{2}=11.1$ mark the corresponding $\mathrm{EP}_{\mathrm{n}}$. The curves display the amount of strong acid (normalized by $\mathrm{C}_{\mathrm{T}}$ ) required to remove the inherent basicity and to attain $\mathrm{pH}_{0}$ (blue curve), $\mathrm{pH}_{1}$ (green curve), and $\mathrm{pH}_{2}$ (red curve). Of course, the highest amount (blue curve) is required to attain the lowest $\mathrm{pH}$, namely $\mathrm{pH}_{0}=4.2$. Negative ANC values indicate that the system's acidity should be removed to attain the $\mathrm{EP}_{\mathrm{n}}$ (which is the same as the addition of a strong base-see Equation (66) for BNC). Curves of BNC are shown in the bottom diagram, which is the mirror image of the top diagram.
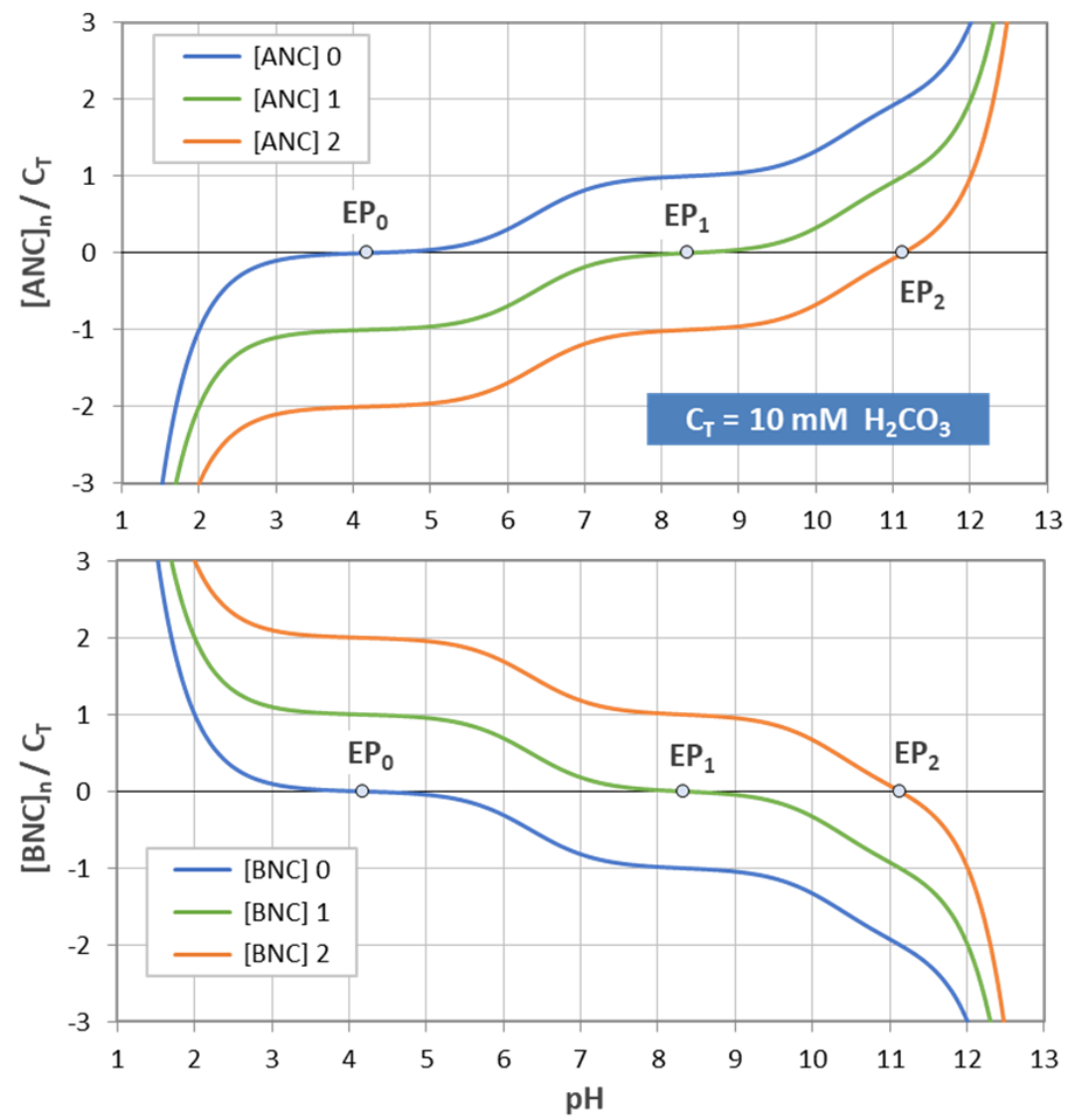

Figure 17. Normalized $[\mathrm{ANC}]_{\mathrm{n}}$ and $[\mathrm{BNC}]_{\mathrm{n}}$ for carbonic acid with $\mathrm{C}_{\mathrm{T}}=10 \mathrm{mM}$.

\subsubsection{Buffer Intensity}

Let us start with the normalized buffer capacity in Equation (63). Using Equation (41) yields:

$$
\text { normalized buffer capacity : } \quad \Delta \mathrm{n}(\mathrm{pH})=\left\{\mathrm{Y}_{1}(\mathrm{pH})-\mathrm{j}\right\}+\frac{\mathrm{w}(\mathrm{pH})}{\mathrm{C}_{\mathrm{T}}}
$$

Via $\mathrm{pH}$ derivation, we obtain:

normalized buffer intensity: buffer intensity:

$$
\begin{array}{ll}
\beta=\mathrm{d} \Delta \mathrm{n} / \mathrm{dpH}=\mathrm{dn} / \mathrm{dpH} & \text { (unitless) } \\
\beta_{\mathrm{C}}=\mathrm{dC}_{\mathrm{B}} / \mathrm{dpH}=\beta \mathrm{C}_{\mathrm{T}} & \text { (in } \mathrm{mM} \text { ) }
\end{array}
$$

[Note: The last equation is valid if $\mathrm{C}_{\mathrm{T}}=$ const (standard case), otherwise we have to use $\left.\mathrm{dC}_{\mathrm{B}} / \mathrm{dpH}=\beta \mathrm{C}_{\mathrm{T}}+\mathrm{n}\left(\mathrm{dC}_{\mathrm{T}} / \mathrm{dpH}\right)\right]$. 
The acid-neutralizing capacity is re-established by integrating $\beta_{C}$ over a definite $\mathrm{pH}$ interval (usually starting from an equivalence point $\mathrm{EP}_{\mathrm{n}}$ ):

$$
[\mathrm{ANC}]_{\mathrm{n}}=\int_{\mathrm{pH}}^{\mathrm{pH}} \beta_{\mathrm{C}}\left(\mathrm{pH}^{\prime}\right) \mathrm{d} \mathrm{pH}^{\prime}
$$

Using the $\mathrm{pH}$ derivatives in Appendix C.2, the following analytical formulas for the first and second $\mathrm{pH}$ derivative of Equation (68) are obtained:

$$
\begin{array}{cl}
\text { normalized buffer intensity : } & \beta(x) \equiv \frac{d n}{d p H}=(\ln 10)\left(Y_{2}-Y_{1}^{2}+\frac{w+2 x}{C_{T}}\right) \\
\text { 1st derivative of } \beta: & \frac{d \beta}{d p H}=(\ln 10)^{2}\left(Y_{3}-3 Y_{1} Y_{2}+2 Y_{1}^{3}+\frac{w}{C_{T}}\right)
\end{array}
$$

Figure 18 displays the titration curve (blue) together with the buffer intensity $\beta$ (green) and its first derivative (red) for the $\mathrm{H}_{2} \mathrm{CO}_{3}$ system with $\mathrm{C}_{\mathrm{T}}=100 \mathrm{mM}$. The calculations are performed using Equations (68), (72), and (73). The small circles indicate the EPs and semi-EPs. The EPs are the extreme points of $\beta$ (see also Table 7):

$\begin{array}{llll}\mathrm{EP}_{\mathrm{n}} & \text { (integer } \mathrm{n} \text { ) } & \Leftrightarrow & \text { minimum buffer intensity } \beta \\ \text { semi-EP } & \text { (half-integer } \mathrm{n}) & \Leftrightarrow & \text { maximum buffer intensity } \beta\end{array}$

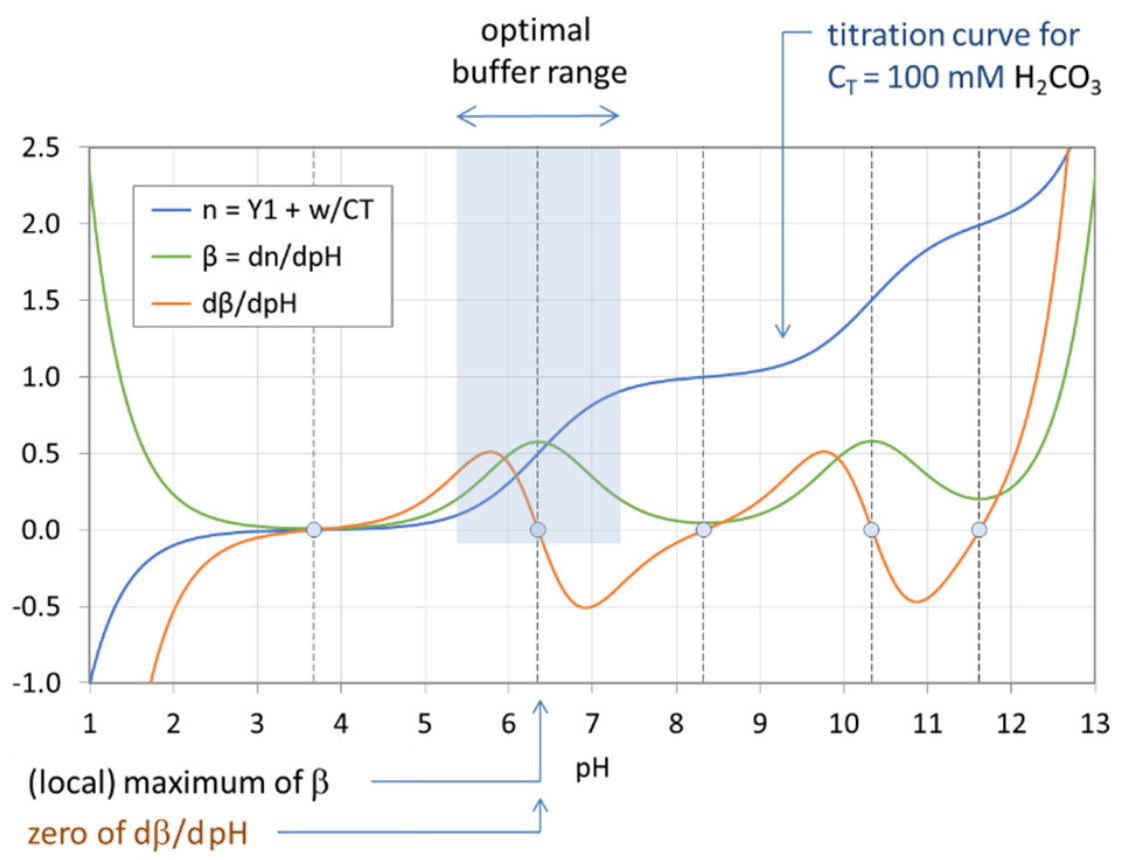

Figure 18. Optimal buffer range of the $\mathrm{H}_{2} \mathrm{CO}_{3}$ system with $\mathrm{C}_{\mathrm{T}}=100 \mathrm{mM}$.

A good $\mathrm{pH}$ buffer should mitigate $\mathrm{pH}$ changes when the system is attacked by a strong base or strong acid. This means that the $\mathrm{pH}$ change $\Delta \mathrm{pH}$ should be small when $\mathrm{n}=\mathrm{C}_{\mathrm{B}} / \mathrm{C}_{\mathrm{T}}$ changes by $\Delta \mathrm{n}$. In other words, the slope of the titration curve in Figure $18, \Delta \mathrm{n} / \Delta \mathrm{pH}$, should be large for maximum buffering capability. The buffer intensity, $\beta=\mathrm{dn} / \mathrm{dpH}$, is just the measure of this slope. Thus, the $\mathrm{pH}$ at the point where $\beta$ reaches its maximum signals the optimal buffer range (bounded by $\mathrm{pH}_{\max } \pm 1$ ). More examples are given in Figures 19 and 20. Since each titration curve (blue) is an ever-increasing function, its $\mathrm{pH}$ derivative, i.e., the buffer intensity $\beta$, is always positive (green curves). [One interesting fact is that the number of zeros of the red curve differs in Figures 19 and 20-this phenomenon will be discussed in Section 3.2.2]. 

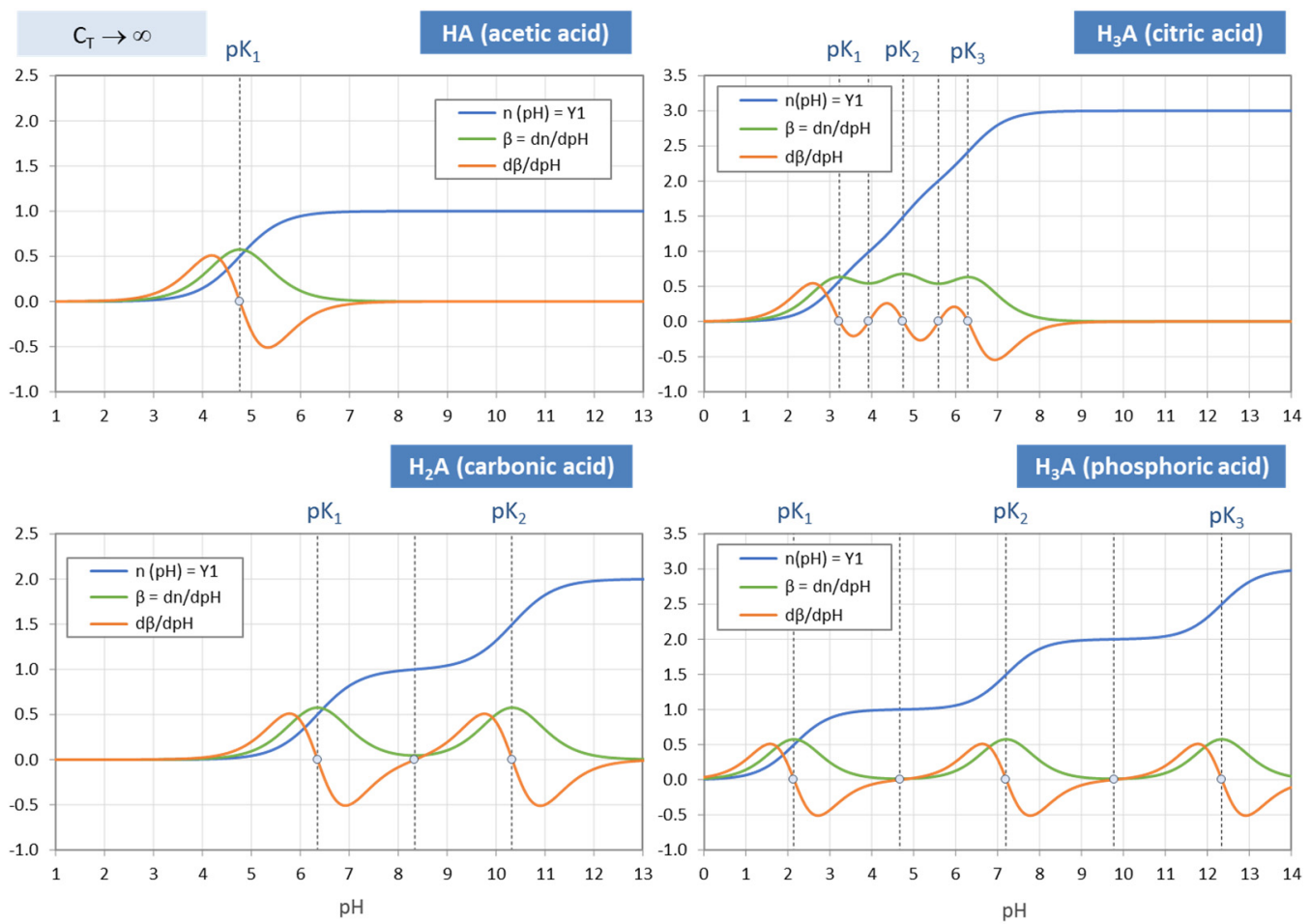

Figure 19. Normalized buffer capacity (blue), buffer intensity (green), and $d \beta / d p H$ (red) for four acids and $C_{T} \rightarrow \infty$.
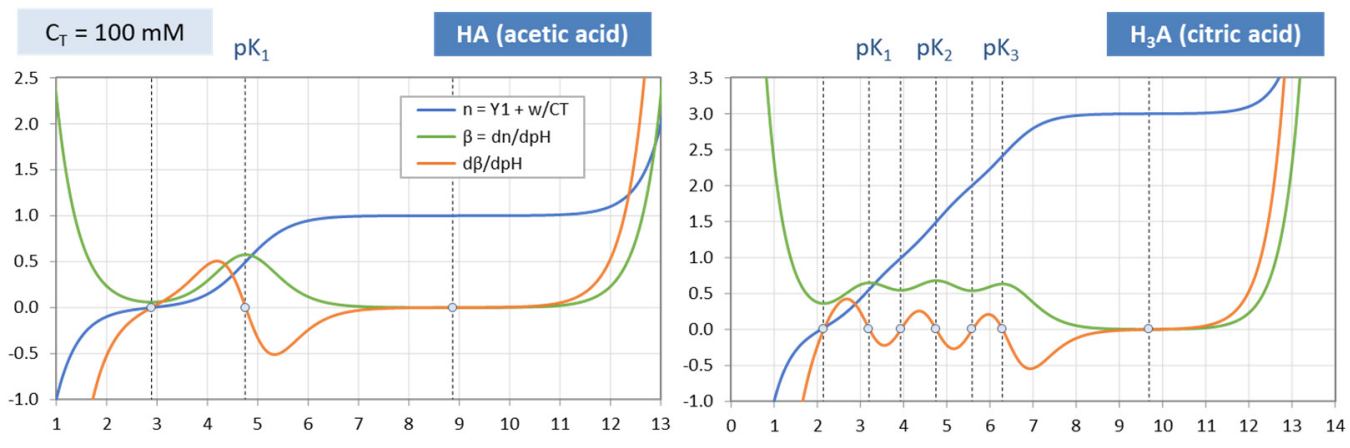

$\mathrm{H}_{2} \mathrm{~A}$ (carbonic acid)
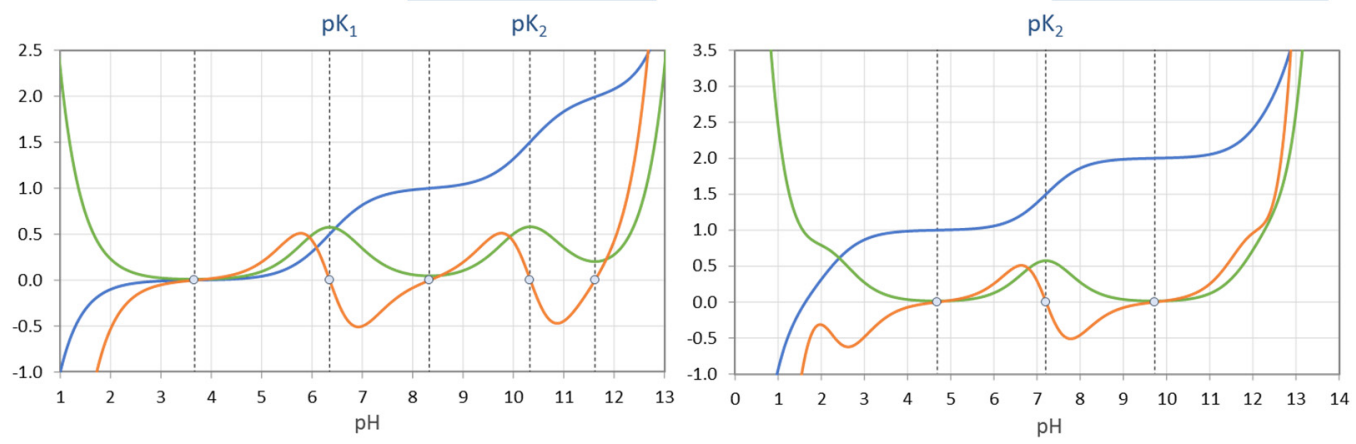

Figure 20. Same as Figure 19, but for $\mathrm{C}_{\mathrm{T}}=100 \mathrm{mM}$.

2.5. Alternative and Statistical Approaches

2.5.1. Dissociation vs. Association Reactions

Acids can be described either by dissociation reactions (deprotonation), as shown in Section 2.1.2 and Equation (13), or as association reactions (protonation or complex 
formation). The corresponding cumulative (overall) equilibrium constants $k_{j}$ and $\beta_{j}$ differ significantly:

$$
\begin{array}{lll}
\text { dissociation: } & \mathrm{H}_{\mathrm{N}} \mathrm{A}=\mathrm{jH}^{+}+\mathrm{H}_{\mathrm{N}-\mathrm{j}} \mathrm{A}^{-\mathrm{j}} & \mathrm{k}_{\mathrm{j}}=\frac{\mathrm{x}^{\mathrm{j}}[\mathrm{j}]}{[0]}=\mathrm{K}_{1} \mathrm{~K}_{2} \ldots \mathrm{K}_{\mathrm{j}} \\
\text { association: } & \mathrm{j} \mathrm{H} \mathrm{H}^{+}+\mathrm{A}^{-\mathrm{N}}=\mathrm{H}_{\mathrm{j}} \mathrm{A}^{-(\mathrm{N}-\mathrm{j})} & \beta_{\mathrm{j}}=\frac{[\mathrm{N}-\mathrm{j}]}{\mathrm{x}^{\mathrm{j}}[\mathrm{N}]}=\frac{\mathrm{k}_{\mathrm{N}-\mathrm{j}}}{\mathrm{k}_{\mathrm{N}}}
\end{array}
$$

They are related to the acidity constants $\mathrm{K}_{\mathrm{j}}$ (single-step deprotonation) as follows:

$$
\begin{array}{ll}
k_{j}=\prod_{i=1}^{j} K_{i}=\frac{\beta_{N-j}}{\beta_{N}} \quad \text { and } k_{0}=1 \\
\beta_{j}=\prod_{i=N+1-j}^{N} \frac{1}{K_{i}}=\frac{k_{N-j}}{k_{N}} \quad \text { and } \beta_{0}=1
\end{array}
$$

This relationship is sketched in Figure 21. In particular, we have $\beta_{1}=1 / \mathrm{K}_{N}$, $\beta_{2}=\left(\mathrm{K}_{\mathrm{N}-1} \mathrm{~K}_{\mathrm{N}}\right)^{-1}$, and $\beta_{\mathrm{N}}=1 / \mathrm{k}_{\mathrm{N}}$. Note that $\beta_{\mathrm{j}}$ is not the reciprocal of $\mathrm{k}_{\mathrm{j}}$, because $\beta_{\mathrm{j}} \mathrm{k}_{\mathrm{j}} \neq 1$ (except for $\mathrm{j}=\mathrm{N}$ ). While dissociation reactions are preferred in hydrochemistry, association reactions are used in other fields (e.g., organic and biochemistry, ligand theory).

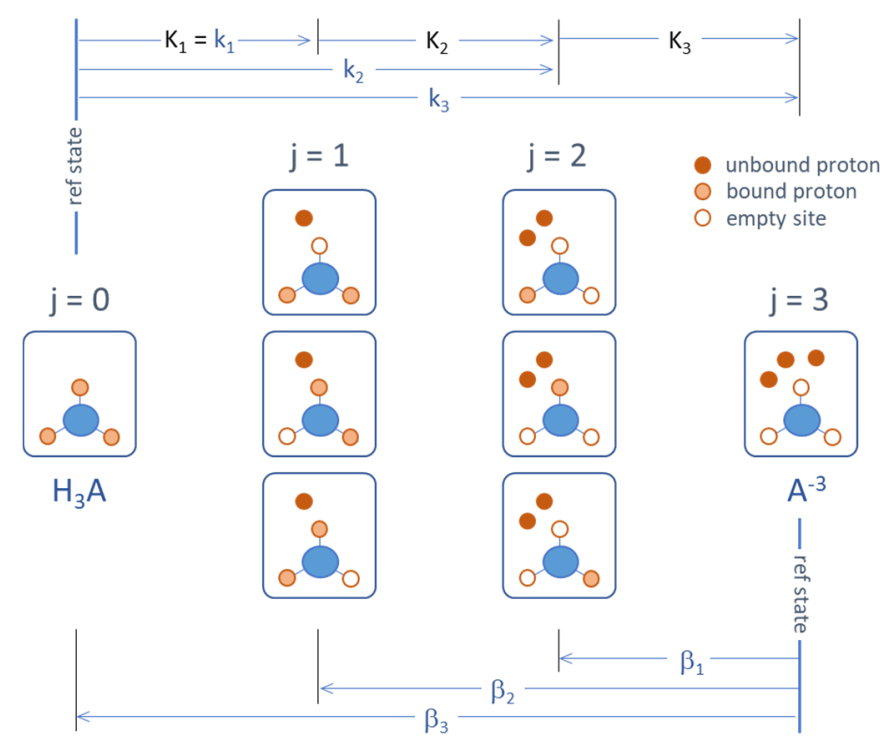

Figure 21. Micro- and macrostates of a triprotic acid and the corresponding (cumulative) equilibrium constants.

The formula in Equation (17) now acquires a kind of partner or mirror equation (based on $\beta_{\mathrm{j}}$ ):

$$
\begin{array}{ll}
\frac{1}{a_{0}}=1+\frac{k_{1}}{x}+\frac{k_{2}}{x^{2}}+\ldots+\frac{k_{N}}{x^{N}} & =\sum_{j=0}^{N} \frac{k_{j}}{x^{j}} \\
\frac{1}{a_{N}}=1+\beta_{1} x+\beta_{2} x^{2}+\ldots+\beta_{N} x^{N} & =\sum_{j=0}^{N} \beta_{j} x^{j}
\end{array}
$$

The ionization fractions $a_{j}$ express the probability that $j$ protons are released from its fully protonated state $\mathrm{H}_{N} A$. Conversely, we denote by $\tilde{a}_{j}=a_{N-j}$ the probability that $j$ protons are bound to the fully deprotonated species $\mathrm{A}^{-\mathrm{N}}$. Thus, we have:

$$
\begin{array}{ll}
\text { j protons released: } & a_{j}=\left(k_{j} / x^{j}\right) a_{0} \\
\text { j protons bound: } & \tilde{a}_{j}=a_{N-j}=\left(k_{N-j} / x^{N-j}\right) a_{0}=\left(\beta_{j} x^{j}\right) a_{N}=\left(\beta_{j} x^{j}\right) \tilde{a}_{0}
\end{array}
$$

Special cases are $\mathrm{a}_{0}=\tilde{\mathrm{a}}_{\mathrm{N}}$ and $\tilde{\mathrm{a}}_{0}=\mathrm{a}_{\mathrm{N}}$. The last expression on the right-hand side represents the definition for the ionization fractions in [26] (where $\tilde{a}_{j}$ is abbreviated as $f_{j}$ ). 
The collection of a $\tilde{j}_{j}$ provides an alternative set of ionization fractions from which acid-base theory can be developed.

\subsubsection{Microstates vs. Macrostates}

A polyprotic acid $\mathrm{H}_{\mathrm{N}} \mathrm{A}$ is a molecule with $\mathrm{N}$ proton-binding sites. Each site is capable of binding 1 proton; the corresponding site-variable has two states: $\alpha_{i}=0$ (empty) and 1 (occupied). In total, there are $2^{\mathrm{N}}$ microstates $\alpha^{(v)}=\left(\alpha_{1}, \alpha_{2}, \ldots \alpha_{\mathrm{N}}\right)$, which form a statistical ensemble. The microstates can be grouped into $\mathrm{N}+1$ macrostates [j], characterized by the number $\mathrm{j}$ of protons released from the fully protonated state $\mathrm{H}_{\mathrm{N}} \mathrm{A}$ (undissociated acid). The number of microstates that form the macrostate [j] is equal to the number of microstates that form the macrostate $[\mathrm{N}-\mathrm{j}]$ and is given by

$$
\left(\begin{array}{c}
N \\
j
\end{array}\right)=\frac{N !}{(N-j) ! j !}
$$

Among them are two microstates that are themselves macrostates, namely:

$$
\begin{aligned}
& \alpha^{(0)}=(0,0, \ldots 0): \mathrm{A}^{-\mathrm{N}} \quad \text { fully dissociated state ("empty") } \quad \mathrm{j}=\mathrm{N} \text { protons released } \\
& \alpha^{\left(2^{\wedge} \mathrm{N}-1\right)}=(1,1, \ldots 1): \mathrm{H}_{\mathrm{N}} \mathrm{A} \quad \text { undissociated state (fully occupied) } \quad \mathrm{j}=0 \text { protons released }
\end{aligned}
$$

One of these two states can be chosen as the reference state (with Gibbs energy $G=0$ ). The other $2^{\mathrm{N}}-1$ microstates are then coupled to this reference state by $2^{\mathrm{N}}-1$ microscopic equilibrium constants $\kappa_{\gamma}$. In this report, the reference state is $\mathrm{H}_{N} \mathrm{~A}=[0]$ defined by $\mathrm{j}=0$; the corresponding reaction type is the dissociation in Equation (74). In contrast, for association reactions in Equation (75), the reference state is $\mathrm{A}^{-\mathrm{N}}$.

A monoprotic acid $(\mathrm{N}=1)$ has two macrostates (being the two microstates defined above) and is completely determined by a single acidity constant $K_{1}=\kappa_{1}$. The case $\mathrm{N}=2$ (diprotic acid) has four microstates $(0,0),(0,1),(1,0)$, and $(1,1)$, from which three macrostates are formed $j=0,1$, and 2 , whereby the macrostate $j=1$ includes the two microstates $(0,1)$ and $(1,0)$. For $\mathrm{N}=3$, the six microstates and three macrostates are shown in Figure 21 (which constitutes the third row of Pascal's triangle).

\subsubsection{Probability Distributions and Averages}

The two ionization fractions associated with the two reference states, $\mathrm{a}_{0}$ and $\mathrm{a}_{\mathrm{N}}$, are distinguished from all others by having a sigmoidal (S-shaped) curve, as discussed in Section 2.1.4. Their asymptotical values for $\mathrm{pH}= \pm \infty$ are 0 and 1 , so that $\mathrm{a}_{0}$ and $\mathrm{a}_{\mathrm{N}}$ embody cumulative distribution functions which gives the area under the probability density functions $\mathrm{f}_{0}$ and $\mathrm{f}_{\mathrm{N}}$ :

$$
f_{j} \equiv \frac{d a_{j}}{d p H}=\ln 10\left(j-Y_{1}\right) a_{j} \Leftrightarrow a_{j}=\int_{-\infty}^{p H} f_{j}\left(p H^{\prime}\right) d p H^{\prime}(\text { for } j=0 \text { and } N)
$$

Two examples are shown in Figure 22, where $a_{j}$ and its antiderivative $f_{j}$ are drawn with the same color (red for $j=0$ and blue for $j=N$ ). The minima and maxima of $f_{0}$ and $\mathrm{f}_{\mathrm{N}}$ correspond to the inflection points of $\mathrm{a}_{0}$ and $\mathrm{a}_{\mathrm{N}}$. The asymptotic behavior of $\mathrm{a}_{0}$ and $\mathrm{a}_{\mathrm{N}}$ dictates that the probability densities are automatically normalized to 1 :

$$
\int_{-\infty}^{+\infty} f_{N} d p H=-\int_{-\infty}^{+\infty} f_{0} d p H=1
$$

Here, the minus sign reflects the fact that the slopes of $\mathrm{a}_{0}$ and $\mathrm{a}_{\mathrm{N}}$ are opposite. 

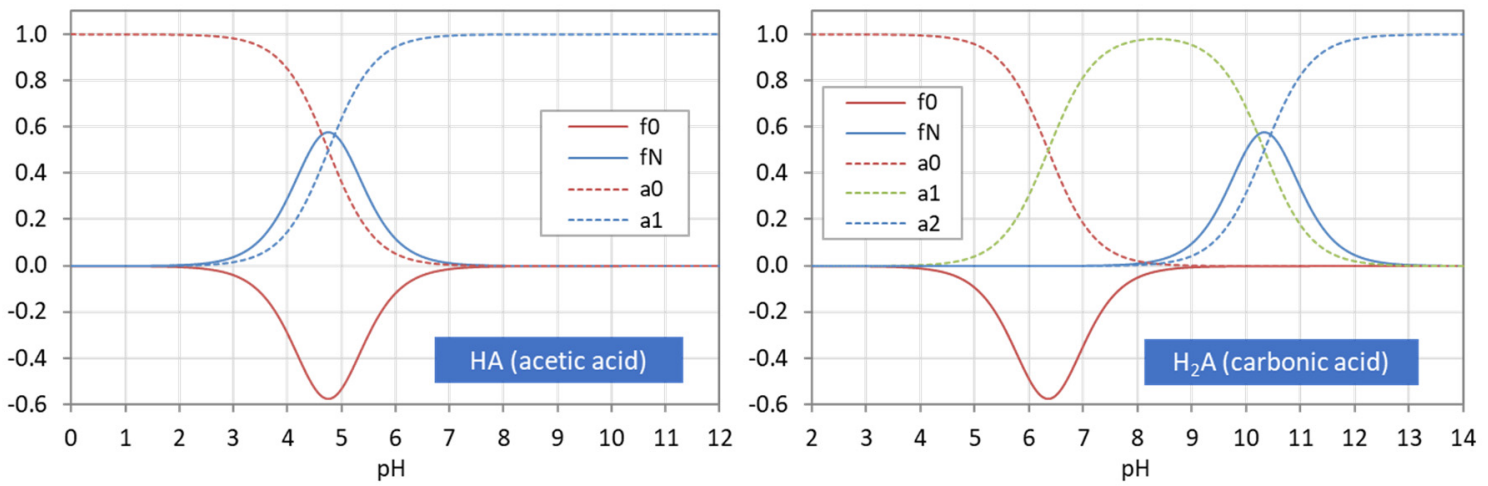

Figure 22. Ionization fractions $a_{j}$ (dashed curves) and probability density functions $f_{0}$ and $f_{N}$.

Monoprotic acids are special. The two probability densities, shown as blue and red solid curves in the left diagram, are the same except for a minus sign:

$$
\mathrm{f}_{\mathrm{N}=1}=\ln 10 \frac{\mathrm{K}_{1} / \mathrm{x}}{\left(1+\mathrm{K}_{1} / \mathrm{x}\right)^{2}}=-\mathrm{f}_{0}
$$

$\mathrm{a}_{0}$, which is the $\mathrm{pH}$ derivative of $\mathrm{f}_{0}$, is also known as the protonation probability of an isolated site, i.e., the probability that a monoprotic acid remains undissociated:

$$
\mathrm{a}_{0}=\frac{1}{1+\mathrm{K}_{1} / \mathrm{x}}=\frac{1}{1+10^{\mathrm{pH}-\mathrm{pK}_{1}}}
$$

This function, which is shown as the dashed red curve in the left diagram in Figure 22, bears a striking similarity to the Fermi-Dirac distribution in statistical physics $[37,38]$, where $\mathrm{pK}_{1}$ mimics the Fermi energy (except for a prefactor $\left(\mathrm{k}_{\mathrm{B}} \mathrm{T}\right)^{-1}$ consisting of the Boltzmann constant and temperature).

The ionization fraction $\mathrm{a}_{\mathrm{j}}$, as a number between 0 and 1 , represents the probability that $\mathrm{j}$ protons are released (at a given $\mathrm{pH}$ ). The average number $\langle\mathrm{j}\rangle$ of protons released is then obtained by averaging over all ionization fractions $\mathrm{a}_{\mathrm{j}}$ :

$$
\langle j\rangle=\frac{\sum_{j=0}^{N} j \cdot a_{j}}{\sum_{j=0}^{N} a_{j}}=\sum_{j=0}^{N} j \cdot a_{j}=Y_{1}
$$

In other words, the first moment $\mathrm{Y}_{1}$ embodies the average number of released protons. Note that $\langle\mathrm{j}\rangle=[\mathrm{j}]_{\mathrm{avg}} / \mathrm{C}_{\mathrm{T}}$ is a real number between 0 and $\mathrm{N}$, as displayed by the $\mathrm{Y}_{1}$ curves in Figure 6. The result in Equation (87) can be generalized to any power $L$ of $a_{j}$, interpreting the moments $\mathrm{Y}_{\mathrm{L}}$ (originally introduced in Equation (22)) as expectation values:

$$
\left\langle j^{\mathrm{L}}\right\rangle=\mathrm{Y}_{\mathrm{L}}
$$

\subsubsection{Partition Functions and Moments in Statistics}

The ensemble of $\mathrm{N}+1$ macrostates [j] is specified by $\mathrm{N}$ acidity constants $\mathrm{K}_{\mathrm{j}}$ (or ionization fractions $\mathrm{a}_{\mathrm{j}}$ ). As in statistical mechanics, we can introduce a partition function, as a sum over all states [j], from which relevant "thermodynamic" quantities are then obtained by differentiation. Depending on the reference state (either [0] or $[\mathrm{N}]$ ), there are two ways to define the partition function:

$$
\begin{array}{ll}
\text { ref. state }[0]=\mathrm{H}_{\mathrm{N}} \mathrm{A}: & \mathcal{Q} \equiv \frac{[0]}{[0]}+\frac{[1]}{[0]}+\frac{[2]}{[0]}+\ldots+\frac{[\mathrm{N}]}{[0]}=\sum_{\mathrm{j}=0}^{\mathrm{N}}\left(\frac{\mathrm{a}_{\mathrm{j}}}{\mathrm{a}_{0}}\right)=\frac{1}{\mathrm{a}_{0}} \\
\text { ref. state }[\mathrm{N}]=\mathrm{A}^{-\mathrm{N}}: & \mathcal{Z} \equiv \frac{[\mathrm{N}]}{[\mathrm{N}]}+\frac{[\mathrm{N}-1]}{[\mathrm{N}]}+\ldots+\frac{[0]}{[\mathrm{N}]}=\sum_{\mathrm{j}=0}^{\mathrm{N}}\left(\frac{\mathrm{a}_{\mathrm{j}}}{\mathrm{a}_{\mathrm{N}}}\right)=\frac{1}{\mathrm{a}_{\mathrm{N}}}
\end{array}
$$


The first approach is based on dissociation reactions (defined by cumulative acidity constants $\mathrm{k}_{\mathrm{j}}$ ), the second on association reactions (defined by $\beta_{\mathrm{j}}$ ). In particular, the so-called binding polynomial $\mathcal{Z}$ was introduced in [32] for the description of ligands that bind to macromolecules. Both partition functions are interrelated by $\mathcal{Q} / \mathcal{Z}=\mathrm{a}_{\mathrm{N}} / \mathrm{a}_{0}=\mathrm{k}_{\mathrm{N}} / \mathrm{x}^{\mathrm{N}}$.

The two partition functions belong to the isothermal-isobaric ensemble (also called the canonical NPT ensemble, where N, P, T refer to particle number, pressure, and temperature) which leads straight to the Gibbs energy $(\mathrm{J} / \mathrm{mol})$ :

$$
\mathrm{G}=-\mathrm{RT} \ln \mathcal{Q}
$$

where $\mathrm{R}$ and $\mathrm{T}$ are the gas constant and temperature, respectively. In thermodynamics, the partial derivative of $\mathrm{G}$ with respect to the chemical potential $\mu$ equals the (average) particle number. Applying it to $\mathrm{H}^{+}$yields (with $\mu_{\mathrm{H}^{+}}=\mathrm{RT} \ln \mathrm{x}$ ):

$$
\langle\mathrm{j}\rangle=\left(\frac{\partial \mathrm{G}}{\partial \mu_{\mathrm{H}^{+}}}\right)_{\mathrm{P}, \mathrm{T}}=-\frac{\mathrm{d} \ln \mathcal{Q}}{\mathrm{d} \ln \mathrm{x}}
$$

The same applies to $\mathcal{Z}$, except for a minus sign. From Equations (89) and (90) and using Equation (A16), we then obtain:

$$
\begin{array}{lrl}
\text { avg number of released protons : } & \langle\mathrm{j}\rangle=-\frac{\mathrm{d} \ln \mathcal{Q}}{\mathrm{d} \ln \mathrm{x}}=\frac{\mathrm{d} \ln \mathrm{a}_{0}}{\mathrm{~d} \ln \mathrm{x}}=\mathrm{Y}_{1} \\
\text { avg number of bound protons : } & \mathrm{N}-\langle\mathrm{j}\rangle=\frac{\mathrm{d} \ln \mathcal{Z}}{\mathrm{d} \ln \mathrm{x}}=-\frac{\mathrm{d} \ln \mathrm{a}_{\mathrm{N}}}{\mathrm{d} \ln \mathrm{x}}=\mathrm{N}-\mathrm{Y}_{1}
\end{array}
$$

Comparing it to the outcome of Equation (87), everything falls into the right place nicely. Note: In the particularly simple case of monoprotic acids $(\mathrm{N}=1)$, the average number of protons released is just $\mathrm{a}_{1}$, and the average number of bound protons is $\mathrm{a}_{0}$.

Higher-order derivatives of $\mathrm{G}$ ( or $\ln Q$ ) with respect to $\mu$ deliver fluctuation measures (in the form of variance, skewness and kurtosis). In particular, for the fluctuation of $j$ around its mean, $\delta j \equiv j-\langle j\rangle$, we get:

$$
\left\langle(\delta \mathrm{j})^{\mathrm{L}}\right\rangle=(-)^{\mathrm{L}}\left(\frac{\mathrm{d}}{\mathrm{d} \ln \mathrm{x}}\right)^{\mathrm{L}} \ln \mathcal{Q}=\frac{1}{(\ln 10)^{\mathrm{L}-1}}\left(\frac{\mathrm{d}}{\mathrm{dpH}}\right)^{\mathrm{L}-1} \mathrm{Y}_{1} \quad \text { for } \mathrm{L} \geq 2
$$

For $\mathrm{L}=1$, this expression is zero because $\langle\boldsymbol{\delta} \mathrm{j}\rangle=\left\langle\mathrm{j}-\mathrm{Y}_{1}\right\rangle=\mathrm{Y}_{1}-\mathrm{Y}_{1}=0$. Most interesting are the moments for $\mathrm{L}=2,3$, and 4 :

$$
\begin{array}{lll}
\text { variance } \sigma^{2}: & \left\langle\left(j-\mathrm{Y}_{1}\right)^{2}\right\rangle=\mathrm{Y}_{2}-\mathrm{Y}_{1}{ }^{2} & =\frac{1}{\ln 10}\left(\frac{\mathrm{d} \mathrm{Y}_{1}}{\mathrm{dpH}}\right) \\
\text { skewness : } & \left\langle\left(j-\mathrm{Y}_{1}\right)^{3}\right\rangle=\mathrm{Y}_{3}-3 \mathrm{Y}_{2} \mathrm{Y}_{1}+2 \mathrm{Y}_{1}{ }^{3} & =\frac{1}{(\ln 10)^{2}}\left(\frac{\mathrm{d}^{2} \mathrm{Y}_{1}}{\mathrm{dpH}}\right) \\
\text { excess kurtosis : } & \left\langle\left(j-\mathrm{Y}_{1}\right)^{4}\right\rangle-3 \sigma^{4}=\left(\mathrm{Y}_{4}-4 \mathrm{Y}_{3} \mathrm{Y}_{1}+6 \mathrm{Y}_{2} \mathrm{Y}_{1}{ }^{2}-3 \mathrm{Y}_{1}{ }^{4}\right)-3 \sigma^{4} & =\frac{1}{(\ln 10)^{3}}\left(\frac{\mathrm{d}^{3} \mathrm{Y}_{1}}{\mathrm{dpH}}\right)
\end{array}
$$

(These formulas can be verified using Equations (A18) through (A20) in Appendix C).

Skewness measures the lack of symmetry. Kurtosis is a measure of whether the distribution is heavy tailed or light tailed; "excess kurtosis" is kurtosis relative to the normal distribution (with a kurtosis of 3 ).

\subsubsection{Decoupled Sites Representation and Simms Constants}

In physics, microscopically complicated systems are often described by the concept of noninteracting quasiparticles (e.g., phonons, magnetons, excitons). This idea was adopted in the decoupled sites representation (DSR) $[33,34]$ by replacing the polyprotic acid with $\mathrm{N}$ interacting proton-binding sites by a sum of $\mathrm{N}$ noninteracting quasisites. As we know from statistical mechanics, partition functions of noninteracting entities factorize into products of individual partition functions (each of them characterizing a virtual monoprotic 
acid with $\mathrm{g}_{\mathrm{i}}$ as its equilibrium constant). Applying this to the partition functions in Equations (89) and (90) using Equations (78) and (79), we obtain:

$$
\begin{array}{ll}
\mathcal{Q}=1+\frac{k_{1}}{\mathrm{x}}+\frac{\mathrm{k}_{2}}{\mathrm{x}^{2}}+\ldots+\frac{\mathrm{k}_{\mathrm{N}}}{\mathrm{x}^{\mathrm{N}}} & =\prod_{\mathrm{i}=1}^{\mathrm{N}}\left(1+\frac{\mathrm{g}_{\mathrm{i}}}{\mathrm{x}}\right) \\
\mathcal{Z}=1+\beta_{1} \mathrm{x}+\beta_{2} \mathrm{x}^{2}+\ldots+\beta_{\mathrm{N}} \mathrm{x}^{\mathrm{N}} & =\prod_{\mathrm{i}=1}^{\mathrm{N}}\left(1+\frac{\mathrm{x}}{\mathrm{g}_{\mathrm{i}}}\right)
\end{array}
$$

The $N$ equilibrium constants $g_{i}$, also known as Simms constants $[20,29,30]$, differ from the $\mathrm{N}$ acidity constants $\mathrm{K}_{\mathrm{j}}$ of the real polyprotic acid (which are deprotonation constants of the jth proton). The relationship can be established by multiplying out the $\mathrm{N}$ products in (99) and (100). After a coefficient comparison, the conversion between the cumulative equilibrium constants and Simms constants is found to be:

$$
\begin{aligned}
& \mathrm{k}_{1}=\sum_{\mathrm{i}=1}^{\mathrm{N}} \mathrm{g}_{\mathrm{i}}, \quad \mathrm{k}_{2}=\sum_{\mathrm{i}=1}^{\mathrm{N}} \sum_{\mathrm{j}<\mathrm{i}}^{\mathrm{N}} \mathrm{g}_{\mathrm{i}} \mathrm{g}_{\mathrm{j}}, \quad \ldots \quad \mathrm{k}_{\mathrm{N}}=\prod_{\mathrm{i}=1}^{\mathrm{N}} \mathrm{g}_{\mathrm{i}} \\
& \beta_{1}=\sum_{i=1}^{N} \frac{1}{g_{i}}, \quad \beta_{2}=\sum_{i=1}^{N} \sum_{j<i}^{N} \frac{1}{g_{i} g_{j}}, \quad \ldots \quad \beta_{N}=\prod_{i=1}^{N} \frac{1}{g_{i}}
\end{aligned}
$$

The full set of equations for the $k_{j}$ encompasses $2^{N}-1$ single terms $\left(g_{1}, g_{2}, g_{3}\right.$, $g_{1} g_{2}, g_{2} g_{3}, g_{1} g_{3}, g_{1} g_{2} g_{3}$ for $N=3$, for example), each of them represents one microscopic equilibrium constant. For $\mathrm{N}=1$ we have the trivial result:

$$
\text { monoprotic acid: } \quad \mathrm{K}_{1}=\mathrm{g}_{1}=\mathrm{k}_{1}=1 / \beta_{1}
$$

Note that a quasisite is a collective phenomenon formed by the interaction of all (real) proton-binding sites.

\subsubsection{Polyprotic Acids as Mixtures of Monoprotic Acids}

Since the description of acid-base equilibria is centered on $n=Y_{1}+w / C_{T}$ in Equation (41), it is sufficient to focus on $Y_{1}$. Applying DSR from Section 2.5.5 for the polyprotic acid, we get:

$$
\mathrm{Y}_{1}=\mathrm{Y}_{1}^{(\text {mono } 1)}+\mathrm{Y}_{1}^{(\text {mono } 2)}+\cdots+\mathrm{Y}_{1}^{(\text {mono } \mathrm{N})}
$$

whereby

$$
\mathrm{Y}_{1}^{(\text {mono } \mathrm{j})}=\mathrm{a}_{1}^{(\text {mono } \mathrm{j})}=\frac{1}{1+\mathrm{x} / \mathrm{g}_{\mathrm{j}}} \quad\left(=\sum_{\mathrm{i}=\mathrm{j}}^{\mathrm{N}} \mathrm{a}_{\mathrm{i}}\right)
$$

The last equation in brackets indicates the relation to the ionization fractions $a_{j}$ based on $\mathrm{K}_{\mathrm{j}}$ values.

In fact, the mathematical treatment of a sum of monoprotic acids is much easier to handle than the polyprotic acid as a whole. However, the use of virtual acidity constants $g_{i}$ instead of the $K_{j}$ shifts the problem to a complicated relationship between the $g_{i}$ and $K_{j}$ values (cf. Equations (101) and (102)).

The criterion for representing the $\mathrm{H}_{\mathrm{N}} \mathrm{A}$ by a mixture of $\mathrm{N}$ monoprotic acids (each of amount $C_{T}$ and one acidity constant $\mathrm{K}_{\mathrm{j}}$ ) is that all $\mathrm{K}_{\mathrm{j}}$ values should be well "separated" from each other:

$$
\mathrm{K}_{1} \gg \mathrm{K}_{2} \gg \ldots \gg \mathrm{K}_{\mathrm{N}} \quad \Leftrightarrow \quad \mathrm{K}_{1} \approx \mathrm{g}_{1}, \mathrm{~K}_{2} \approx \mathrm{g}_{2}, \ldots \mathrm{K}_{\mathrm{N}} \approx \mathrm{g}_{\mathrm{N}}
$$

This assertion is not immediately obvious, but you can clarify it easily for $\mathrm{N}=2$ or 3 , for example.

\subsubsection{The World of Acidity Constants}

Polyprotic acids are specified by the $\mathrm{N}$ acidity constants $\mathrm{K}_{\mathrm{j}}$ (or $\mathrm{pK} \mathrm{K}_{\mathrm{j}}$ values), which describe the step-by-step dissociation without any indication from which specific site the 
$\mathrm{H}^{+}$is released. So, any of all the $\mathrm{N}$ binding sites can contribute to $\mathrm{K}_{1}$ (making $\mathrm{K}_{1}$ the largest value). For $\mathrm{K}_{2}$, as the second dissociation step, the proton comes from any one of the remaining $\mathrm{N}-1$ sites, and so on. This implies the order by size: $K_{1}>K_{2}>\ldots>K_{N}$.

Consider a molecule with identical quasisites of strength $\mathrm{g}$. We then have:

$$
\mathrm{k}_{\mathrm{j}}=\left(\begin{array}{c}
\mathrm{N} \\
\mathrm{j}
\end{array}\right) \mathrm{g} \text { and } \mathrm{K}_{\mathrm{j}}=\frac{\mathrm{N}-\mathrm{j}+1}{\mathrm{j}} \mathrm{g}
$$

where $K_{j}$ decreases from $K_{1}=N g$ to $K_{N}=g / N$. This can also be expressed by $\mathrm{pK}_{\mathrm{N}}-\mathrm{pK}_{1}=2 \lg \mathrm{N}$, which is the minimum separation between the first and the last dissociation constant. For a diprotic and triprotic acid it is 0.60 and 0.95 , respectively. The minimum requirement for two adjacent acidity constants is:

$$
\frac{K_{j}}{K_{j+1}}=\frac{j+1}{j} \frac{N-j+1}{N-j}
$$

This implies once again the sequence: $K_{1}>K_{2}>\ldots>K_{N}$. Conversely, the more the $g_{i}$ deviate from each other, the more the $\mathrm{K}_{\mathrm{j}}$ (and $\mathrm{pK}_{\mathrm{j}}$ ) values drift apart until the condition in Equation (106) is reached (typical for inorganic acids).

The nonlinear relationships between the different types of acidity constants is summarized in Table 4 and Figure 23. The link between the acidity constants $K_{j}$ and Simms constant $g_{i}$ is particularly tricky and obtainable via the cumulative constants (which are sums over all combinations of products of $\left.g_{i}\right)$. To extract the $g_{i}$ values from a set of given acidity constants requires solving polynomials of order $\mathrm{N}$.

\begin{tabular}{|c|c|c|c|c|}
\hline \multirow{2}{*}{$\begin{array}{l}\text { N Acidity } \\
\text { Constants }\end{array}$} & \multicolumn{2}{|c|}{$N+1$ Cumulative Constants for } & \multirow{2}{*}{$\begin{array}{l}\text { N Simms } \\
\text { Constants }\end{array}$} & \multirow{2}{*}{$\begin{array}{c}2^{\mathrm{N}}-1 \\
\text { Microscopic } \\
\text { Constants }\end{array}$} \\
\hline & Dissociation & Association & & \\
\hline \multirow[t]{2}{*}{$\mathrm{K}_{1}, \mathrm{~K}_{2}, \ldots, \mathrm{K}_{\mathrm{N}}$} & $\mathrm{k}_{0}=1$ & $\beta_{0}=1$ & $\mathrm{~g}_{1}, \mathrm{~g}_{2}, \ldots, \mathrm{g}_{\mathrm{N}}$ & $g_{1}, g_{2}, g_{3}, \ldots$ \\
\hline & $\mathrm{k}_{\mathrm{j}}=\prod_{\mathrm{i}=1}^{\mathrm{j}} \mathrm{K}_{\mathrm{i}}$ & $\beta_{j}=\prod_{i=N+1-j}^{N} \frac{1}{K_{i}}$ & $\begin{array}{c}\text { of Equations (101) } \\
\text { and (102)) }\end{array}$ & $\begin{array}{l}\mathrm{g}_{1} \mathrm{~g}_{2} \mathrm{~g}_{3}, \ldots \\
\mathrm{g}_{1} \mathrm{~g}_{2} \cdots \mathrm{g}_{\mathrm{N}}\end{array}$ \\
\hline
\end{tabular}

Table 4. Macroscopic and microscopic acidity constants.

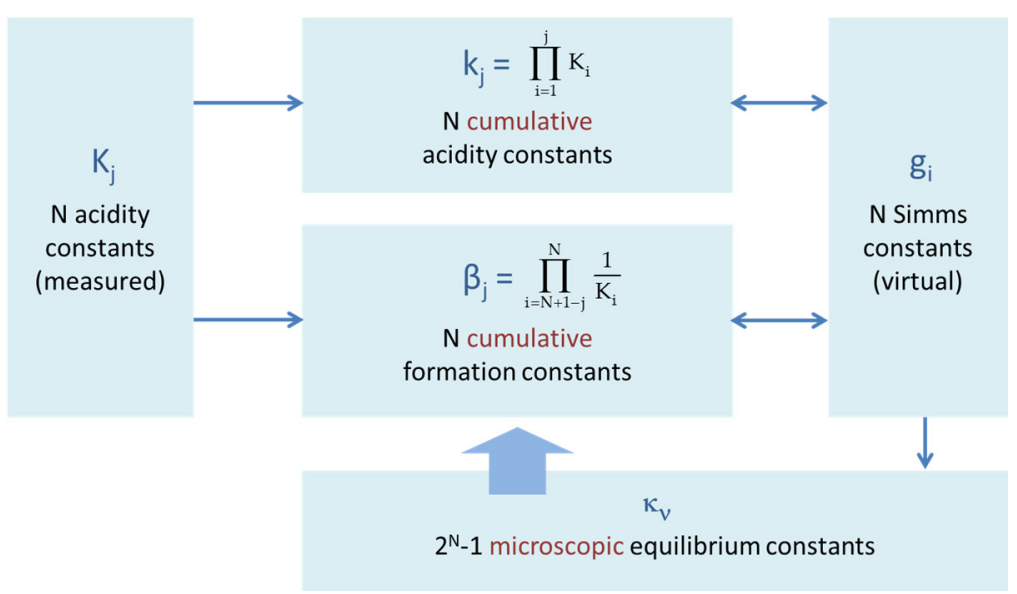

Figure 23. Interrelation between different types of equilibrium constants of a polyprotic acid $\mathrm{H}_{\mathrm{N}} \mathrm{A}$.

\section{Applications}

\subsection{More About Acids}

3.1.1. Strong Acids vs. Weak Acids

Monoprotic Acids. Unlike weak acids, strong acids dissociate completely in water. Let us consider a monoprotic acid specified by $\mathrm{K}_{\mathrm{a}}$ and the amount $\mathrm{C}_{\mathrm{T}} \equiv[\mathrm{HA}]_{\mathrm{T}}$ (which is de 
facto the acid's initial concentration before it dissolves). In the equilibrium state, the total concentration splits into an undissociated and a dissociated part:

$$
\mathrm{C}_{\mathrm{T}}=[\mathrm{HA}]+\left[\mathrm{A}^{-}\right] \text {or } 1=\mathrm{a}_{0}+\mathrm{a}_{1}
$$

The difference between strong and weak acids is summarized in Table 5 .

Table 5. Strong vs. weak acids (greatly simplified).

\begin{tabular}{ccc}
\hline & Strong Acid & Weak Acid \\
\hline acidity constant & $\mathrm{K}_{\mathrm{a}} \gg 1$ & $\mathrm{~K}_{\mathrm{a}} \leq 1$ \\
$\mathrm{pK}=-\lg \mathrm{K}_{\mathrm{a}}$ & $\mathrm{pK}_{\mathrm{a}}<0$ & $\mathrm{pK}_{\mathrm{a}}>0$ \\
{$\left[\mathrm{H}^{+}\right] \approx\left\{\mathrm{H}^{+}\right\}=10^{-} \mathrm{pH}$} & {$\left[\mathrm{H}^{+}\right] \approx \mathrm{C}_{\mathrm{T}}$} & {$\left[\mathrm{H}^{+}\right] \ll \mathrm{C}_{\mathrm{T}}$} \\
undissociated acid & {$[\mathrm{HA}] \approx 0$ or $\mathrm{a}_{0} \approx 0$} & {$[\mathrm{HA}] \approx \mathrm{C}_{\mathrm{T}}$ or $\mathrm{a}_{0} \approx 1$} \\
dissociated acid & {$\left[\mathrm{A}^{-}\right] \approx \mathrm{C}_{\mathrm{T}}$ or $\mathrm{a}_{1} \approx 1$} & {$\left[\mathrm{~A}^{-}\right] \ll \mathrm{C}_{\mathrm{T}}$ or $\mathrm{a}_{1} \ll 1$} \\
\hline
\end{tabular}

Polyprotic Acids. Protons are released sequentially one after the other, with the first proton being the fastest and most easily lost, followed by the second, then the third, etc. This yields the following ranking of acidity constants of a polyprotic acid (as discussed in Section 2.5.7):

$$
\mathrm{K}_{1}>\mathrm{K}_{2}>\mathrm{K}_{3}>\ldots \text { or } \mathrm{pK}_{1}<\mathrm{pK}_{2}<\mathrm{pK}_{3}<\ldots
$$

Examples are given in Table 1, Table 12, and Table 14.

The concept/distinction in Table 5 can also be applied for N-protic acids if we rename the acidity constant $K_{a}$ by the 1 st dissociation constant $K_{1}$. From Equation (17) we then get:

$$
\text { undissociated fraction : } \mathrm{a}_{0}=\frac{\left[\mathrm{H}_{\mathrm{N}} \mathrm{A}\right]}{\mathrm{C}_{\mathrm{T}}} \approx \frac{1}{1+\mathrm{K}_{1} / \mathrm{x}}
$$

The undissociated fraction as a function of $\mathrm{pH}$ is displayed in Figure 24 for several acids. As expected, strong acids are completely dissociated in real-world applications $(\mathrm{pH} \geq 0)$. The small circles mark the position of the corresponding $\mathrm{pK}_{1}$ values (which are the inflection points of $\mathrm{a}_{0}$ ).

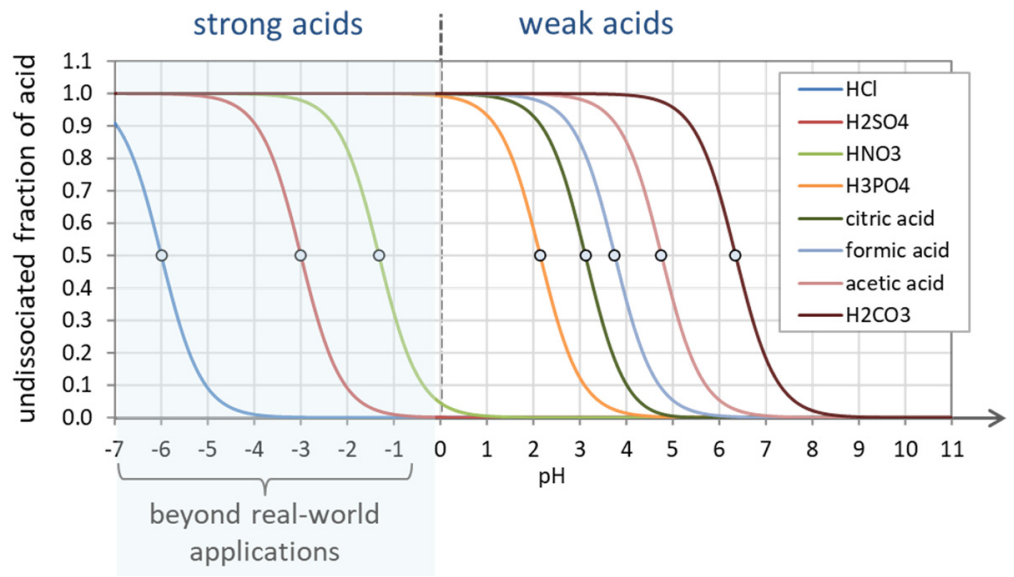

Figure 24. Undissociated fraction $\mathrm{a}_{0}$ for strong and weak acids. Strong acids are completely dissociated in the $\mathrm{pH}$ range above $\mathrm{pH} \approx 0$.

\subsubsection{Weak Acids vs. Diluted Acids}

A weak acid and a diluted acid are two different things. The first relies on the acidity constants $\mathrm{K}_{\mathrm{a}}$ (which is a thermodynamic property of the acid that nobody can change), while the second relies on the amount $\mathrm{C}_{\mathrm{T}}$ of a given acid:
weak acid $\leftrightarrow$ strong acid
$\Leftrightarrow$
small $\mathrm{K}_{\mathrm{a}} \leftrightarrow$ large $\mathrm{K}_{\mathrm{a}}$
dilute acid $\leftrightarrow$ concentrated acid
$\Leftrightarrow$
small $\mathrm{C}_{\mathrm{T}} \leftrightarrow$ large $\mathrm{C}_{\mathrm{T}}$ 
One cannot make a weak acid strong, but one can change the degree of dilution (or concentration). Table 6 summarizes the principal differences between the degree of strength and the degree of dilution. The basic idea is also depicted in Figure 25. For polyprotic acids, replace $\mathrm{K}_{\mathrm{a}}$ by $\mathrm{K}_{1}$.

Table 6. Degree of strength vs. degree of dilution.

\begin{tabular}{|c|c|c|c|c|c|c|}
\hline & \multicolumn{3}{|c|}{ Degree of Strength } & \multicolumn{3}{|c|}{ Degree of Dilution } \\
\hline determined by & \multicolumn{3}{|c|}{ acidity constant $\mathrm{K}_{\mathrm{a}}$} & \multicolumn{3}{|c|}{ amount of acid $C_{T}$} \\
\hline relationships & $\begin{array}{c}\text { weak acid } \\
\text { small } \mathrm{K}_{\mathrm{a}} \\
\text { (positive } \mathrm{pK} \mathrm{K}_{\mathrm{a}}\end{array}$ & $\begin{array}{l}\leftrightarrow \\
\leftrightarrow \\
\leftrightarrow\end{array}$ & $\begin{array}{c}\text { strong acid } \\
\text { large } \mathrm{K}_{\mathrm{a}} \\
\text { negative } \mathrm{pK}_{\mathrm{a}} \text { ) }\end{array}$ & $\begin{array}{l}\text { diluted acid } \\
\text { small } C_{\mathrm{T}}\end{array}$ & $\begin{array}{l}\leftrightarrow \\
\leftrightarrow\end{array}$ & $\begin{array}{c}\text { concentr. Acid } \\
\text { large } C_{\mathrm{T}}\end{array}$ \\
\hline compares & \multicolumn{3}{|c|}{ two different acids } & \multicolumn{3}{|c|}{ dilution of the same acid } \\
\hline describes & \multicolumn{3}{|c|}{ release of $\mathrm{H}^{+}$} & \multicolumn{3}{|c|}{ dilution of $\mathrm{H}^{+}$} \\
\hline type & \multicolumn{3}{|c|}{$\begin{array}{l}\text { fundamental property } \\
\text { (cannot be changed) }\end{array}$} & \multicolumn{3}{|c|}{$\begin{array}{l}\text { control parameter } \\
\text { (can be changed) }\end{array}$} \\
\hline
\end{tabular}

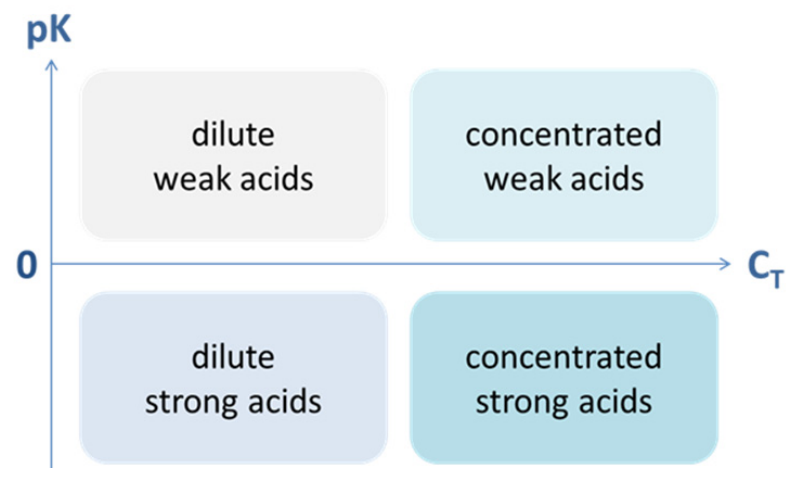

Figure 25. Weak/strong vs. diluted/concentrated acids.

\subsubsection{Strong Polyprotic Acids (Simplification)}

For the same N, the mathematical description of strong N-protic acids is simpler than that of weak acids. This is because strong acids never occur in the undissociated state at $\mathrm{pH} \geq 0$ (at least one $\mathrm{H}^{+}$is always released). Since the amount of the undissociated species is zero, $[0]=0$ and $\mathrm{a}_{0}=0$, we can skip the calculation of the 1st dissociation step. Thus, we remove Equation (28) or Equation (36) from the set of $\mathrm{N}+3$ equations and ignore the acidity constant $K_{1}$ (keeping in mind that $K_{1}$ is a large number). That is good news, because $\mathrm{K}_{1}$ of strong acids is often not known precisely enough.

The cumulative acidity constants $\mathrm{k}_{\mathrm{j}}$ in Equation (18) and the ionization fractions $\mathrm{a}_{\mathrm{j}}$ in Equation (17) simplify as follows:

$$
\begin{gathered}
k_{1}=1, \quad k_{2}=K_{2}, \quad k_{3}=K_{2} K_{3}, \quad \text { etc. } \\
a_{j}=\left(\frac{k_{j}}{x^{j-1}}\right) a_{1} \quad \text { with } \quad a_{1}=\left(1+\frac{K_{2}}{x}+\frac{K_{2} K_{3}}{x^{2}}+\ldots\right)^{-1} \text { for } j>1
\end{gathered}
$$

Polynomials. For strong acids, the polynomial in Equation (44) becomes one degree less in $x$ (i.e., the summation now starts with $j=1$ ):

$$
0=\sum_{j=1}^{N}\left\{x^{2}+(n-j) C_{T} x-K_{w}\right\} k_{j} x^{N-j}
$$


Example $N=1$. For a strong monoprotic acid, the sum in Equation (113) runs only over one term, $\mathrm{j}=1$. Using $\mathrm{k}_{1}=1$, we get a quadratic equation:

$$
0=x^{2}+(n-1) C_{T} x-K_{w}
$$

Note that this equation contains no acidity constant. Example $N=2$. For a strong diprotic acid, the polynomial in Equation (113) becomes a cubic equation:

$$
0=x^{3}+\left\{(n-1) C_{T}+K_{2}\right\} x^{2}-\left\{(n-2) C_{T} K_{2}-K_{w}\right\} x-K_{2} K_{w}
$$

This equation can also be obtained directly from Equation (46) by applying the condition $\mathrm{x} / \mathrm{K}_{1}=0$.

\subsubsection{Mixtures of Acids}

Until now we considered acid-base systems with one polyprotic acid. It is not difficult to extend the approach to mixtures of several polyprotic acids:

$$
\text { acid } a+\operatorname{acid} b+\operatorname{acid} c+\ldots \quad \text { with amounts } C_{a}, C_{b}, C_{c}, \ldots
$$

The total sum of all acids will be abbreviated by $C_{T}=C_{a}+C_{b}+C_{c}+\ldots$ The equivalent fraction $n=n(x)$, i.e., the titration curve, of the multi-acid system (plus a strong base of amount $C_{B}=n_{T}$ ) is then described by:

$$
\mathrm{n}=\widetilde{\mathrm{Y}}_{1}(\mathrm{x})+\frac{\mathrm{w}(\mathrm{x})}{\mathrm{C}_{\mathrm{T}}}
$$

It has the same structure as Equation (41), except $Y_{1}$ is replaced by the generalized moment $\tilde{Y}_{1}$ as a superposition of the individual acid's $Y_{1}$ :

$$
\widetilde{Y}_{1}=n_{a} Y_{1}^{(a)}+n_{b} Y_{1}^{(b)}+n_{c} Y_{1}^{(c)}+\ldots \quad \text { with coefficients } n_{\alpha}=\frac{C_{\alpha}}{C_{T}}
$$

The generalized moments are built from the ionization fractions in the usual way (i.e., according to Equation (22)):

$$
\widetilde{\mathrm{Y}}_{\mathrm{L}}^{(\alpha)}=\sum_{\mathrm{j}=1}^{\mathrm{N}_{\alpha}} \mathrm{j}_{\mathrm{j}} \mathrm{a}_{\mathrm{j}}^{(\alpha)}
$$

Here the ionization fractions $\mathrm{a}_{\mathrm{j}}{ }^{(\alpha)}$ are determined by the (cumulative) acidity constants of the individual acid's $k_{j}{ }^{(\alpha)}$, according to Equation (17). The sum runs from $\mathrm{j}=1$ to $\mathrm{N}^{(\alpha)}$, which is the number of protons of acid $\alpha=a, b, c$.

Example. Given is a mixture of two acids: phosphoric acid plus carbonic acid with equal amounts: $C_{\text {phos }}=C_{\text {carb }}=C_{T} / 2$. The first moment $\tilde{Y}_{1}$ of the two-acid system is displayed as the blue curve in the upper diagram of Figure 26. It is simply the sum of $\mathrm{Y}_{1}$ (phos) and $\mathrm{Y}_{1}{ }^{\text {(carb) }}$. This curve approaches the value 5 when $\mathrm{pH} \rightarrow 14$, which is the degree of the two-acid system $(\mathrm{N}=3+2=5)$. The bottom diagram in Figure 26 displays the individual ionization fractions of the two acids. To recall: the blue curve $\left(\mathrm{Y}_{1}\right)$ in the top diagram represents the "titration curve" in the high- $\mathrm{C}_{\mathrm{T}}$ limit. 


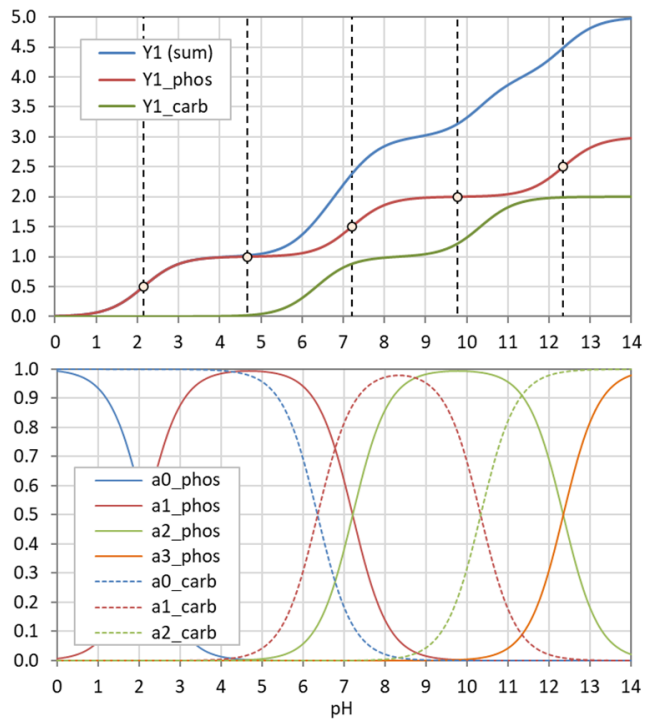

Figure 26. $\mathrm{Y}_{1}$ and $\mathrm{a}_{\mathrm{j}}$ for a system composed of phosphoric and carbonic acid.

\subsection{Equivalence Points and Ionization Fractions}

3.2.1. Trajectories of EPs in $\mathrm{pH}-\mathrm{C}_{\mathrm{T}}$ Diagrams

Equation (60) can be rearranged into the form

$$
\mathrm{C}_{\mathrm{T}}=\frac{\mathrm{w}(\mathrm{pH})}{\mathrm{n}-\mathrm{Y}_{1}(\mathrm{pH})}
$$

Now it is easy to plot all $\mathrm{EP}_{\mathrm{n}}$ values as distinct curves/trajectories into a $\mathrm{pH}-\mathrm{C}_{\mathrm{T}}$ diagram (one curve for an integer or half-integer value of $n$ ). This is performed in Figure 27 for four acids. The dashed curves and lines are the approximations overtaken from Figure 14.
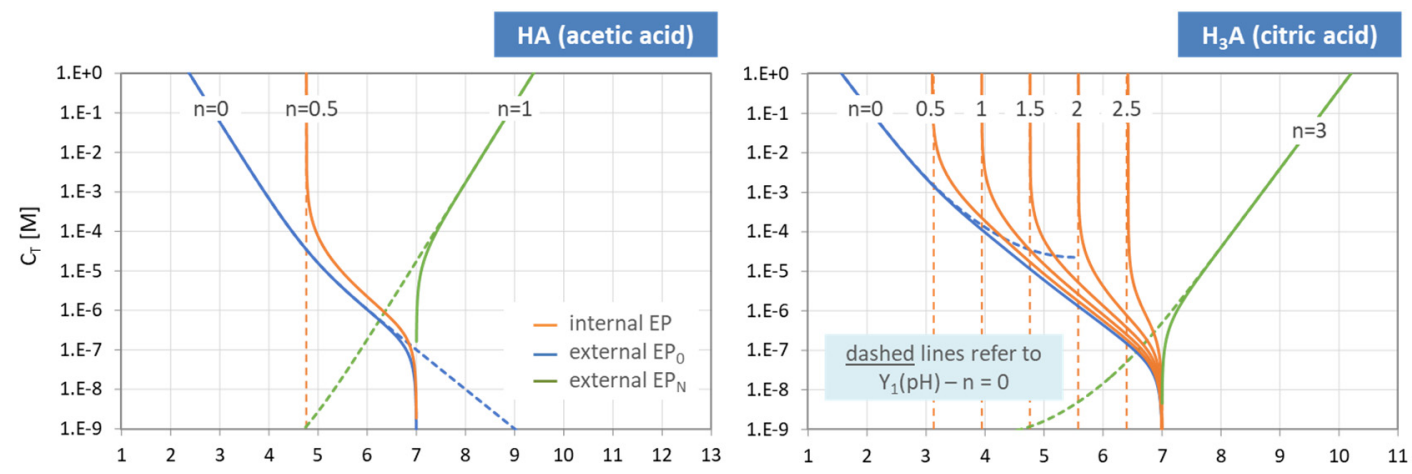

$\mathrm{H}_{2} \mathrm{~A}$ (carbonic acid)
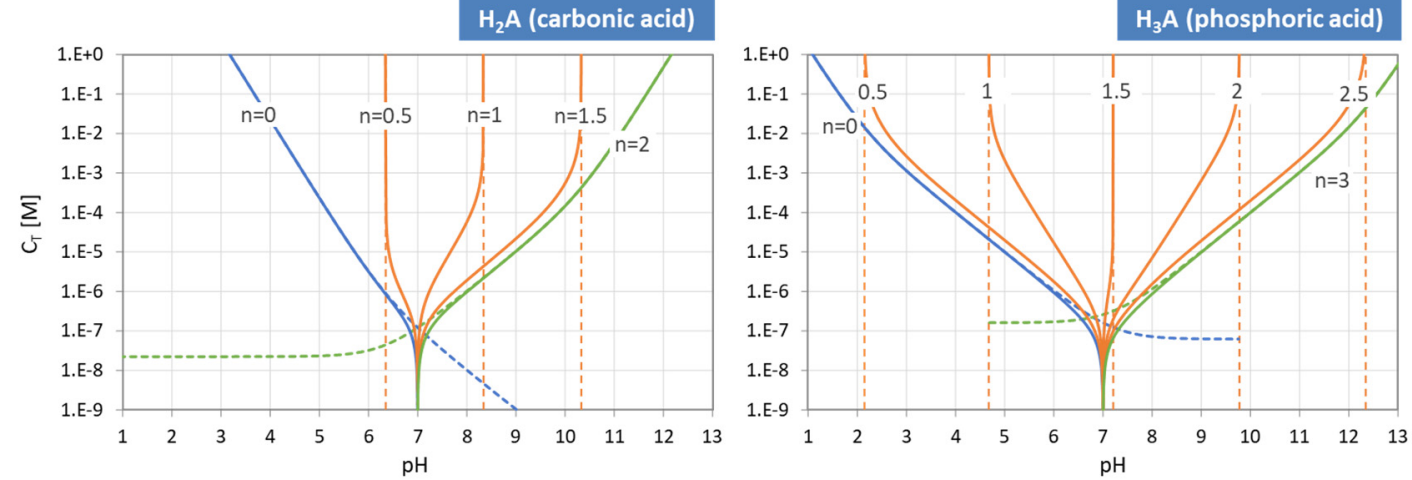

Figure 27. $\mathrm{pH}-\mathrm{C}_{\mathrm{T}}$ diagrams with trajectories of EPs and semi-EPs for four acids. Calculations are based on Equation (117). 
The genesis of the $\mathrm{EP}_{\mathrm{n}}$ trajectories is explained in Figure 28, which consists of two diagrams. In the top diagram, there are the two uncoupled subsystems located at the opposite ends of the $\mathrm{C}_{\mathrm{T}}$ scale:

$$
\begin{aligned}
& \text { 1-component system "acid": } \mathrm{C}_{\mathrm{T}} \rightarrow \infty \\
& \text { 1-component system " } \mathrm{H}_{2} \mathrm{O} \text { ": } \mathrm{C}_{\mathrm{T}} \rightarrow 0
\end{aligned}
$$

The bottom diagram shows the situation when the two isolated subsystems are coupled together. Starting at $\mathrm{pH}=7$, the curves fan out when $\mathrm{C}_{\mathrm{T}}$ increases until they fit the "pureacid" values at the top of the chart. The whole behavior is choreographed by Equation

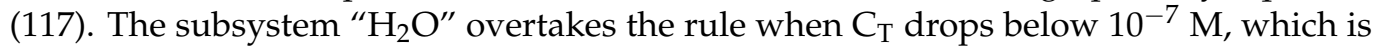
just the amount of $\mathrm{H}^{+}$and $\mathrm{OH}^{-}$in pure water.
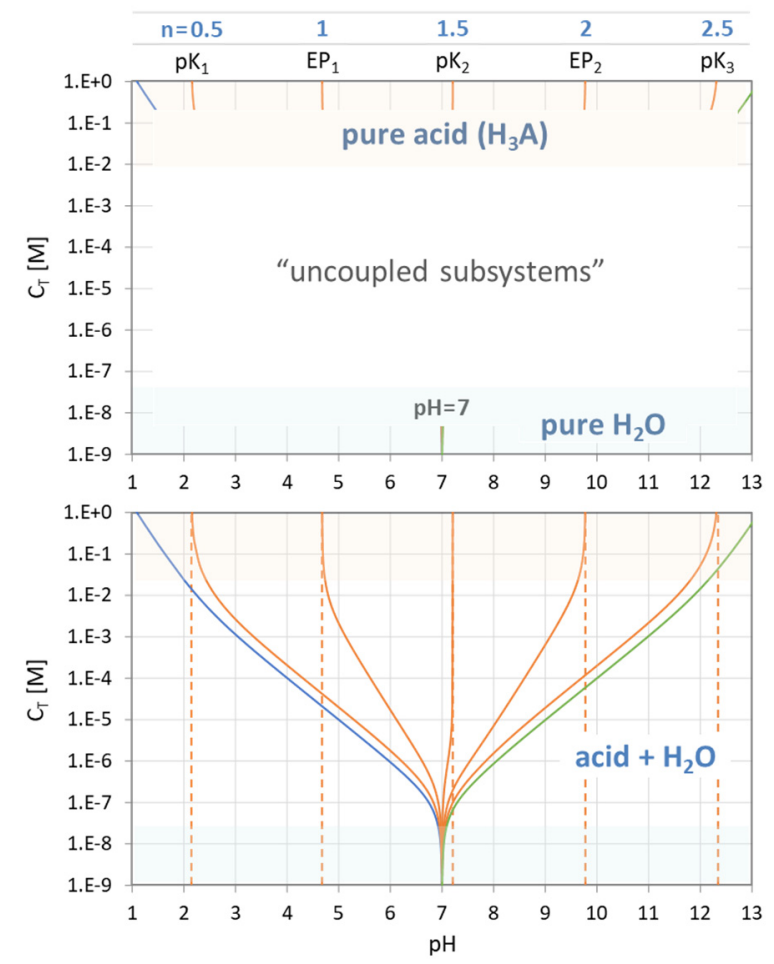

Figure 28. Trajectories of EPs and semi-EPs for phosphoric acid $\left(\mathrm{H}_{3} \mathrm{PO}_{4}\right)$ for the uncoupled (top) and coupled system (bottom).

The behavior of the two isolated subsystems can be deduced from Equation (117) by setting either the nominator or the denominator to zero:

$$
\mathrm{C}_{\mathrm{T}}=\frac{\mathrm{w}(\mathrm{pH})}{\mathrm{n}-\mathrm{Y}_{1}(\mathrm{pH})} \Leftrightarrow\left\{\begin{array}{clc}
\mathrm{w}=0 & \Rightarrow & \mathrm{C}_{\mathrm{T}}=0 \\
\mathrm{n}-\mathrm{Y}_{1}=0 & \Rightarrow & \mathrm{C}_{\mathrm{T}} \rightarrow \infty
\end{array}\right.
$$

In math jargon, the corresponding $\mathrm{pH}$ values of the "pure acid" subsystem are the poles of

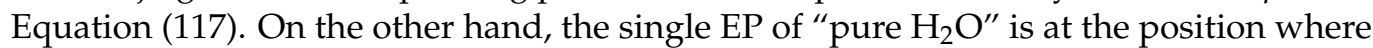
the nominator in Equation (117) becomes zero (which is exactly at $\mathrm{pH}=7$ ): $\mathrm{EP}$ of pure $\mathrm{H}_{2} \mathrm{O} \Leftrightarrow 0=\mathrm{w}(\mathrm{x}) \Leftrightarrow \mathrm{C}_{\mathrm{T}}=0$.

\subsubsection{EPs as Inflection Points of Titration Curves}

The (internal) equivalence points are usually acknowledged as inflection points of titration curves. This statement, however, is not rigorously applicable. Mathematically, an inflection point is a point on a curve at which the curvature or concavity changes sign (plus 
to minus or vice versa). This happens at points where the 2 nd derivative of the titration curve $\mathrm{n}(\mathrm{pH})$ is zero:

$$
\text { criterion for inflection points : } \frac{\mathrm{d}^{2} \mathrm{n}}{\mathrm{d} \mathrm{pH}^{2}}=\frac{\mathrm{d} \beta}{\mathrm{dpH}}=0
$$

1-Component System. For the 1-component system (i.e., $\mathrm{C}_{\mathrm{T}} \gg \mathrm{w}$ ), the formulas for the buffer capacity and its $\mathrm{pH}$ derivative in Equations (72) and (73) simplify:

$$
\begin{aligned}
\beta(\mathrm{x}) & =(\ln 10)\left(\mathrm{Y}_{2}-\mathrm{Y}_{1}^{2}\right) \\
\frac{\mathrm{d} \beta}{\mathrm{dpH}} & =(\ln 10)^{2}\left(\mathrm{Y}_{3}-3 \mathrm{Y}_{1} \mathrm{Y}_{2}+2 \mathrm{Y}_{1}^{3}\right)
\end{aligned}
$$

The $2 \mathrm{~N}-1$ internal equivalence points are then fully determined by the $\mathrm{pK}_{\mathrm{j}}$ values, while the $\mathrm{Y}_{\mathrm{L}}$ 's are given by (see Appendix C.1):

$$
\begin{array}{lll}
Y_{L}=\frac{1}{2}\left\{(j-1)^{L}+j^{2}\right\} & \text { for semi-EP } P_{n} \text { at } p K_{j} & \left(n=j-\frac{1}{2}\right) \\
Y_{L}=j^{L} & \text { for } \mathrm{EP}_{n} \text { at } p H_{j} \equiv \frac{1}{2}\left(\mathrm{pK}_{j}+\mathrm{pK}_{\mathrm{j}+1}\right) & (\mathrm{n}=\mathrm{j})
\end{array}
$$

Inserting the $\mathrm{Y}_{\mathrm{L}}$ 's into Equation (120) yields for

$$
\begin{array}{lll}
\text { semi-EP }: & \beta\left(\mathrm{pK}_{\mathrm{j}}\right)=\frac{1}{4}(\ln 10)=0.576 & \text { (maximum) } \\
\text { EP }_{\mathrm{n}}: & \beta\left(\mathrm{pH}_{\mathrm{j}}\right)=0 & \text { (minimum) }
\end{array}
$$

Plugging the $\mathrm{Y}_{\mathrm{L}}$ values into Equation (121) results—after doing some school algebrain exactly the required condition for inflection points:

$$
\frac{\mathrm{d} \beta}{\mathrm{dpH}}\left(\mathrm{pK}_{\mathrm{j}}\right)=0 \quad \text { and } \quad \frac{\mathrm{d} \beta}{\mathrm{dpH}}\left(\mathrm{pH}_{\mathrm{j}}\right)=0
$$

\begin{tabular}{|c|c|c|}
\hline Function/Curve & $\begin{array}{c}\text { semi-EP }_{\mathbf{n}} \\
\left.\text { (half-integer } n=j-\frac{1}{2}\right) \\
\text { at } \mathrm{pK}_{\mathbf{j}}\end{array}$ & $\begin{array}{l}\left.\underset{E P_{n}}{(i n t e g e r} n=j\right) \\
\text { at } \mathrm{pH}_{j}\end{array}$ \\
\hline $\begin{array}{l}\text { titration curve } \mathrm{n}=\mathrm{n}(\mathrm{pH}) \\
\text { (normalized buffer capacity) }\end{array}$ & inflection points & inflection points \\
\hline buffer intensity $\beta=\mathrm{dn} / \mathrm{dpH}$ & maxima & minima \\
\hline $\mathrm{d} \beta / \mathrm{dpH}=\mathrm{d}^{2} \mathrm{n} / \mathrm{dpH} \mathrm{H}^{2}$ & zeros & zeros \\
\hline ionization fraction $a_{j}$ & inflection point & maximum \\
\hline
\end{tabular}

The zeros of $\mathrm{d} \beta / \mathrm{dpH}$ for mono-, di-, and triprotic acids are shown as small circles in Figure 19. Of special interest are the semi-EPs at $\mathrm{pK}_{1}, \mathrm{pK}_{2}$ and $\mathrm{pK}_{3}$ where the buffer intensity (green curves) reaches its maximum value 0.576, as predicted by Equation (124). At exactly these $\mathrm{pK}$ values the titration curve (blue) has its inflection points. These findings are summarized in Table 7.

Table 7. Equivalence points as local extrema and inflection points.

3-Component System. The additional terms $(\mathrm{w}+\mathrm{x}) / \mathrm{C}_{\mathrm{T}}$ and $\mathrm{w} / \mathrm{C}_{\mathrm{T}}$ that enter the 3component system in Equations (72) and (73) disturb the nice and simple picture discussed above. This can be seen if you compare Figure 19 (for the 1-component system) with Figure 20 (for the 3-component system): The function $\mathrm{d} \beta / \mathrm{dpH}$ (red curve) changes its shape and, thus, the position and number of its zeros. The deviation from the "ideal case" grows the more the acid is diluted (i.e., the smaller $\mathrm{C}_{\mathrm{T}}$ ). A strict and simple assignment between zeros, inflection points, and EPs is no longer possible. 


\subsubsection{Ionization Fractions-Two Approaches}

The formula for the ionization fractions in Equation (17) can be approximated in two different ways:

Approach 1: "piecewise log-scale approximation" for $\lg \mathrm{a}_{\mathrm{j}}$

Approach 2: "midpoint approximation" for $\mathrm{a}_{\mathrm{j}}$

Approach 1. This is an approximation for the logarithm of $\mathrm{a}_{\mathrm{j}}$, i.e., for $\lg \mathrm{a}_{\mathrm{j}}$. It is exactly the approach used in textbooks as a graphical method for solving algebraic equations of equilibrium systems in double-log diagrams.

The approximate formula for $\lg a_{j}$ provides a "curve" consisting of several linear functions in $\mathrm{pH}$ (straight lines):

$$
\lg \mathrm{a}_{\mathrm{j}} \approx(\mathrm{j}-\mathrm{i}) \mathrm{pH}+\left(\mathrm{pk}_{\mathrm{i}}-\mathrm{pk}_{\mathrm{j}}\right) \quad \text { for the ith interval }
$$

where $\mathrm{pk}_{\mathrm{i}}=\mathrm{pK}_{1}+\mathrm{pK}_{2}+\ldots+\mathrm{pK}_{\mathrm{i}}$ and $\mathrm{pk}_{0}=0$. This approach is shown (by the colored dashed lines) in the upper-left diagram in Figure 29.
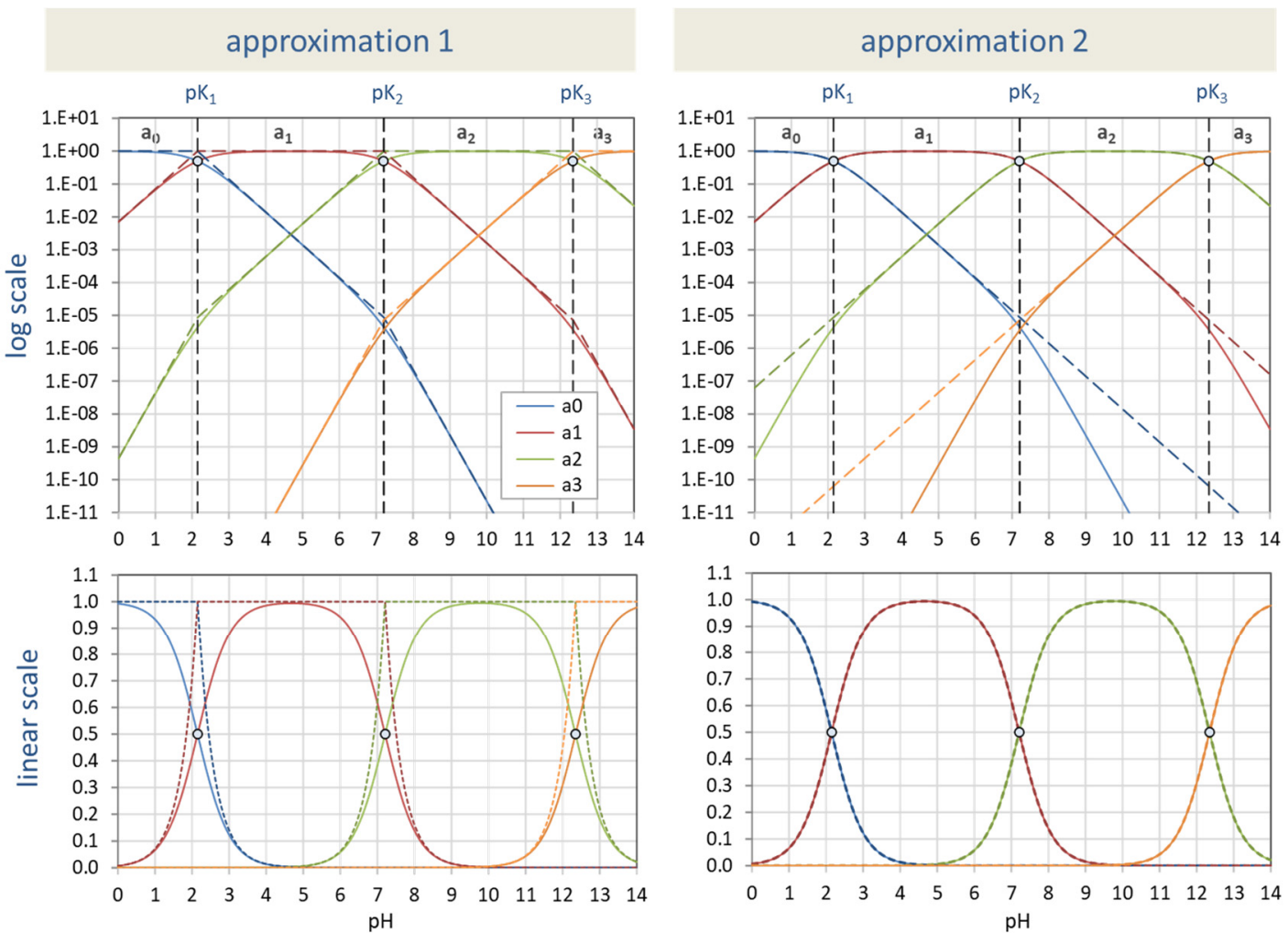

Figure 29. Ionization fractions for phosphoric acid in two approximations (dashed lines) vs. exact description based on Equation (17).

Approach 2. This approach is motivated by the fact that the curves in Figure 3 look pretty elementary, so one wonders if they can be described by a much simpler formula. This is indeed so; you can replace the exact formulas in Equation (17) by:

$\mathrm{a}_{0} \approx\left(1+\frac{\mathrm{K}_{1}}{\mathrm{x}}\right)^{-1}, \mathrm{a}_{\mathrm{j}} \approx\left(\frac{\mathrm{x}}{\mathrm{K}_{\mathrm{j}}}+1+\frac{\mathrm{K}_{\mathrm{j}+1}}{\mathrm{x}}\right)^{-1}($ for $\mathrm{j}=1$ to $\mathrm{N}-1), \quad$ and $\quad \mathrm{a}_{\mathrm{N}} \approx\left(\frac{\mathrm{x}}{\mathrm{K}_{\mathrm{N}}}+1\right)^{-1}$

The approach relies on no more than two (adjacent) pK values; all other pK values are ignored. Thus, the approach is exact for mono- and diprotic acids; for acids with $\mathrm{N}>2$, it deviates from the exact description, albeit insignificantly. The small deviations can only be recognized in logarithmic plots—as shown for phosphoric acid $(\mathrm{N}=3)$ in the top right diagram in Figure 29. 
Summary. The two approaches are complementary, as shown in Figure 29. Approach 1 offers a very clever approximation in log-plots but fails to reproduce the S-shaped and bellshaped curves in $\mathrm{pH}-\mathrm{a}_{\mathrm{j}}$ diagrams (dashed curves in the bottom left diagram). Conversely, Approach 2 reproduces the $a_{j}$ curves perfectly, but if we look more closely, we see deviations in the log-plots for values below $10^{-5}$ (dashed curves in the top-right diagram).

\subsection{Alkalinity and Carbonate System}

\subsubsection{Alkalinity and Acidity}

In carbonate systems, ANC is known as alkalinity and BNC as acidity. Again, we have to distinguish between different types of alkalinity and acidity depending on the reference point $\mathrm{EP}_{\mathrm{n}}$ chosen. The carbonic acid has three integer-valued EPs; hence there are three types of alkalinity (cf. Figure 30):

$\begin{array}{lll}\text { total alkalinity (M alkalinity): } & {[\text { Alk }]} & =[\text { ANC }]_{n=0} \\ \text { P alkalinity: } & {[\mathrm{P}-\mathrm{Alk}]} & =[\mathrm{ANC}]_{\mathrm{n}=1} \\ \text { caustic alkalinity: } & {[\mathrm{OH}-\mathrm{Alk}]} & =[\mathrm{ANC}]_{\mathrm{n}=2}\end{array}$

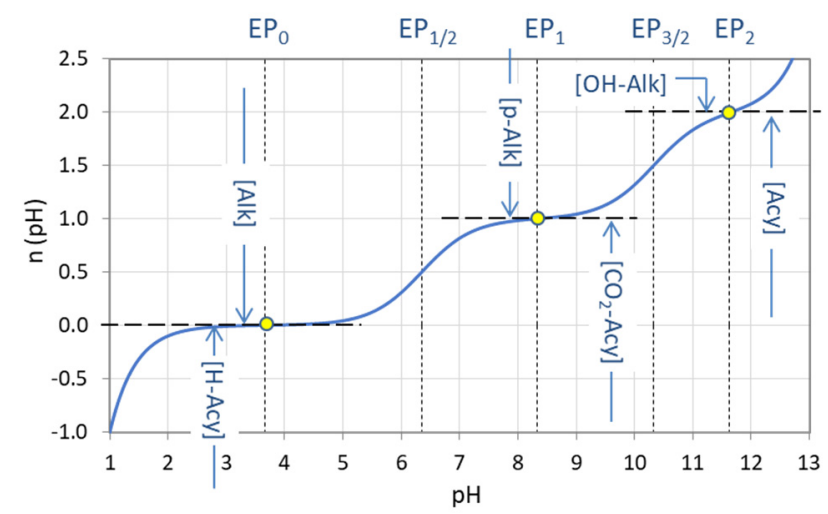

Figure 30. Titration curve $\mathrm{n}=\mathrm{n}(\mathrm{pH})$ for carbonic acid $\left(\mathrm{C}_{\mathrm{T}}=10 \mathrm{mM}\right)$ with equivalence points and the corresponding types of alkalinity and acidity.

Correspondingly, there are three types of acidity:

$$
\begin{array}{lll}
\text { mineral acidity: } & {[\mathrm{H}-\mathrm{Acy}]} & =[\mathrm{BNC}]_{\mathrm{n}=0} \\
\mathrm{CO}_{2} \text { acidity: } & {\left[\mathrm{CO}_{2}-\mathrm{Acy}\right]} & =[\mathrm{BNC}]_{\mathrm{n}=1} \\
\text { acidity: } & {[\mathrm{Acy}]} & =[\mathrm{BNC}]_{\mathrm{n}=2}
\end{array}
$$

Alkalinity and acidity are complementary. From Equation (66) we get:

$$
\begin{array}{lllll}
{[\mathrm{ANC}]_{0}=-[\mathrm{BNC}]_{0}} & \Rightarrow & & {[\mathrm{Alk}]} & =-[\mathrm{H}-\mathrm{Acy}] \\
{[\mathrm{ANC}]_{1}=-[\mathrm{BNC}]_{1}} & \Rightarrow & & {[\mathrm{P}-\mathrm{Alk}]} & =-\left[\mathrm{CO}_{2}-\mathrm{Acy}\right] \\
{[\mathrm{ANC}]_{2}=-[\mathrm{BNC}]_{2}} & \Rightarrow & & {[\mathrm{OH}-\mathrm{Alk}]} & =-[\text { Acy }]
\end{array}
$$

Of all three types of alkalinity, total alkalinity is the most important; it is given by

$$
[\mathrm{Alk}] \equiv[\mathrm{ANC}]_{0}=\mathrm{C}_{\mathrm{B}}=\mathrm{nC}_{\mathrm{T}}
$$

Using Equation (67), the difference between total alkalinity (M-alkalinity) and P-alkalinity yields the amount of $C_{T}$ as follows:

$$
[\mathrm{Alk}]-[\mathrm{P}-\mathrm{Alk}]=[\mathrm{ANC}]_{0}-[\mathrm{ANC}]_{1}=\mathrm{C}_{\mathrm{T}}(=\mathrm{DIC})
$$

In carbonate systems, this is just the molar concentration of dissolved inorganic carbon (DIC).

\subsection{2. $\mathrm{pH}$ as Reference Point of ANC and BNC}

In Section 2.4.1, ANC and BNC have been defined with respect to an equivalence point $\mathrm{EP}_{\mathrm{n}}$. ANC and BNC can also be defined with respect to a particular $\mathrm{pH}$ value (which 
can be any chosen value). In practice it is common to use the $\mathrm{pH}$ of the equivalence points $\mathrm{EP}_{0}$ and $\mathrm{EP}_{1}$ of the carbonate system:

$$
\mathrm{EP}_{0}: \quad \mathrm{pH} \approx 4.3 \text { and } \mathrm{EP}_{1}: \mathrm{pH} \approx 8.2
$$

The two EPs are shown as yellow dots in Figure 30. The usefulness of this choice is that these are the $\mathrm{pH}$ values of common indicators: indicator methylorange (titration endpoint 4.2 to 4.5 ) and indicator phenolphthalein (titration endpoint 8.2 to 8.3 ). The measured amount of strong acid or base to reach these endpoints are called:
ANC to $\mathrm{pH}$ 4.3:
$[\mathrm{ANC}]_{\mathrm{pH} 4.3} \quad(\approx[\mathrm{Alk}])$
ANC to $\mathrm{pH}$ 8.2:
BNC to $\mathrm{pH} 4.3$ :
BNC to $\mathrm{pH} 8.2$ :

$\begin{array}{ll}{[\mathrm{ANC}]_{\mathrm{pH} 8.2}} & (\approx[\mathrm{P}-\mathrm{Alk}]) \\ {[\mathrm{BNC}]_{\mathrm{pH} 4.3}} & (\approx-[\mathrm{Alk}]) \\ {[\mathrm{BNC}]_{\mathrm{pH} 8.2}} & (\approx-[\mathrm{P}-\mathrm{Alk}])\end{array}$

The measured "ANC to $\mathrm{pH} 4.3$ " corresponds to the total alkalinity (or M-alkalinity) of the system; the measured "ANC to $\mathrm{pH} 8.2$ " to the P-alkalinity. Here, the abbreviation "M" refers to the indicator methylorange and "P" to phenolphthalein.

\subsubsection{Acid-Base Titration with $\mathrm{H}_{2} \mathrm{CO}_{3}$ as Titrant}

During titration, a titrant is added to the analyte to reach the target $\mathrm{pH}$ or equivalence point. Two cases (which are opposite of each other) will be considered:

var $A \quad 100 \mathrm{mM} \mathrm{H}_{2} \mathrm{CO}_{3}$ solution is titrated by a strong base/acid $(\mathrm{NaOH}$ and $\mathrm{HCl})$

var $B \quad 100 \mathrm{mM} \mathrm{NaOH}$ solution is titrated by $\mathrm{H}_{2} \mathrm{CO}_{3}$

In var $A C_{T}$ is kept fixed (and $C_{B}$ is varied), while in var $B C_{B}$ is kept fixed (and $C_{T}$ is varied). The aim is to calculate the carbonate speciation as a function of $\mathrm{pH}$. In both cases, we start with the ionization fractions $a_{j}$ (based on Equation (17) and shown in the bottom left diagram in Figure 3), which are the same for var $A$ and var $B$. From each $a_{j}$, we then get the species concentration by multiplication with $\mathrm{C}_{\mathrm{T}}$ : $[\mathrm{j}]=\mathrm{C}_{\mathrm{T}} \mathrm{a}_{\mathrm{j}}$. The main point is that var $A$ and $\operatorname{var} B$ differ in the $C_{\mathrm{T}}$ value:

$$
\begin{array}{lll}
\operatorname{var} A & C_{\mathrm{T}}=\text { const } & \text { with } C_{\mathrm{T}}=100 \mathrm{mM} \\
\operatorname{var} B & C_{\mathrm{T}}=\left(C_{\mathrm{B}}-\mathrm{w}\right) / \mathrm{Y}_{1} & \text { with } C_{\mathrm{B}}=100 \mathrm{mM}
\end{array}
$$

where the last line is taken from Equation (43).

The obtained species distribution is displayed in Figure 31: var $A$ (left) and var $B$ (right diagrams). The gray curve represents the total concentration $C_{T}$ as the sum of all carbonate species. The top and bottom diagrams only differ by the concentration scale: the $y$ axis is linear or logarithmic, respectively.
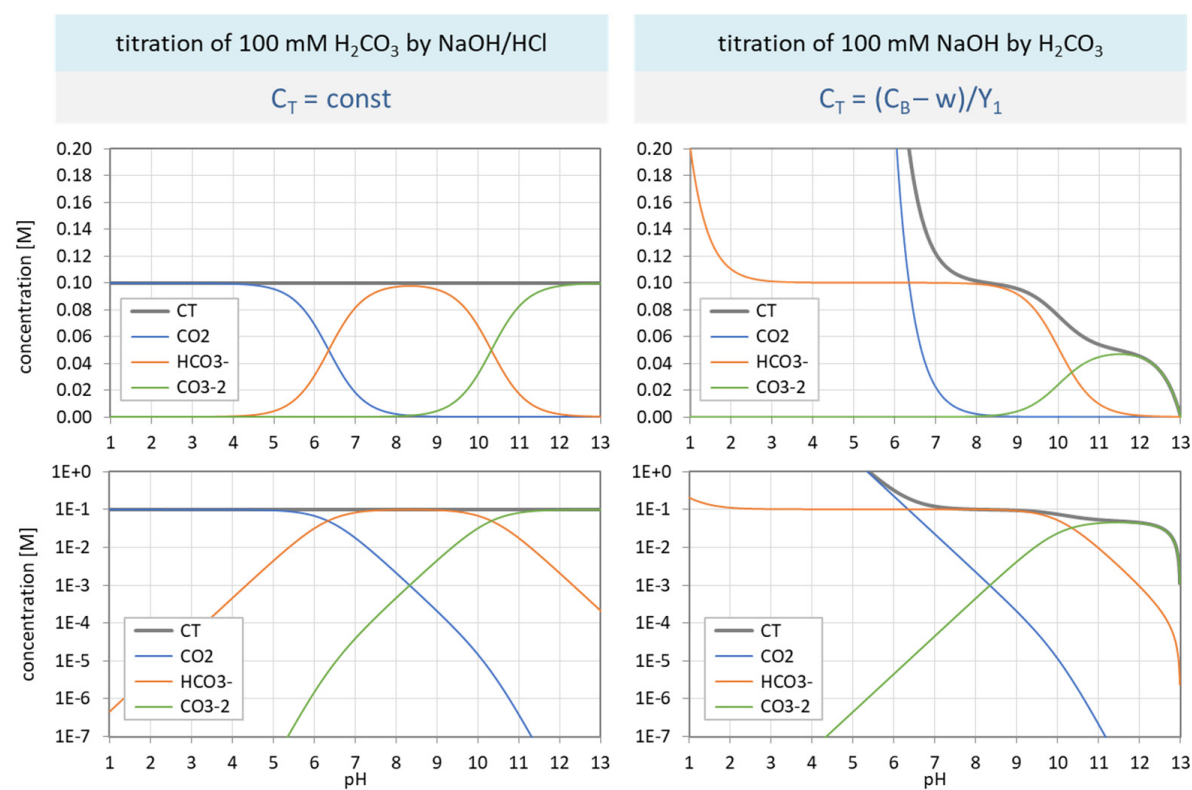

Figure 31. Species distribution of $\mathrm{H}_{2} \mathrm{CO}_{3}$ as a function of $\mathrm{pH}$ for var $A$ (left) and var $B$ (right). Top diagrams: concentrations in linear scale; bottom diagrams: logarithmic scale. 
Although both variants rely on exactly the same ionization fractions, the $\mathrm{pH}$ dependence of the species in var $A$ and $\operatorname{var} B$ differ significantly. While the species distribution in var $A$ (top left) replicates the shapes of the ionization fractions, var $B$ is completely out of line. [Note: $\operatorname{In} \operatorname{var} B, \mathrm{pH}<5$ is not available in practice.]

\subsubsection{Open vs. Closed $\mathrm{CO}_{2}$ System}

In an open $\mathrm{CO}_{2}$ system, the solution is in equilibrium with the $\mathrm{CO}_{2}$ of the atmosphere. Let us compare it with the closed system:

var $A$ titration of $100 \mathrm{mM} \mathrm{H}_{2} \mathrm{CO}_{3}$ solution as "closed $\mathrm{CO}_{2}$ system" (as in Section 3.3.3) var $\mathrm{C}$ titration of $100 \mathrm{mM} \mathrm{H}_{2} \mathrm{CO}_{3}$ solution as "open $\mathrm{CO}_{2}$ system"

As in Section 3.3.3, we start with the same ionization fractions $\mathrm{a}_{\mathrm{j}}$ for both var $A$ and var $C$, as shown in in the left bottom diagram in Figure 3. As in Section 3.3.3, the two variants differ only in the functional dependence of $C_{T}$, which will be derived now.

The "open system" is described by Henry's law that partitions the $\mathrm{CO}_{2}$ between the aqueous and gas phase: $\mathrm{CO}_{2}(\mathrm{aq})$ is proportional to $\mathrm{CO}_{2}(\mathrm{~g})$, whereas $\mathrm{CO}_{2}(\mathrm{aq})$ is the undissociated acid $\mathrm{H}_{2} \mathrm{CO}_{3}$, i.e., the uncharged species [0]. Thus, we can write:

$$
[0]=\mathrm{K}_{\mathrm{H}} \cdot \mathrm{P} \quad \text { with } \quad \mathrm{K}_{\mathrm{H}}=10^{-1.47} \mathrm{M} / \mathrm{atm}\left(\text { at } 25^{\circ} \mathrm{C}\right)
$$

and with $\mathrm{P}$ as the partial $\mathrm{CO}_{2}$ pressure. Using $[0]=\mathrm{C}_{\mathrm{T}} \mathrm{a}_{0}$, we obtain:

$$
\text { open } \mathrm{CO}_{2} \text { system : } \quad \mathrm{C}_{\mathrm{T}}=\frac{\mathrm{K}_{\mathrm{H}} \mathrm{P}}{\mathrm{a}_{0}}
$$

Thus, the two variants differ in the $\mathrm{C}_{\mathrm{T}}$ value:

$$
\begin{array}{lll}
\operatorname{var} A & \mathrm{C}_{\mathrm{T}}=\text { const } & \text { with } \mathrm{C}_{\mathrm{T}}=100 \mathrm{mM} \\
\operatorname{var} \mathrm{C} & \mathrm{C}_{\mathrm{T}}=\mathrm{K}_{\mathrm{H}} \mathrm{P} / \mathrm{a}_{0} & \text { with } \mathrm{P}=0.00039 \mathrm{~atm}\left(=10^{-3.408} \mathrm{~atm}\right)
\end{array}
$$

The carbonate speciation is displayed in Figure 32: var $A$ (left) and $\operatorname{var} C$ (right diagrams).
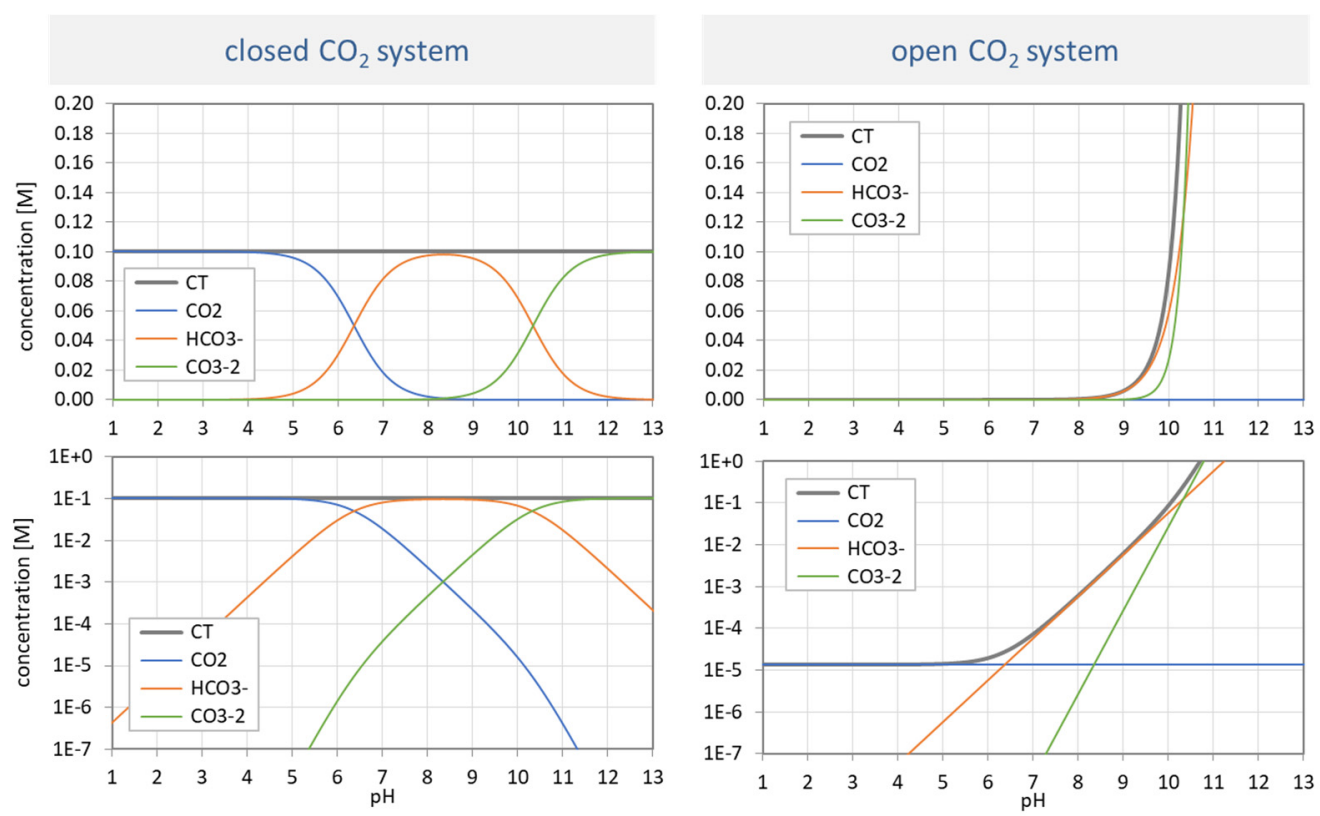

Figure 32. Species distribution of $\mathrm{H}_{2} \mathrm{CO}_{3}$ as a function of $\mathrm{pH}$ for $\operatorname{var} A$ (left) and $\operatorname{var} \mathrm{C}$ (right). Top diagrams: concentrations in linear scale; bottom diagrams: logarithmic scale.

The conclusions are similar to Section 3.3.3. Although both variants rely on exactly the same ionization fractions, the $\mathrm{pH}$ dependence of the species in var $A$ and $\operatorname{var} C$ is completely different. While the species distribution in var $A$ (top left) replicates the shapes 
of the ionization fractions, $\operatorname{var} C$ does not. The more alkaline the solution becomes, the more $\mathrm{CO}_{2}$ is sucked out of the atmosphere (which increases the $\mathrm{C}_{\mathrm{T}}$ exponentially). [Note: In $\operatorname{var} C, \mathrm{pH}<5$ is not available in practice.]

Resume. The three variants ( $\operatorname{var} A$, var $B$, var $C$ ) discussed in the last two sections exhibit the universality of the ionization fractions $a_{j}$ (shown in the bottom left diagram in Figure 3). They are independent of the chosen model, i.e., the functional dependence of $C_{T}$.

\subsubsection{Seawater}

The analytical formulas in Equation (41) and Equation (117) are based on the assumption that activities could be replaced by concentrations, $\{\mathrm{j}\} \rightarrow[\mathrm{j}]$. This is valid either for dilute systems with near-zero ionic strength $(I \approx 0)$, or for non-dilute systems when the thermodynamic equilibrium constants are replaced by conditional constants, $\mathrm{K} \rightarrow{ }^{\mathrm{C}} \mathrm{K}$.

Seawater has $I \approx 0.7 \mathrm{M}$, which is at the upper limit of the validity range of common activity models (as discussed in Appendix B). Hence, in oceanography, chemists prefer conditional equilibrium constants ${ }^{c} \mathrm{~K}$. In the literature, there are several compilations for ${ }^{\mathrm{c}} \mathrm{K}$; one example is given in Table 8.

Table 8. Thermodynamic and conditional equilibrium constants for $\mathrm{H}_{2} \mathrm{CO}_{3}$ in pure water and seawater (at $\left.25^{\circ} \mathrm{C}, 1 \mathrm{~atm}\right) ;{ }^{\mathrm{C}} \mathrm{K}$ values from [39].

\begin{tabular}{ccc}
\hline & $\begin{array}{c}\text { Thermodynamic } \mathbf{K} \\
\text { (Pure Water, } \mathbf{I}=\mathbf{0})\end{array}$ & $\begin{array}{c}\text { Conditional }{ }^{\mathbf{c}} \mathbf{K} \\
\text { (Seawater, } \mathbf{I}=\mathbf{0 . 7} \mathbf{M})\end{array}$ \\
\hline $\mathrm{pK}_{1}$ & 5.18 & 6.0 \\
$\mathrm{pK}_{2}$ & 10.33 & 9.1 \\
$\mathrm{pK}_{\mathrm{w}}$ & 14.0 & 13.9 \\
\hline
\end{tabular}

Figure 33 (left diagram) compares the results calculated by Equation (117) for both the standard case (solid lines based on thermodynamic equilibrium constants $\mathrm{K}$ ) and seawater (dashed lines based on conditional constants ${ }^{\mathrm{C}} \mathrm{K}$ ). The solid curves in Figure 33 are identical to the solid curves for $\mathrm{n}=0,1$, and 2 shown in the bottom left diagram in Figure 27.
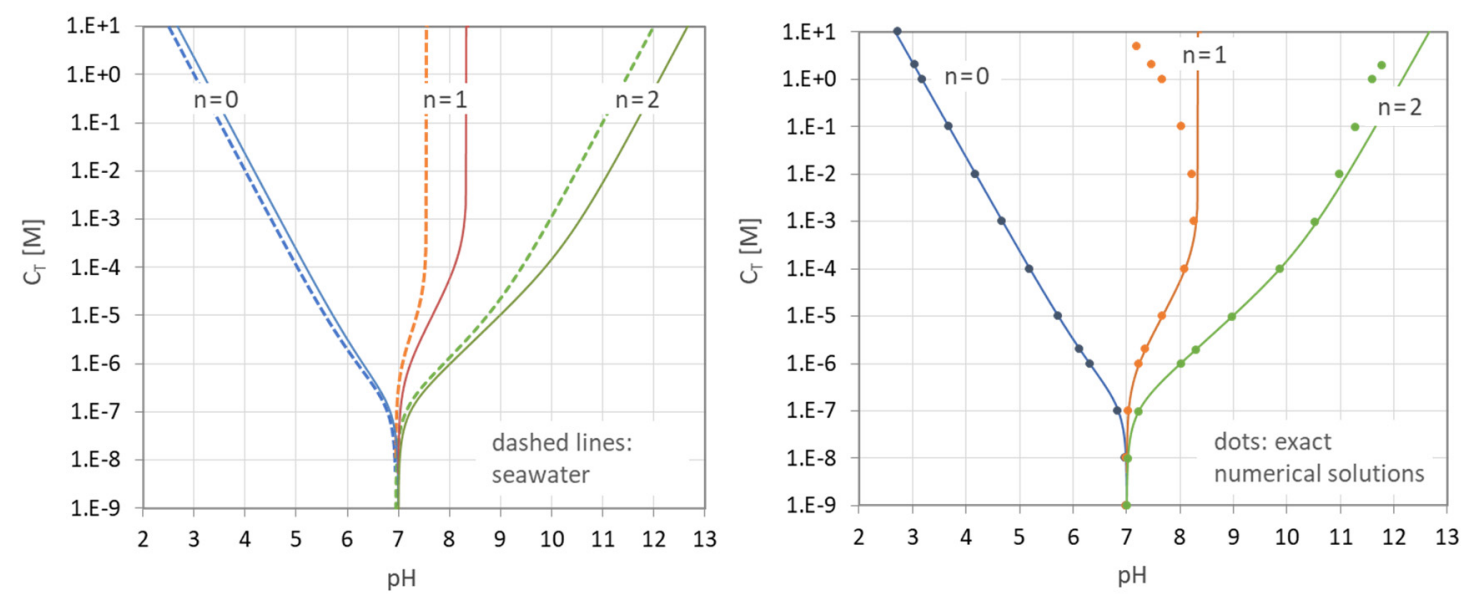

Figure 33. $\mathrm{pH}-\mathrm{C}_{\mathrm{T}}$ diagrams of the carbonic-acid system. (Left): $\mathrm{H}_{2} \mathrm{CO}_{3}$ in pure water (solid lines) vs. $\mathrm{H}_{2} \mathrm{CO}_{3}$ in seawater (dashed lines). (Right): closed-form expression (117) vs. numerical model (dots).

\subsubsection{From Ideal to Real Solutions}

All calculations so far (except in Section 3.3.5) were performed for the ideal case (i.e., no activity corrections, no aqueous complexation). Modern hydrochemistry software does not adhere to those restrictions; they perform activity corrections per se. In this respect, 
they are able to predict the relationship between $\mathrm{pH}$ and a given $\mathrm{C}_{\mathrm{T}}$ for real systems more accurately.

Given is a carbonic acid system titrated with $\mathrm{NaOH}$. Figure 33 (right diagram) compares the results of the analytical formula in Equation (117) (solid lines) with the numericalmodel predictions (dots) using PhreeqC [11]. (Similar results are obtained when $\mathrm{NaOH}$ is replaced by $\mathrm{KOH})$.

As expected, deviations between the ideal and real case only occur at high $C_{T}$ values. There are two reasons: (i) with rising $C_{T}$, the ionic strength increases; consequently, the activity corrections are large and cannot be ignored; and (ii) numerical models consider the formation of aquatic complexes such as $\mathrm{NaHCO}_{3}{ }^{-}$and $\mathrm{Na}_{2} \mathrm{CO}_{3}(\mathrm{aq})$, which are absent in the analytical approach. The aquatic complexes become particularly relevant at high concentrations for $n=1$ and 2. [Note: At very high values of $C_{T}$ between 1 and $10 \mathrm{M}$ $\mathrm{Na}_{2} \mathrm{CO}_{3}$ (i.e., the most upper part of the green curve), we exit the applicability range of common activation models.]

\section{Beyond Ordinary Acids}

\subsection{Zwitterionic Acids}

\subsubsection{Zwitterions and Amino Acids}

A zwitterion is a molecule with functional groups, of which at least one has a positive and one has a negative electrical charge. The net charge of the entire molecule is zero.

Amino acids are the best-known examples of zwitterions. They contain an amine group (basic) and a carboxylic group (acidic). The $\mathrm{NH}_{2}$ group is the stronger base, and so it picks up $\mathrm{H}^{+}$from the $\mathrm{COOH}$ group to form a zwitterion (i.e., the amine group deprotonates the carboxylic acid):

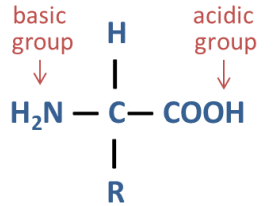

amino acid<smiles>[R]C([NH3+])C(=O)[O-]</smiles>

zwitterion

Here, $\mathrm{R}$ denotes the side chain (glycine: $\mathrm{R}=\mathrm{H}$, alanine: $\mathrm{R}=\mathrm{CH}_{3}$, and so on).

The (neutral) zwitterion is the usual form amino acids exist in water. Depending on the $\mathrm{pH}$, there are two other forms-anionic and cationic:<smiles>[2H]C([14CH3])C(=O)O</smiles>

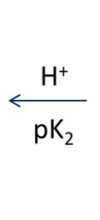

zwitterion<smiles>[R]C(N)C(=O)[O-]</smiles>

(at high $\mathrm{pH}$ )

This parallels the behavior of a diprotic acid:

$$
\underset{\begin{array}{c}
\mathrm{H}_{2} \mathrm{~A} \text { undissolved acid } \\
\text { (at low } \mathrm{pH} \text { ) }
\end{array}}{\stackrel{\mathrm{H}^{+}}{\mathrm{pK}_{1}}} \quad \mathrm{HA}^{-} \quad \stackrel{\mathrm{H}^{+}}{\mathrm{pK}_{2}} \quad \begin{gathered}
\mathrm{A}^{-2} \\
\text { amphoteric }
\end{gathered}
$$

When an amino acid dissolves in water, it acts as both an acid and a base. Unlike amphoteric compounds, which can only form either a cationic or an anionic species, a zwitterion has both ionic states simultaneously. 


\subsubsection{Zwitterions as Diprotic Acids}

The acid-base behavior of the simplest zwitterions (with 1 amine group and 1 carboxylic group) resembles that of a diprotic acid, as summarized in Table 9. In both cases, there are $\mathrm{N}=2$ dissociation steps (controlled by two acidity constants $\mathrm{K}_{1}$ and $\mathrm{K}_{2}$ ) and three species: [0], [1], and [2], where [0] refers to the highest protonated species. The number of $\mathrm{H}^{+}$ in the highest protonated species is $\mathrm{N}=2$ for both acid types.

Table 9. Diprotic acids ( $\mathrm{N}=2$ ): ordinary acid vs. zwitterion (simplest amino acid).

\begin{tabular}{|c|c|c|c|c|c|c|}
\hline & \multicolumn{3}{|c|}{ Diprotic Acid } & \multicolumn{3}{|c|}{$\begin{array}{c}\text { Zwitterion } \\
\text { (Simplest Amino Acid) }\end{array}$} \\
\hline 1st dissociation & \multirow{2}{*}{\multicolumn{2}{|c|}{$\begin{array}{l}\mathrm{H}_{2} \mathrm{~A}=\mathrm{H}^{+}+\mathrm{HA}^{-} \\
\mathrm{HA}^{-}=\mathrm{H}^{+}+\mathrm{A}^{-2}\end{array}$}} & $\mathrm{~K}_{1}$ & \multirow{2}{*}{\multicolumn{2}{|c|}{$\begin{array}{c}\mathrm{H}_{2} \mathrm{~A}^{+}=\mathrm{H}^{+}+\mathrm{HA} \\
\mathrm{HA}=\mathrm{H}^{+}+\mathrm{A}^{-}\end{array}$}} & $\mathrm{K}_{1}$ \\
\hline 2nd dissociation & & & $\mathrm{K}_{2}$ & & & $\mathrm{~K}_{2}$ \\
\hline species & $\mathrm{H}_{2} \mathrm{~A}$ & $\mathrm{HA}^{-}$ & $\mathrm{A}^{-2}$ & $\mathrm{H}_{2} \mathrm{~A}^{+}$ & HA & $\mathrm{A}^{-}$ \\
\hline abbreviation & {$[0]$} & [1] & {$[2]$} & {$[0]$} & {$[1]$} & [2] \\
\hline ionic fraction $a_{j}$ & $a_{0}$ & $a_{1}$ & $a_{2}$ & $a_{0}$ & $\mathrm{a}_{1}$ & $\mathrm{a}_{2}$ \\
\hline charge $z_{j}$ & 0 & -1 & -2 & 1 & 0 & -1 \\
\hline average charge $z_{a v}$ & \multicolumn{3}{|c|}{$\left(0 \cdot\left[\mathrm{H}_{2} \mathrm{~A}\right]-1 \cdot\left[\mathrm{HA}^{-}\right]-2 \cdot\left[\mathrm{A}^{-2}\right]\right) / \mathrm{C}_{\mathrm{T}}$} & \multicolumn{3}{|c|}{$\left(1 \cdot\left[\mathrm{H}_{2} \mathrm{~A}^{+}\right]-0 \cdot[\mathrm{HA}]-1 \cdot\left[\mathrm{A}^{-}\right]\right) / \mathrm{C}_{\mathrm{T}}$} \\
\hline
\end{tabular}

The only difference is the offset $Z=1$, where $Z$ represents the positive charge of the highest protonated species (which equals the number of amine groups in the molecule). Ordinary acids have $Z=0$. The offset determines the individual charge of species $\mathrm{j}$ : $\mathrm{Z}_{\mathrm{j}}=\mathrm{Z}-\mathrm{j}$. It confirms the statement that the offset $\mathrm{Z}$ equals the charge of the highest protonated species $(j=0): Z=z_{0}$.

Table 10 shows the different ionic characters (cationic, neutral, anionic) of the three species of an ordinary diprotic acid versus the simplest zwitterion.

Table 10. The three species of an ordinary diprotic acid vs. the simplest zwitterion.

\begin{tabular}{cccccc}
\hline \multicolumn{7}{c}{ Diprotic Acid $(\mathbf{Z}=\mathbf{0})$} & \multicolumn{2}{c}{ Zwitterion $(\mathbf{Z}=\mathbf{1})$} \\
\hline$[0]:$ & {$\left[\mathrm{H}_{2} \mathrm{~A}\right]$} & (neutral) & {$\left[\mathrm{H}_{2} \mathrm{~A}^{+}\right]$} & (cation) & highest protonation \\
{$[1]:$} & {$\left[\mathrm{HA}^{-}\right]$} & (anion) & {$[\mathrm{HA}]$} & (neutral) & \\
{$[2]:$} & {$\left[\mathrm{A}^{-2}\right]$} & $($ anion) & {$\left[\mathrm{A}^{-}\right]$} & (anion) & fully deprotonated \\
\hline
\end{tabular}

4.1.3. Model Extension for Zwitterionic Acids $\left(\mathrm{H}_{\mathrm{N}} \mathrm{A}^{+\mathrm{Z}}\right)$

Zwitterionic acids extend the concept of ordinary acids to non-zero integers $Z>0$. An $\mathrm{N}$-protic zwitterionic acid $\mathrm{H}_{\mathrm{N}} \mathrm{A}^{+\mathrm{Z}}$ has $\mathrm{N}+1$ species:

$$
\left.[\mathrm{j}] \equiv\left[\mathrm{H}_{\mathrm{N}-\mathrm{j}} \mathrm{A}^{\mathrm{Z}-\mathrm{j}}\right] \quad \text { with charge } \mathrm{z}_{\mathrm{j}}=\mathrm{Z}-\mathrm{j} \quad \text { (for } \mathrm{j}=0 \text { to } \mathrm{N}\right)
$$

$\mathrm{N}$ is the number of $\mathrm{H}^{+}$in the highest protonated species and $\mathrm{Z}$ is the positive charge of the highest protonated species. Of all $\mathrm{N}+1$ species, three species are particularly interesting, as listed in Table 11.

Table 11. Three exceptional cases out of $\mathrm{N}+1$ acid species.

\begin{tabular}{ccccc}
\hline & & & Ordinary Acid & Zwitterion \\
& & & $\mathbf{Z}=\mathbf{0}$ & $\mathbf{1} \leq \mathbf{Z}<\mathbf{N}$ \\
\hline$j=0$ & {$[0]=\left[\mathrm{H}_{N} \mathrm{~A}^{+\mathrm{Z}}\right]$} & highest protonation & neutral & cation \\
$\mathrm{j}=\mathrm{Z}$ & {$[\mathrm{Z}]=\left[\mathrm{H}_{\mathrm{N}-\mathrm{Z}} \mathrm{A}\right]$} & undissociated acid & neutral, $[\mathrm{Z}]=[0]$ & neutral \\
$\mathrm{j}=\mathrm{N}$ & {$[\mathrm{N}]=\left[\mathrm{A}^{-(\mathrm{N}-\mathrm{Z})}\right]$} & fully deprotonated & anion & anion \\
\hline
\end{tabular}

The central formula in Equation (41) interconnects three components $\left(\mathrm{H}_{2} \mathrm{O}, \mathrm{H}_{\mathrm{N}} \mathrm{A}\right.$, strong base) via the charge-balance equation. Thus, an extension of the acid-base model to 
zwitterions requires a redefinition of the charge-balance equation. For this purpose, we introduce two quantities:

$$
\begin{array}{ll}
\text { total charge of acid : } & \mathrm{Z}_{\mathrm{T}} \equiv \sum_{\mathrm{j}=0}^{\mathrm{N}} \mathrm{z}_{\mathrm{j}}[\mathrm{j}] \\
\text { average charge of acid : } & \mathrm{z}_{\mathrm{av}} \equiv \frac{\mathrm{Z}_{\mathrm{T}}}{\mathrm{C}_{\mathrm{T}}}=\sum_{\mathrm{j}=0}^{\mathrm{N}} \mathrm{z}_{\mathrm{j}} \mathrm{a}_{\mathrm{j}}
\end{array}
$$

where $z_{j}$ is the charge of the acid species $j$ :

$$
Z_{j}=Z-j \text { with }\left\{\begin{array}{l}
Z=0 \\
Z \geq 1
\end{array} \quad \text { for }\right. \text { fwitterionic acids }
$$

Inserting Equation (135) into Equation (134) yields for the average charge:

$$
\mathrm{z}_{\mathrm{av}}=\sum_{j=0}^{\mathrm{N}}(\mathrm{Z}-\mathrm{j}) \mathrm{a}_{\mathrm{j}}=\mathrm{Z} \sum_{\mathrm{j}=0}^{\mathrm{N}} \mathrm{a}_{\mathrm{j}}-\sum_{\mathrm{j}=0}^{\mathrm{N}} \mathrm{j} \mathrm{a}_{\mathrm{j}}=\mathrm{Z}-\mathrm{Y}_{1}
$$

where Equations (23) and (24) are applied. Due to $Y_{1}=Y_{1}(x)$, the average charge $z_{a v}$ is $p H$ dependent. Examples for $z_{a v}$ are given in Table 9 (last line).

Now let us turn to the charge balance:

$$
0=\left[\mathrm{B}^{+}\right]+\left[\mathrm{H}^{+}\right]-\left[\mathrm{OH}^{-}\right]+\text {total charge of acid }
$$

As we already know, $\left[\mathrm{B}^{+}\right]$is equal to $\mathrm{C}_{\mathrm{B}}=\mathrm{nC}_{\mathrm{T}}$, and $\left[\mathrm{H}^{+}\right]-\left[\mathrm{OH}^{-}\right]$can be expressed by $\mathrm{w}(\mathrm{x})$. Then, after dividing by $\mathrm{C}_{\mathrm{T}}$, we obtain:

$$
0=\mathrm{n}-\frac{\mathrm{w}}{\mathrm{C}_{\mathrm{T}}}+\mathrm{z}_{\mathrm{av}}=\mathrm{n}-\frac{\mathrm{w}}{\mathrm{C}_{\mathrm{T}}}+\left(\mathrm{Z}-\mathrm{Y}_{1}\right)
$$

This provides the extension of Equation (41) to the general case of zwitterionic acids $(\mathrm{Z} \geq 1$ ):

$$
\mathrm{n}=\left(\mathrm{Y}_{1}(\mathrm{x})-\mathrm{Z}\right)+\frac{\mathrm{w}(\mathrm{x})}{\mathrm{C}_{\mathrm{T}}}
$$

The only difference to the original formula is the constant offset $Z$, which disappears when performing the $\mathrm{pH}$ derivative. Thus, the formulas for the buffer intensity $\beta$ and its $\mathrm{pH}$ derivation in Equations (69) and (70) are the same for zwitterionic acids and ordinary acids.

To sum up, the description of ordinary acids and zwitterionic acids is based on the same formulas (except the offset $Z$ ). That is, everything relies on exactly the same building blocks (ionization fractions $a_{j}$ and moments $Y_{L}$ ), as introduced in Section 2.1. The offset $Z$, as the new ingredient, only enters the titration formula (i.e., normalized buffer capacity) in Equation (138); the buffer intensity $\beta$ and its $\mathrm{pH}$ derivative are independent of $Z$.

\subsubsection{Glycine $(\mathrm{Z}=1)$ vs. Carbonic Acid $(\mathrm{Z}=0)$}

The simplest amino acid is glycine $\left(\mathrm{NH}_{2}-\mathrm{CH}_{2}-\mathrm{COOH}\right)$, which we abbreviate as HA with $A=$ Gly. Its structural formula has the shortest side chain $(R=H)$. The three species are:

$$
\begin{array}{llll}
{[0]=\left[\mathrm{H}_{2} \mathrm{~A}^{+}\right]} & =\left[\mathrm{H}_{2} \mathrm{Gly}^{+}\right]: & \mathrm{NH}_{3}{ }^{+}-\mathrm{CH}_{2}-\mathrm{COOH} & \text { (glycinium cation) } \\
{[1]=[\mathrm{HA}]} & =[\mathrm{HGly}]: & \mathrm{NH}_{3}{ }^{+}-\mathrm{CH}_{2}-\mathrm{COO}^{-} & \text {(neutral zwitterion) } \\
{[2]=\left[\mathrm{A}^{-}\right]} & =\left[\mathrm{Gly}^{-}\right]: & \mathrm{NH}_{2}-\mathrm{CH}_{2}-\mathrm{COO}^{-} & \text {(glycinate anion) }
\end{array}
$$

Due to the presence of $\mathrm{H}_{2} \mathrm{~A}^{+}$, it is a diprotic acid specified by two acidity constants (which are compared to carbonic acid, also a diprotic acid):

$$
\begin{array}{lll}
\text { glycine: } & \mathrm{pK}_{1}=2.35 & \mathrm{pK}_{2}=9.78 \\
\text { carbonic acid: } & \mathrm{pK}_{1}=6.35 & \mathrm{pK}_{2}=11.33
\end{array}
$$


Figure 34 shows the $\mathrm{pH}$ dependence of the three ionization fractions $\left(\mathrm{a}_{0}, \mathrm{a}_{1}, \mathrm{a}_{2}\right)$ of glycine and carbonic acid. Both diagrams are based on the same formulas given in Equation (17). Figure 35 displays titration curves $n=n(p H)$ based on Equation (138). The right diagram compares the analytical formula for $\mathrm{C}_{\mathrm{T}}=100 \mathrm{mM}$ with numerical results from PhreeqC calculations. The latter are more realistic due to activity corrections for $\mathrm{HCl}$ and $\mathrm{NaOH}$ (especially at high ionic strengths, i.e., for high values of $|\mathrm{n}|$ ).
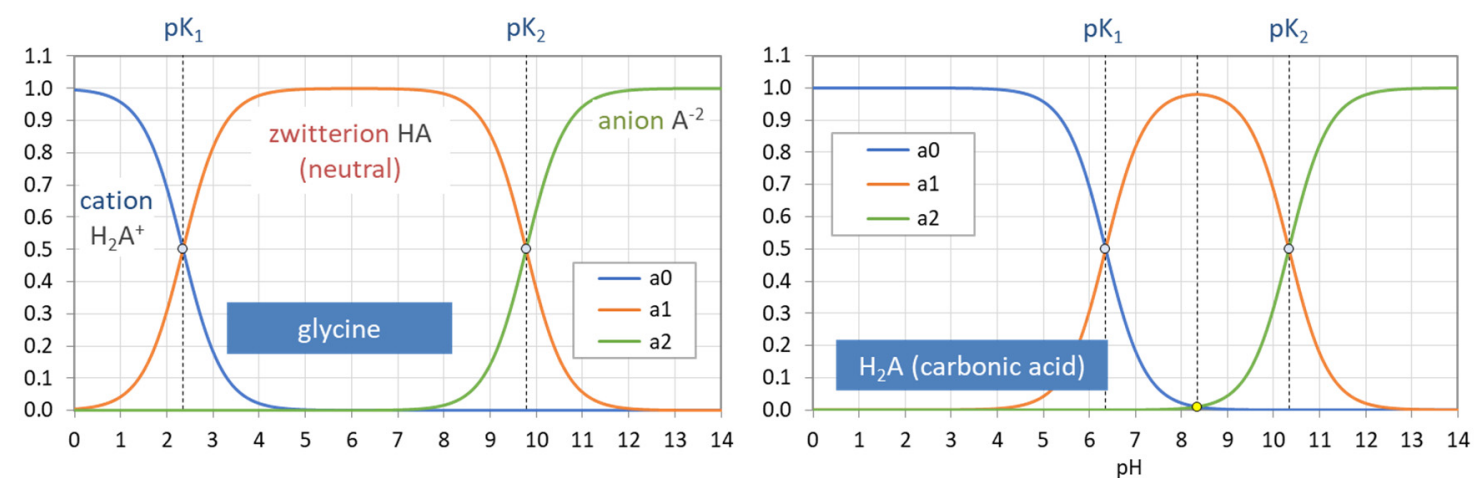

Figure 34. Ionization fractions of two diprotic acids: glycine (left) vs. carbonic acid (right).
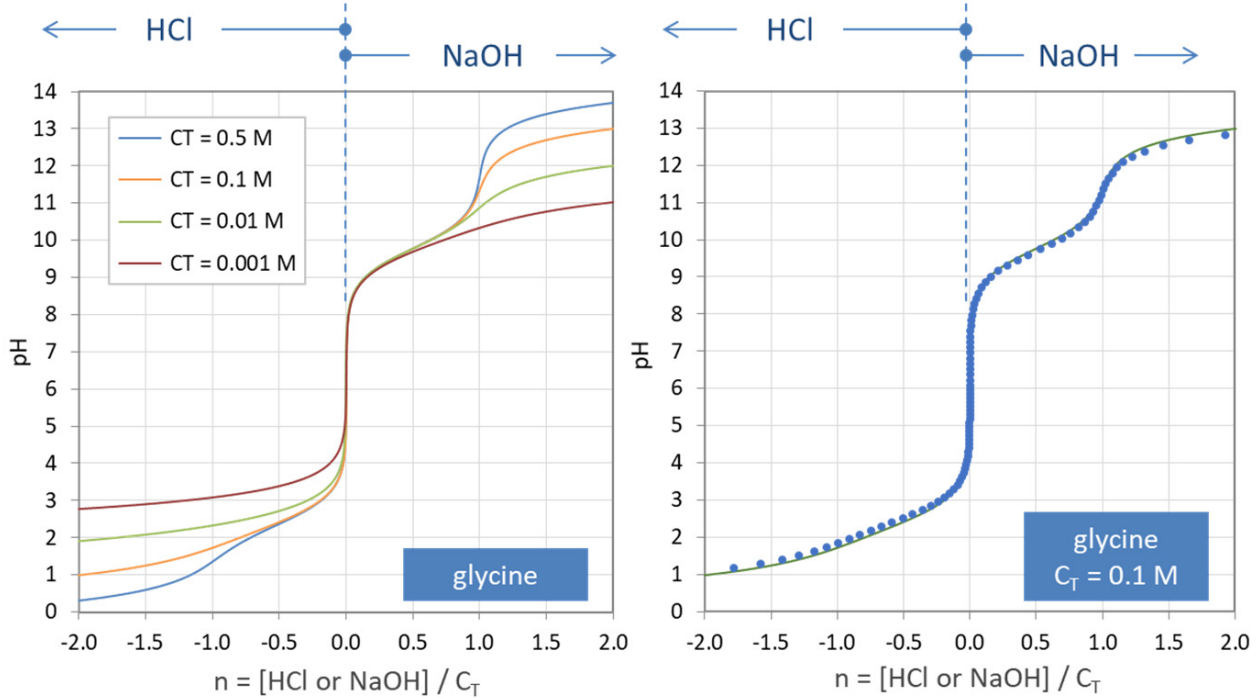

Figure 35. Titration curves $\mathrm{n}=\mathrm{n}(\mathrm{pH})$ for the amino acid glycine. (Left): calculations based on Equation (138) for four amounts of $\mathrm{C}_{\mathrm{T}}$. (Right): comparison with numerical program PhreeqC (dots).

\subsubsection{Polyprotic Zwitterions ( $\mathrm{N}=2$ to 6 )}

In addition to glycine as the simplest zwitterion $(N=2, Z=1)$, we now consider compounds $\mathrm{H}_{\mathrm{N}} \mathrm{A}^{+Z}$ with higher values of $\mathrm{N}$ and/or $\mathrm{Z}$. Examples are given in Table 12 and Figure 36. To recap: $\mathrm{N}$ is the number of $\mathrm{H}^{+}$, and $\mathrm{Z}$ is the positive charge of the highest protonated species.

Table 12. Acidity constants for carbonic acid and zwitterionic acids (the pK values for EDTA are taken from [5]; they differ slightly from those in [17]).

\begin{tabular}{|c|c|c|c|c|c|c|c|c|c|c|c|}
\hline Acid & $\mathbf{N}$ & $\mathrm{Z}$ & $\mathrm{pK}_{1}$ & $\mathrm{pK}_{2}$ & $\mathrm{pK}_{3}$ & $\mathrm{pK}_{4}$ & $\mathrm{pK}_{5}$ & $\mathrm{pK}_{6}$ & {$[\mathbf{j}=0]$} & {$[\mathbf{j}=\mathrm{Z}]$} & {$[\mathbf{j}=\mathbf{N}]$} \\
\hline carbonic acid & 2 & 0 & 6.35 & 11.33 & & & & & $\mathrm{H}_{2} \mathrm{~A}$ & $\mathrm{H}_{2} \mathrm{~A}$ & $\mathrm{~A}^{-2}$ \\
\hline glycine & 2 & 1 & 2.35 & 9.778 & & & & & $\mathrm{H}_{2} \mathrm{~A}^{+}$ & HA & $A^{-1}$ \\
\hline glutamic acid & 3 & 1 & 2.16 & 4.30 & 9.96 & & & & $\mathrm{H}_{3} \mathrm{~A}^{+}$ & $\mathrm{H}_{2} \mathrm{~A}$ & $\mathrm{~A}^{-2}$ \\
\hline NTA & 4 & 1 & 1.0 & 2.0 & 2.942 & 10.28 & & & $\mathrm{H}_{4} \mathrm{~A}^{+}$ & $\mathrm{H}_{3} \mathrm{~A}$ & $\mathrm{~A}^{-3}$ \\
\hline EDTA & 6 & 2 & 0 & 1.5 & 2.16 & 3.119 & 6.281 & 10.94 & $\mathrm{H}_{6} \mathrm{~A}^{+2}$ & $\mathrm{H}_{4} \mathrm{~A}$ & $\mathrm{~A}^{-4}$ \\
\hline
\end{tabular}


<smiles>NCC(=O)O</smiles>

glycine $\mathrm{C}_{2} \mathrm{H}_{5} \mathrm{NO}_{2}$<smiles>NC(CCC(=O)O)C(=O)O</smiles>

glutamic acid $\mathrm{C}_{5} \mathrm{H}_{9} \mathrm{NO}_{4}$<smiles>O=C(O)CN(CC(=O)O)CC(=O)O</smiles>

NTA $\mathrm{C}_{6} \mathrm{H}_{9} \mathrm{NO}_{6}$<smiles>O=C(O)CN(CCN(CC(=O)O)CC(=O)O)CC(=O)O</smiles>

EDTA $\mathrm{C}_{10} \mathrm{H}_{16} \mathrm{~N}_{2} \mathrm{O}_{8}$

Figure 36. Structural formula of four zwitterionic acids.

Figures 37 and 38 present calculations for four zwitterionic acids (from Table 9). The titration curves (blue) are based on Equation (138), while the corresponding buffer capacity $\beta$ (green) and its $\mathrm{pH}$ derivative (red) are based on Equations (69) and (70). The small circles mark the zeros of $\mathrm{d} \beta / \mathrm{dpH}$; they indicate (i) the extrema of $\beta$ and (ii) the inflection points of the titration curves.
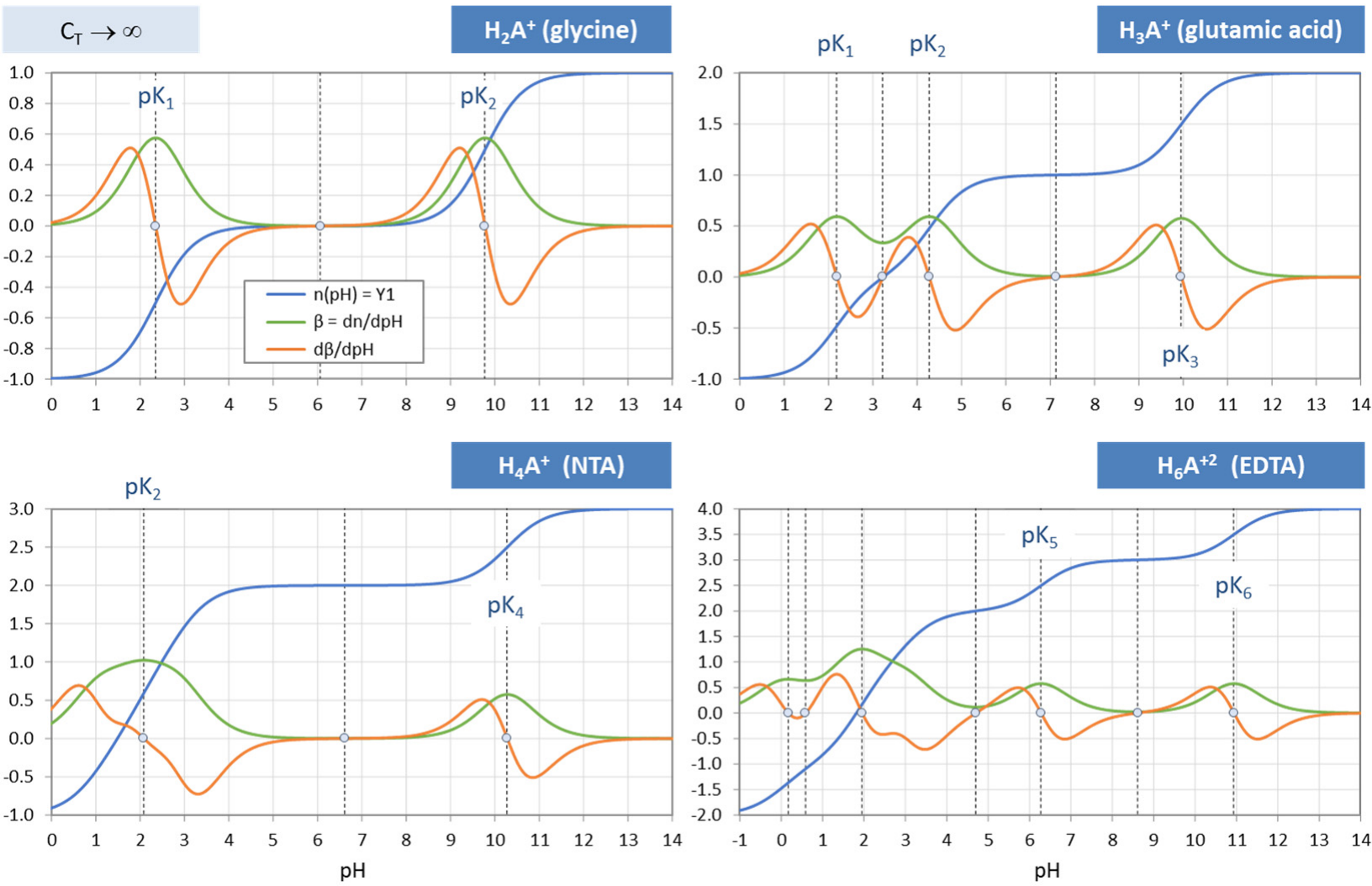

Figure 37. Titration curves $\mathrm{n}(\mathrm{pH})$, buffer capacity $\beta$ and its derivative $\mathrm{d} \beta / \mathrm{dpH}$ for four zwitterionic acids (from Table 12). Calculations for $\mathrm{C}_{\mathrm{T}} \rightarrow \infty$. 


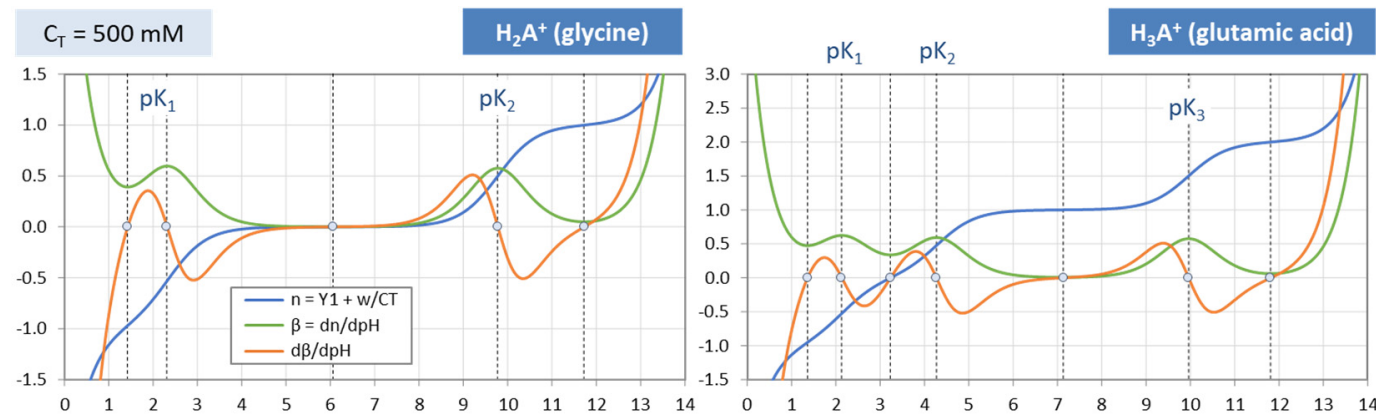

\section{$\mathrm{H}_{4} \mathrm{~A}^{+}$(NTA)}

$H_{6} A^{+2}$ (EDTA)
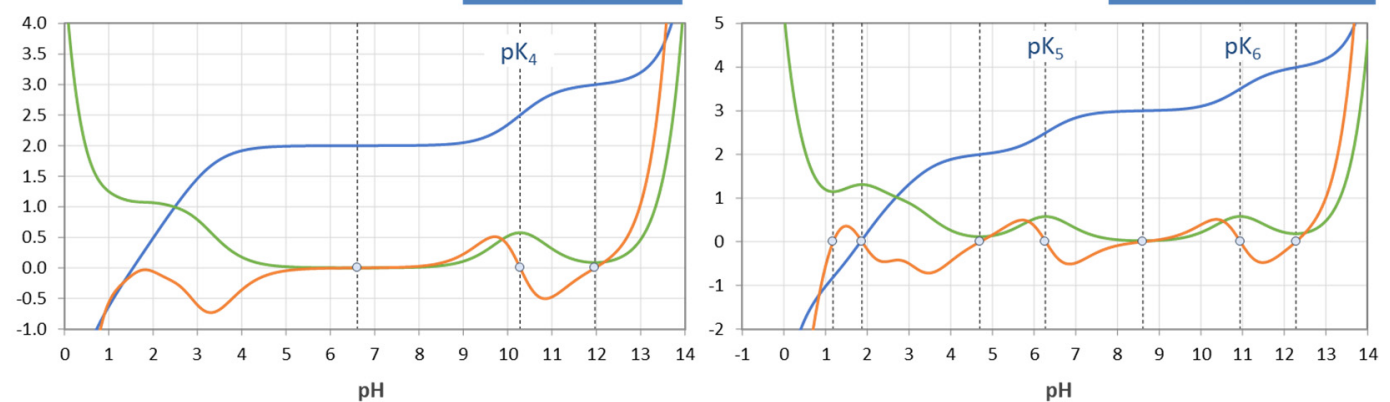

Figure 38. Same as Figure 37, but for $C_{T}=500 \mathrm{mM}$.

\subsubsection{EDTA}

Ethylenediaminetetraacetic acid (EDTA) is particularly interesting because it represents the acid with the highest number of dissociation steps in this report: $\mathrm{N}=6$ (specified by six acidity constants in Table 11). There are $\mathrm{N}+1=7$ acid species; the highest protonated species is $\mathrm{H}_{6} \mathrm{~A}^{+2}$, and the fully deprotonated species is $\mathrm{A}^{-4}$. The two left diagrams in Figure 39 display the $\mathrm{pH}$ dependence of EDTA's seven ionization fractions $\mathrm{a}_{0}$ to $\mathrm{a}_{6}$ based on Equation (17).
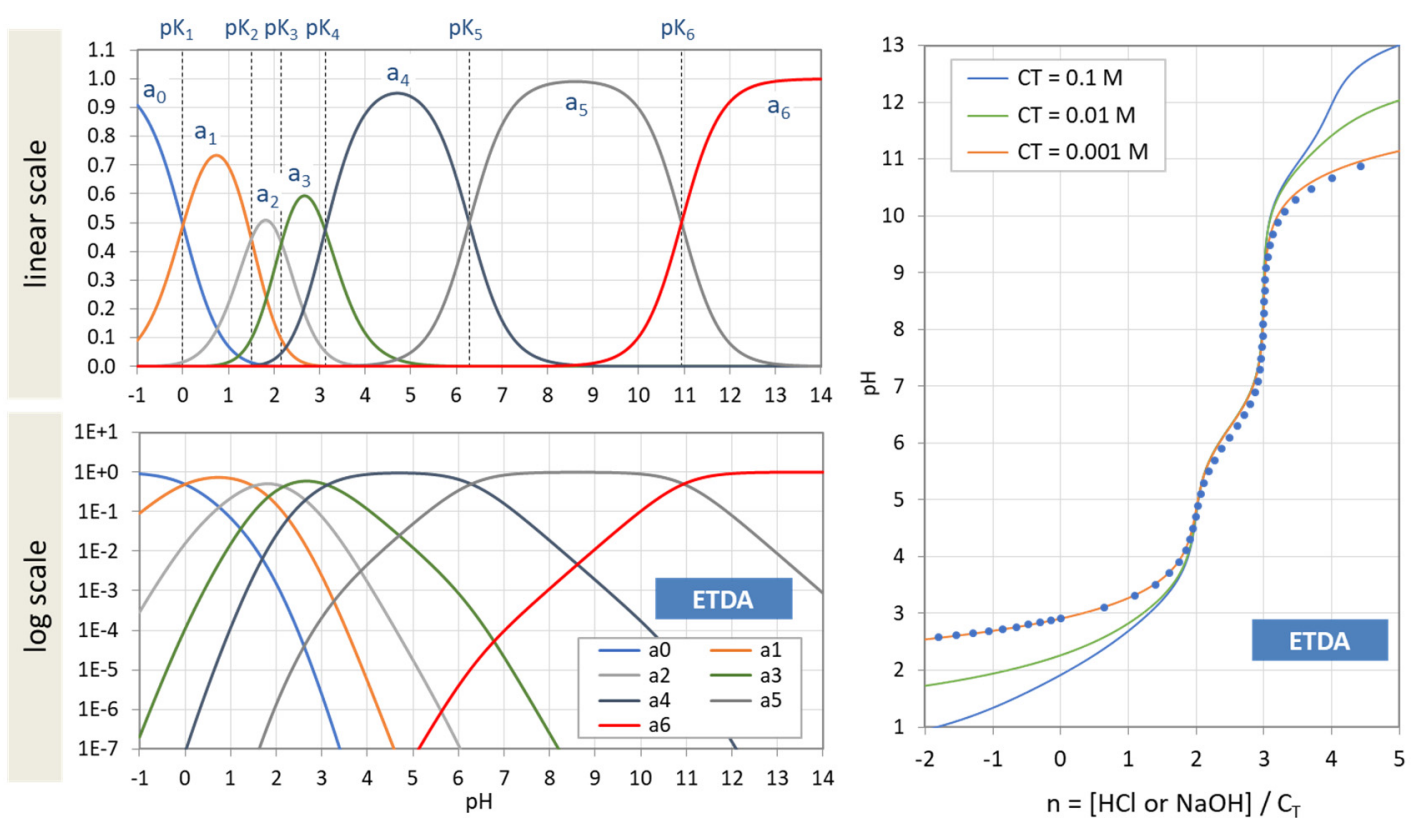

Figure 39. (Left): Ionization fractions of EDTA in linear scale (top) and logarithmic scale (bottom). (Right): Titration curves of EDTA for three values of $C_{T}$ based on Equation (138). The red dots represent numerical calculations with PhreeqC. [Note: Complexation with $\mathrm{Na}$ is ignored.] 
The right diagram in Figure 39 depicts titration curves for three $C_{T}$ values based on Equation (138). The red dots represent numerical calculations with PhreeqC. [Note: In contrast to Figures 37 and 38, which also contain EDTA titration curves, the $\mathrm{x}$ and $\mathrm{y}$ axes are interchanged here.]

\subsubsection{Equivalence Points}

The algebraic relationship between $\mathrm{EP}_{\mathrm{n}}$ and $\mathrm{pH}_{\mathrm{n}}$, originally defined in Equation (60), can easily be extended to zwitterionic acids by taking into account the offset $\mathrm{Z}$ :

$\mathrm{EP}_{\mathrm{n}} \Leftrightarrow \mathrm{pH}_{\mathrm{n}}: \mathrm{n}=\left(\mathrm{Y}_{1}\left(\mathrm{pH}_{\mathrm{n}}\right)-\mathrm{Z}\right)+\frac{\mathrm{w}\left(\mathrm{pH}_{\mathrm{n}}\right)}{\mathrm{C}_{\mathrm{T}}} \quad$ for $\quad \mathrm{n}=-\mathrm{Z}, \ldots-\frac{1}{2}, 0, \frac{1}{2}, \ldots \mathrm{N}-\mathrm{Z}$

The number of equivalence points remains the same: $2 N+1$ (independent of $Z$ ). For $Z$ $=0$, this relation simplifies to Equation (60).

Figure 40 shows the titration curve of glycine for $C_{T}=500 \mathrm{mM}$ (same as in the upper left diagram of Figure 38). The small circles at integer and half-integer values of $\mathrm{n}$ mark the assignment $\mathrm{EP}_{\mathrm{n}} \Leftrightarrow \mathrm{pH}_{\mathrm{n}}$. Since HGly acts as a 2-protic acid, there are $2 \times 2+1=5$ equivalence points in total. The main difference to the diprotic acid $\mathrm{H}_{2} \mathrm{CO}_{3}$ (shown in Figure 15) is the occurrence of EPs with negative integer and half-integer values of $n$.

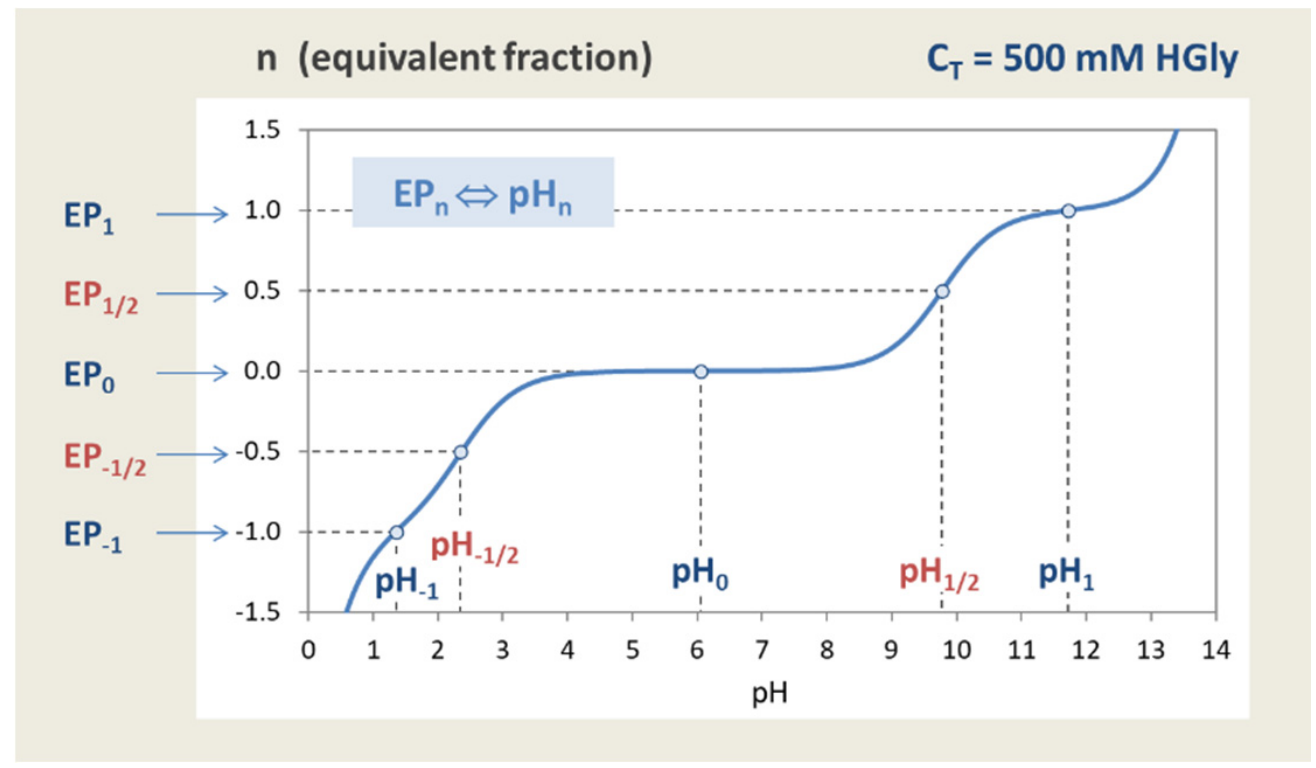

Figure 40. Titration curve of glycine with EPs and semi-EPs located at integer and half-integer $n$.

$\mathrm{pH}-\mathrm{C}_{\mathrm{T}}$ diagrams are obtained after rearranging of Equation (139) to the form:

$$
\mathrm{C}_{\mathrm{T}}=\frac{\mathrm{w}(\mathrm{pH})}{\mathrm{n}+\mathrm{Z}-\mathrm{Y}_{1}(\mathrm{pH})}
$$

This relationship is plotted in Figure 41-one curve for each integer and half-integer value of $\mathrm{n}$. The dashed curves (straight lines) correspond to the 1-component system "acid" (high- $\mathrm{C}_{\mathrm{T}}$ limit). This diagram should be compared with the plots for ordinary acids in Figure 27. 

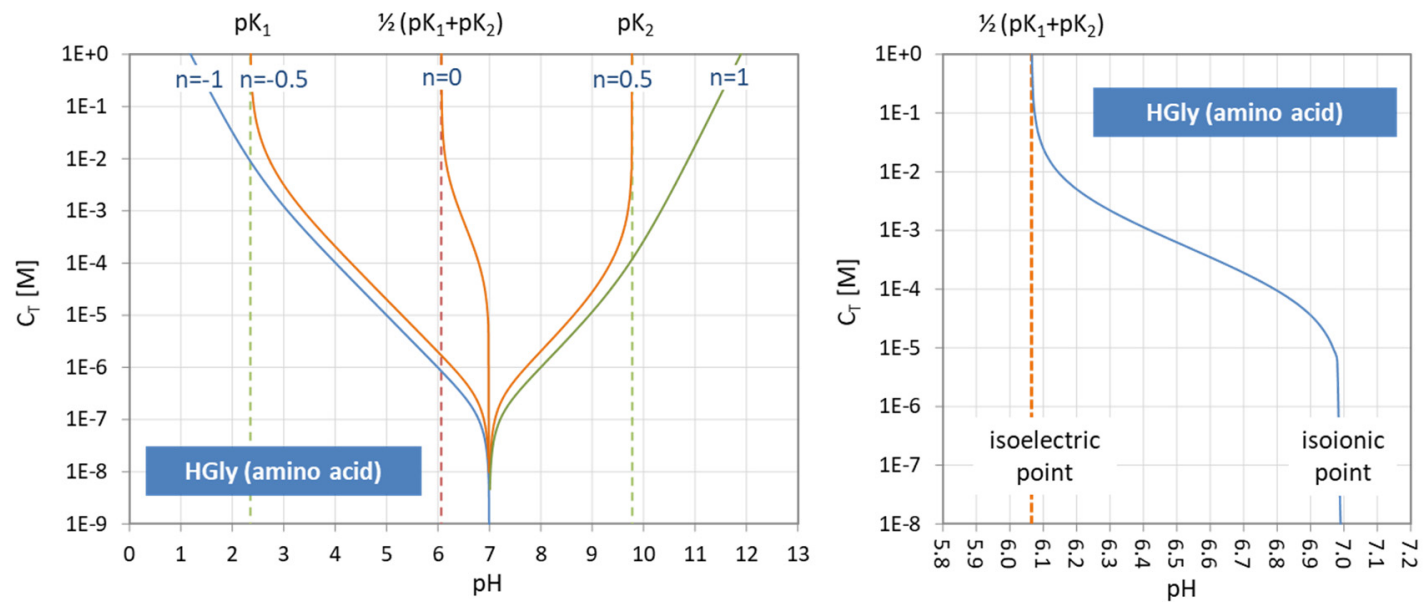

Figure 41. (Left) $\mathrm{pH}-\mathrm{C}_{\mathrm{T}}$ diagrams for glycine. (Right): enlarged section around $\mathrm{EP}_{0}$ showing the isoelectric and isoionic points as a function of $\mathrm{C}_{\mathrm{T}}$.

\subsubsection{Isoionic vs. Isoelectric Points}

The isoionic point is the $\mathrm{pH}$ of the pure, neutral polyprotic acid (i.e., when the neutral zwitterion is dissolved in water). The isoelectric point $\mathrm{pI}$ is the $\mathrm{pH}$ at which the average charge $\mathrm{z}_{\mathrm{av}}$ of the polyprotic acid is zero (the net charge of the solution is always zero):

isoionic point: $\mathrm{pH}_{0}$

isoelectric point: $\mathrm{pI}=\mathrm{pH}$ at which $\mathrm{z}_{\mathrm{av}}=0$
(= $\mathrm{pH}$ of 2-component system "acid $+\mathrm{H}_{2} \mathrm{O}^{\prime}$ )

$(=\mathrm{pH}$ of 1 -component system "acid")

The formula for the isoionic point follows from Equation (139) by setting $\mathrm{n}=0$; the formula for the isoelectric point follows from the definition of $z_{a v}$ in Equation (136):

$$
\begin{array}{cc}
\text { isoionic point : } & Z-Y_{1}(p H)=\frac{w(p H)}{C_{T}} \\
\text { isoelectricpoint : } & Z-Y_{1}(p H)=0
\end{array}
$$

Note that both are implicit functions. With increasing $\mathrm{C}_{\mathrm{T}}$, the isoionic and isoelectric points approach each other until they become identical in the high- $C_{T}$ limit. This behavior is illustrated in the right diagram of Figure 41. For a diprotic acid (e.g., glycine) we have $\mathrm{Z}=1$, which—after insertion into Equation (142)-leads to:

$$
\text { isoelectric point: } \quad 1-\mathrm{Y}_{1}=0 \Leftrightarrow \mathrm{pI}=\frac{1}{2}\left(\mathrm{pK}_{1}+\mathrm{pK}_{2}\right)
$$

The difference between the isoionic and isoelectric points (even if it is numerically

\begin{tabular}{|c|c|}
\hline Isoionic Point & Isoelectric Point (pI) \\
\hline $\mathrm{pH}$ of pure acid & $\begin{array}{l}\mathrm{pH} \text { at which the net charge of all acid species } \\
\text { is zero }\end{array}$ \\
\hline $\begin{array}{c}\text { depends on } \mathrm{C}_{\mathrm{T}} \\
\text { (approaches pI-value for } \mathrm{C}_{\mathrm{T}} \rightarrow \infty \\
\text { and } \mathrm{pH}=7 \text { for } \mathrm{C}_{\mathrm{T}} \rightarrow 0 \text { ) }\end{array}$ & independent of $C_{T}$ \\
\hline $\mathrm{Z}-\mathrm{Y}_{1}(\mathrm{pH})=\mathrm{w}(\mathrm{pH}) / \mathrm{C}_{\mathrm{T}}$ & $\mathrm{Z}-\mathrm{Y}_{1}(\mathrm{pH})=0$ \\
\hline exists for ordinary acids and zwitterions & exists only for zwitterions \\
\hline
\end{tabular}
very small) is summarized in Table 13.

Table 13. Isoionic vs. isoelectric point. 


\subsection{Surface Complexation}

\subsubsection{Definition}

Surface complexation [1] becomes especially simple when Coulomb interactions are ignored. This approximation is valid and useful, e.g., in the vicinity of the point of zero charge (PZC).

Let us consider a surface hydroxyl group $\equiv \mathrm{sOH}$, where $\equiv$ s symbolizes the surface. The uptake and release of protons involves two dissociation steps $(\mathrm{N}=2)$ :

$$
\begin{array}{lll}
\text { 1st dissociation step: } & \equiv \mathrm{sOH}_{2}{ }^{+}=\mathrm{H}^{+}+\equiv \mathrm{sOH} & \mathrm{K}_{1} \\
\text { 2nd dissociation step: } & \equiv \mathrm{sOH}=\mathrm{H}^{+}+\equiv \mathrm{sO}^{-} & \mathrm{K}_{2}
\end{array}
$$

In the absence of Coulomb interactions, $\mathrm{K}_{1}$ and $\mathrm{K}_{2}$ are so-called intrinsic equilibrium constants. Examples are given in Table 14. Similar to the case of the zwitterionic acid $\mathrm{H}_{2} \mathrm{~A}^{+}$, there are $\mathrm{N}+1=3$ (surface) species:

$$
\begin{array}{ll}
{[0]=\left[\equiv \mathrm{SOH}_{2}{ }^{+}\right]} & \text {cationic } \\
{[1]=[\equiv \mathrm{SOH}]} & \text { neutral } \\
{[2]=\left[\equiv \mathrm{sO}^{-}\right]} & \text {anionic }
\end{array}
$$

Table 14. Intrinsic $\mathrm{pK}$ values and $\mathrm{pH}_{\mathrm{pzc}}$ for surface complexation on four (clay) minerals [40].

\begin{tabular}{ccccc}
\hline & Kaolinite & Mica & Goethite & Gibbsite \\
\hline $\mathrm{pK}_{1}$ & 2.52 & 6.01 & 7.13 & 7.53 \\
$\mathrm{pK}_{2}$ & 5.88 & 7.65 & 9.60 & 9.87 \\
$\mathrm{pH}_{\mathrm{pzc}}=\frac{1}{2}\left(\mathrm{pK}_{1}+\mathrm{pK}_{2}\right)$ & 4.20 & 6.83 & 8.37 & 8.70 \\
\hline
\end{tabular}

The sum of all species is the total amount of surface sites $C_{T}$. The formulas for the buffer capacity and the buffer intensity of surface complexation are the same as for zwitterionic acids, namely Equations (69), (70) and (138) for $\mathrm{N}=2$ and $\mathrm{Z}=1$.

\subsubsection{Example Calculations}

The ionization fractions $\mathrm{a}_{0}, \mathrm{a}_{1}$, and $\mathrm{a}_{2}$, based on Equation (17), are shown in Figure 42; they illustrate the species distribution on kaolinite (in the absence of Coulomb interactions).

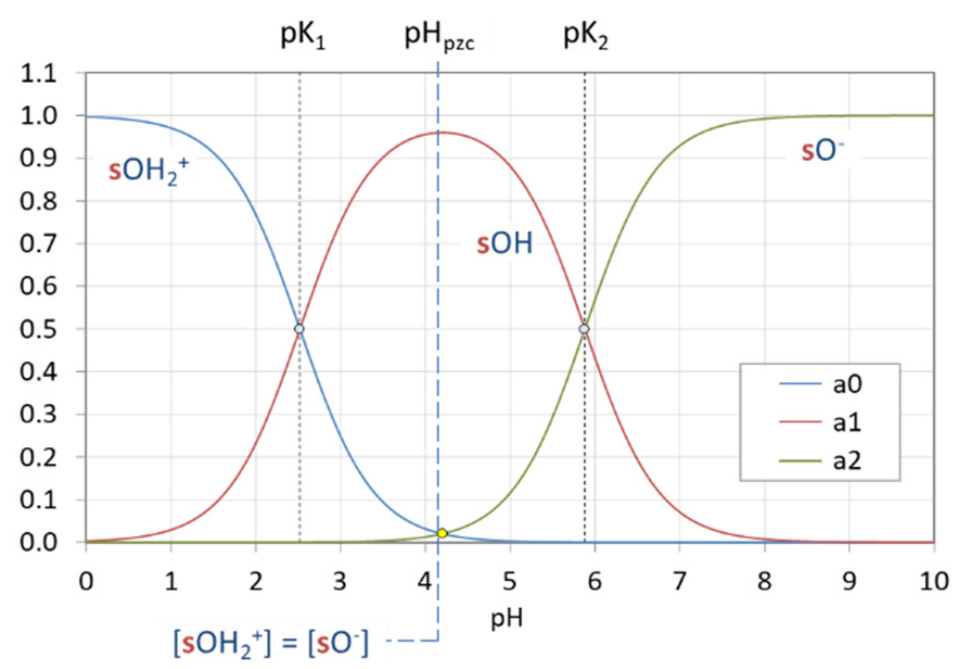

Figure 42. Ionization fractions representing the surface-species distribution on kaolinite (in the absence of Coulomb interactions).

The "average charge" defined in Equation (136) represents the

$$
\text { surface charge : } \mathrm{z}_{\mathrm{av}}=1-\mathrm{Y}_{1}(\mathrm{pH})=\mathrm{a}_{0}-\mathrm{a}_{2}=\frac{1}{\mathrm{C}_{\mathrm{T}}}\left(\left[\equiv \mathrm{sH}_{2} \mathrm{O}^{+}\right]-\left[\equiv \mathrm{sO}^{-}\right]\right)
$$


This quantity is plotted in Figure 43 for the four surface types defined in Table 14. The $\mathrm{pH}$ at which the surface charge is zero $\left(z_{a}=0\right)$ defines the PZC:

$$
\mathrm{pH}_{\mathrm{pzc}}=\frac{1}{2}\left(\mathrm{pK}_{1}+\mathrm{pK}_{2}\right)
$$

The PZC is equivalent to the isoelectric point when there is no adsorption of ions other than $\mathrm{H}^{+}$and $\mathrm{OH}^{-}$(pristine surface).

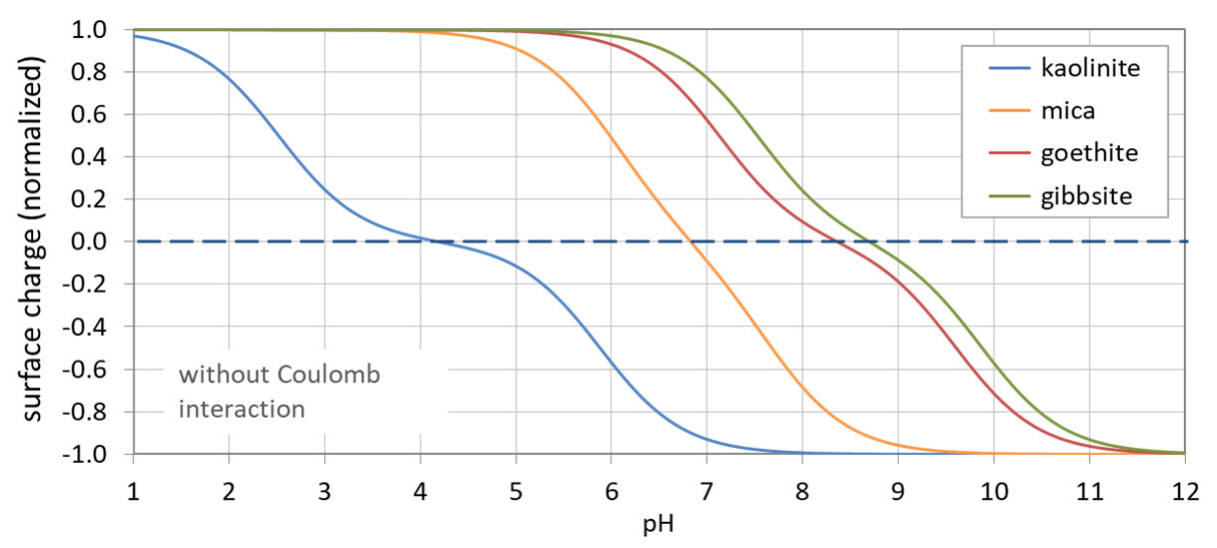

Figure 43. $\mathrm{pH}$ dependence of surface charge for four surfaces (in the absence of Coulomb interactions).

\section{Summary}

Polyprotic acids in the general form $\mathrm{H}_{\mathrm{N}} \mathrm{A}^{+\mathrm{Z}}$ include ordinary acids as a special case $(Z=0)$. They are specified by $N$ acidity constants: $K_{1}, K_{2}, \ldots K_{N}$. The acid-base system is then characterized by:

$$
\begin{array}{lc}
\text { (normalized) buffer capacity: } & \mathrm{n}(\mathrm{x})=\left(\mathrm{Y}_{1}-\mathrm{Z}\right)+\frac{\mathrm{w}}{\mathrm{C}_{\mathrm{T}}} \\
\text { (normalized) buffer intensity: } & \beta(\mathrm{x}) \equiv \frac{\mathrm{dn}}{\mathrm{d} \mathrm{pH}}=(\ln 10)\left(\mathrm{Y}_{2}-\mathrm{Y}_{1}^{2}+\frac{\mathrm{w}+2 \mathrm{x}}{\mathrm{C}_{\mathrm{T}}}\right) \\
\text { 1st derivative of } \beta: & \frac{\mathrm{d} \beta}{\mathrm{d} \mathrm{pH}}=(\ln 10)^{2}\left(\mathrm{Y}_{3}-3 \mathrm{Y}_{1} \mathrm{Y}_{2}+2 \mathrm{Y}_{1}^{3}+\frac{\mathrm{w}}{\mathrm{C}_{\mathrm{T}}}\right)
\end{array}
$$

Here, $\mathrm{n}(\mathrm{x})$ in Equation (147) represents the central formula from which the other two are obtained via $\mathrm{pH}$ derivation. The parameter $\mathrm{Z}$ enters only Equation (147), where it acts as a constant offset; the buffer intensity and its derivative are both independent of $Z$.

The function $\mathrm{n}(\mathrm{x})$ has different meanings/names: (i) equivalent fraction $\left(\mathrm{n}=\mathrm{C}_{\mathrm{B}} / \mathrm{C}_{\mathrm{T}}\right)$, (ii) titration function/curve and (iii) normalized buffer capacity. Discrete values of n, i.e., the integer and half-integer values of $n$, define the equivalence points $\mathrm{EP}_{n}$ and semi-EP $\mathrm{P}_{\mathrm{n}}$. They mark the inflection points of the titration curve, the maxima/minima of $\beta$ and the zeros of $\mathrm{d} \beta / \mathrm{dpH}$. (Note: $\mathrm{n}(\mathrm{x})$ as buffer capacity measures the "distance" from $\mathrm{x}=10^{-\mathrm{pH}}$ to $\mathrm{EP}_{0}$ ). A classification of equivalence points is provided in Section 2.3 and Figure 16.

The analytical formula for $\mathrm{n}(\mathrm{x})$ is the strict mathematical solution of the set of $\mathrm{N}+3$ nonlinear equations ( $\mathrm{N}+1$ mass action and 2 balance equations) defined in Equations (27)-(32). As sketched in Figure 44, there are three mathematical equivalent representations of the $\mathrm{N}$-protic acid-base system (all carrying the same information content): (i) the algebraic set of $\mathrm{N}+3$ equations, (ii) the equivalent-fraction formula as defined in Equation (41) or Equation (147), and (iii) the polynomial of degree $\mathrm{N}+2$ in Equation (44). 


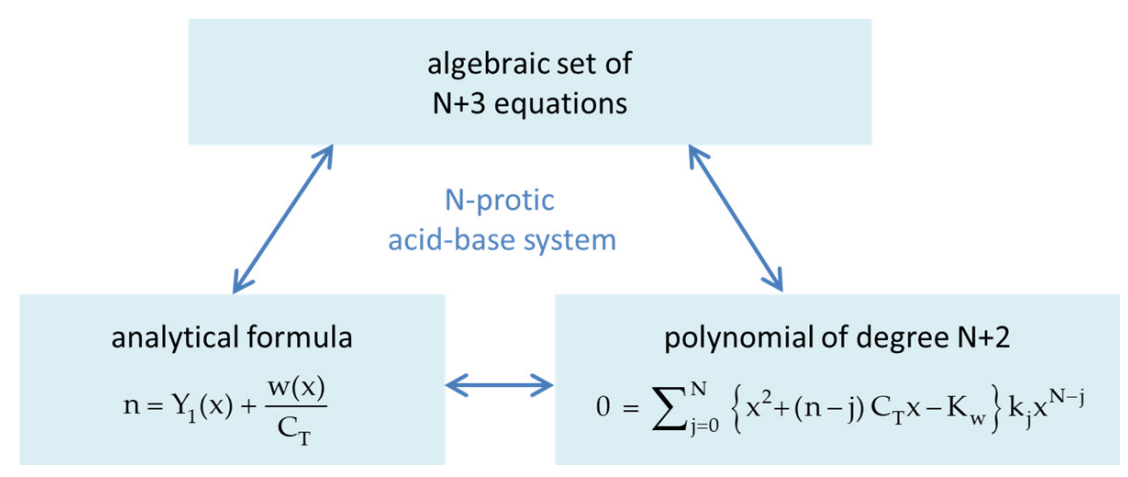

Figure 44. Three mathematically equivalent descriptions of the N-protic acid-base system. The algebraic set of $N+3$ equations is defined in Equations (27)-(32).

The main feature that makes the analytical formula $\mathrm{n}(\mathrm{x})$ so attractive is its easy calculability (no programming or root solver are required). As shown in Figure 45, its construction relies on a 3-layer hierarchy of building blocks: (i) the acidity constants themselves (the only input data), (ii) the ionization fractions that rely on the cumulative acidity constants $\mathrm{k}_{\mathrm{j}}$, and (iii) the moments $Y_{L}$ that are weighted sums of $a_{j}$. These building blocks characterize the 1-component system "N-protic acid". The step from the 1-component to the 3-component system requires two extra input parameters, $C_{T}$ and $C_{B}$, to obtain $n=n(p H)$. The $p H$ derivatives of $\mathrm{n}(\mathrm{pH})$ are again analytical formulas which can easily be constructed from the same building blocks.

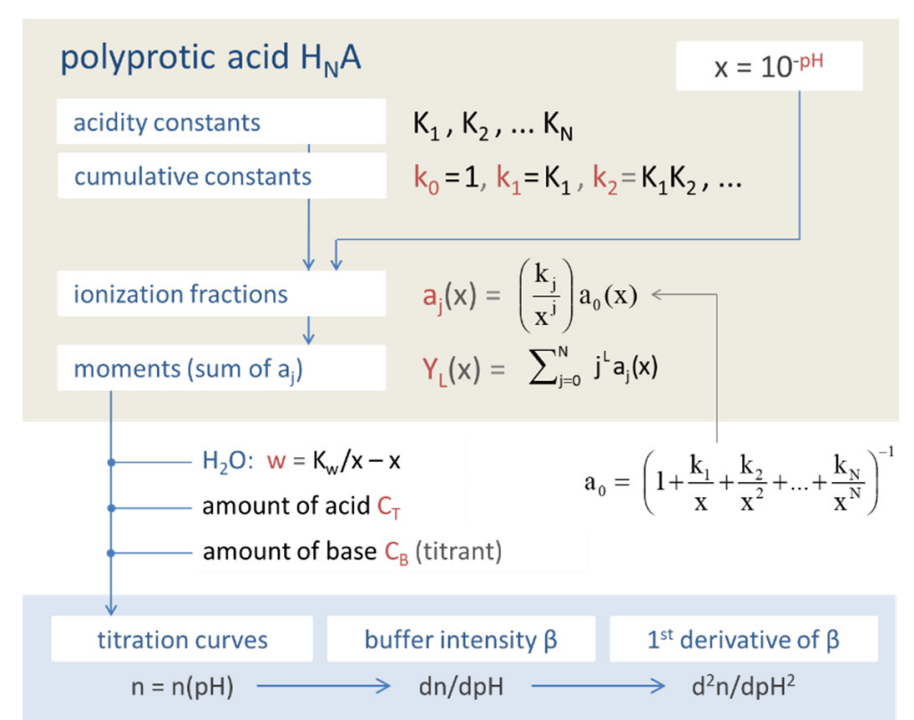

Figure 45. Building-block hierarchy of the acid-base model.

Another advantage: Once you have an analytical formula (explicit function), it can be "modified" according to all rules of mathematics: (i) you can differentiate/integrate the function as in Section 2.4.2, (ii) you can form superpositions (mixtures) as in Section 3.1.4, and (iii) you can invert the function as in Section 2.2.3.

Final Remark. The mathematical framework is based on three assumptions: (i) activities are replaced by concentrations, (ii) no aqueous complex formation, and (iii) no density effects (molality $=$ molarity). These are the limits of the analytical model. Although the current approach deepens our understanding of the acid-base system, it can never replace numerical models such as PhreeqC, which are capable of handling real-world problems more accurately (including activity corrections, an arbitrary number of species and phases, and complex formation). 
Funding: This research received no external funding.

Institutional Review Board Statement: Not applicable.

Informed Consent Statement: Not applicable.

Data Availability Statement: All data used in this article are publicly available (cf. citations in Table 1, Table 8, Table 12, and Table 14).

Conflicts of Interest: The author declares no conflict of interest.

\section{Appendix A. Abbreviations and Symbols}

\begin{tabular}{|c|c|c|}
\hline$a_{j}$ & ionization fractions, $a_{j}=[j] / C_{T}$ & - \\
\hline$\alpha$ & vector of microstates: $\alpha^{(\nu)}=\left(\alpha_{1}, \alpha_{2}, \ldots \alpha_{N}\right)$ & - \\
\hline Acy & acidity & $\mathrm{mol} / \mathrm{L}$ \\
\hline Alk & total alkalinity (M-alkalinity) & $\mathrm{mol} / \mathrm{L}$ \\
\hline ANC & acid-neutralizing capacity & $\mathrm{mol} / \mathrm{L}$ \\
\hline $\mathrm{BNC}$ & base-neutralizing capacity & $\mathrm{mol} / \mathrm{L}$ \\
\hline$\beta$ & buffer intensity (normalized), $\beta=\mathrm{dn} / \mathrm{dpH}$ & - \\
\hline$\beta_{C}$ & buffer intensity, $\beta_{C}=\mathrm{dC}_{\mathrm{B}} / \mathrm{dpH}=\mathrm{C}_{\mathrm{T}} \beta$ & $\mathrm{mol} / \mathrm{L}$ \\
\hline$\beta_{j}$ & cumulative formation constants & $(\mathrm{mol} / \mathrm{L})^{-\mathrm{j}}$ \\
\hline$\gamma_{j}$ & activity correction for species $\mathrm{j}$ & - \\
\hline $\mathrm{C}_{\mathrm{A}}$ & concentration of strong monoprotic acid $\mathrm{C}_{\mathrm{A}}=[\mathrm{HX}]_{\mathrm{T}}$ & $\mathrm{mol} / \mathrm{L}$ \\
\hline $\mathrm{C}_{\mathrm{B}}$ & concentration of strong monoacidic base $C_{\mathrm{B}}=[\mathrm{BOH}]_{\mathrm{T}}$ & $\mathrm{mol} / \mathrm{L}$ \\
\hline $\mathrm{C}_{\mathrm{T}}$ & total concentration of N-protic acid: $\mathrm{C}_{\mathrm{T}}=\left[\mathrm{H}_{\mathrm{N}} \mathrm{A}\right]_{\mathrm{T}}$ & $\mathrm{mol} / \mathrm{L}$ \\
\hline$\delta \mathrm{j}$ & fluctuation of $\mathrm{j}$ around its mean: $\delta \mathrm{j} \equiv \mathrm{j}-\langle\mathrm{j}\rangle$ & - \\
\hline $\mathrm{EP}_{\mathrm{j}}$ & equivalence point (for integer $\mathrm{j}$ ) & - \\
\hline $\mathrm{EP}_{\mathrm{n}}$ & equivalence point (for integer and half-integer $n$ ) & - \\
\hline $\mathrm{f}_{0}, \mathrm{f}_{\mathrm{N}}$ & probability density functions (related to $\mathrm{a}_{0}$ and $\mathrm{a}_{\mathrm{N}}$ ) & - \\
\hline G & molar Gibbs energy & $\mathrm{J} / \mathrm{mol}$ \\
\hline$g_{i}$ & Simms constant & $\mathrm{mol} / \mathrm{L}$ \\
\hline$\gamma_{\mathrm{j}}$ & activity correction for species $j$ & - \\
\hline $\mathrm{I}$ & ionic strength & $\mathrm{mol} / \mathrm{L}$ \\
\hline j & index denoting the aqueous species $j, j=0,1, \ldots N$ & - \\
\hline [j] & molar concentration of aqueous species $\mathrm{j}:[\mathrm{j}]=\left[\mathrm{H}_{\mathrm{N}-\mathrm{j}} \mathrm{A}^{-\mathrm{j}}\right]$ & $\mathrm{mol} / \mathrm{L}$ \\
\hline$\{j\}$ & activity of aqueous species $\mathrm{j}:\{\mathrm{j}\}=\left\{\mathrm{H}_{\mathrm{N}-\mathrm{j}} \mathrm{A}^{-\mathrm{j}}\right\}$ & $\mathrm{mol} / \mathrm{L}$ \\
\hline$\langle\mathrm{j}\rangle$ & mean value of $\mathrm{j}$ (real number between 0 and $\mathrm{N}$ ) & - \\
\hline $\mathrm{K}_{\mathrm{a}}$ & acidity constant (general abbreviation) & $\mathrm{mol} / \mathrm{L}$ \\
\hline${ }^{\mathrm{c}} \mathrm{K}_{\mathrm{a}}$ & conditional acidity constant (non-thermodynamic quantity) & $\mathrm{mol} / \mathrm{L}$ \\
\hline $\mathrm{K}_{\mathrm{j}}$ & acidity constant of dissociation step $\mathrm{j}$ & $\mathrm{mol} / \mathrm{L}$ \\
\hline $\mathrm{K}_{\mathrm{H}}$ & Henry constant & $(\mathrm{mol} / \mathrm{L}) / \mathrm{atm}$ \\
\hline $\mathrm{k}_{\mathrm{j}}$ & cumulative acidity constant, e.g., $\mathrm{k}_{\mathrm{j}}=\mathrm{K}_{1} \mathrm{~K}_{2} \ldots \mathrm{K}_{\mathrm{j}}$ & $(\mathrm{mol} / \mathrm{L})^{\mathrm{j}}$ \\
\hline $\mathrm{K}_{\mathrm{w}}$ & equilibrium constant of autoprotolysis (self-ionization of $\mathrm{H}_{2} \mathrm{O}$ ) & $(\mathrm{mol} / \mathrm{L})^{2}$ \\
\hline $\mathrm{K}_{v}$ & microscopic equilibrium constant & - \\
\hline$\mu_{\mathrm{H}^{+}}$ & chemical potential of $\mathrm{H}^{+}$ & $\mathrm{mol} / \mathrm{L}$ \\
\hline $\mathrm{n}$ & equivalent fraction of titration, $n=\left(C_{B}-C_{A}\right) / C_{T}$ & - \\
\hline $\mathrm{N}$ & number of protons $\left(\mathrm{H}^{+}\right)$of the $\mathrm{N}$-protic acid $\mathrm{H}_{\mathrm{N}} \mathrm{A}$ & - \\
\hline$v$ & label for microstates & - \\
\hline $\mathrm{P}$ & pressure & atm \\
\hline $\mathrm{pH}$ & $=-\lg \left\{\mathrm{H}^{+}\right\}=-\lg \mathrm{x}$ & - \\
\hline $\mathrm{pH}_{\mathrm{j}}$ & $=\frac{1}{2}\left(\mathrm{pK}_{\mathrm{j}}+\mathrm{pK}_{\mathrm{j}+1}\right)$ as $\mathrm{pH}$ of equivalence point $\mathrm{EP}_{\mathrm{j}}$ & - \\
\hline $\mathrm{pH}_{\mathrm{n}}$ & $\mathrm{pH}$ of $\mathrm{EP}_{\mathrm{n}}$ & - \\
\hline $\mathrm{pk}_{\mathrm{j}}$ & $=-\lg \mathrm{k}_{\mathrm{j}}$ & - \\
\hline $\mathrm{pK}_{\mathrm{j}}$ & $=-\lg \mathrm{K}_{\mathrm{j}}$ & - \\
\hline $\mathrm{pH}_{\mathrm{pzc}}$ & $\mathrm{pH}$ of PZC (point of zero charge) & - \\
\hline $\mathrm{pI}$ & isoelectric point & - \\
\hline
\end{tabular}




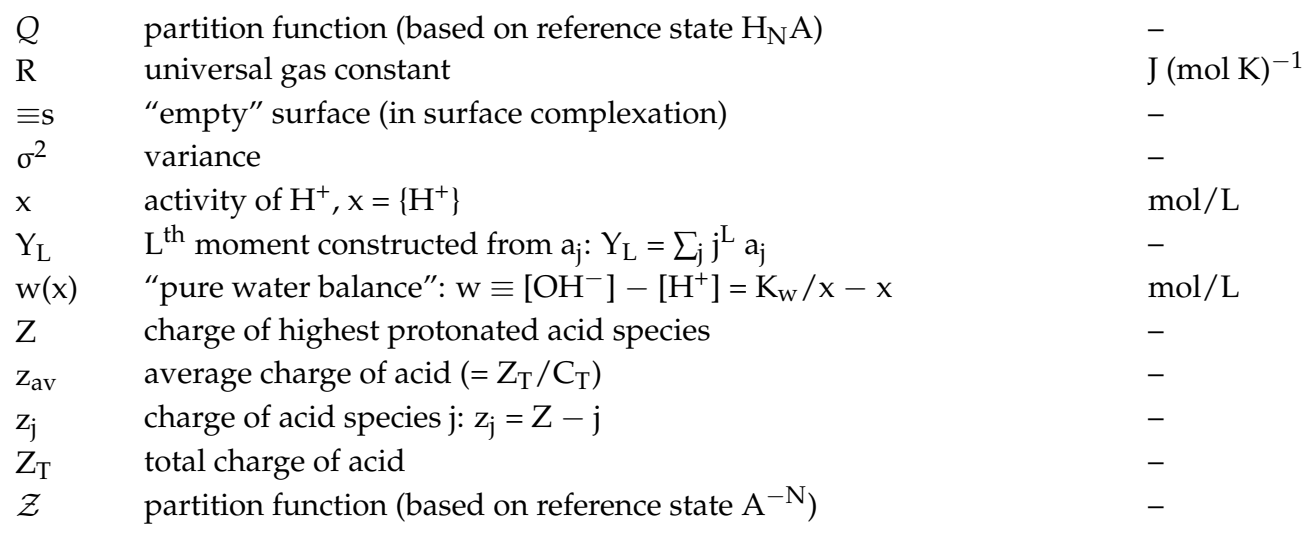

\section{Appendix B. Activity Models}

Appendix B.1. Activity vs. Concentration

Ions in solution interact with each other and with $\mathrm{H}_{2} \mathrm{O}$ molecules. In this way, ions behave chemically like they are less concentrated than they actually are (or measured). This effective concentration, which is available for reactions, is called activity:

$$
\text { activity }=\text { effective concentration } \leq \text { real concentration }
$$

The concentration [j] of the aqueous species $\mathrm{j}$ is converted to the activity $\{\mathrm{j}\}$ using the activity coefficient $\gamma_{\mathrm{j}}$ :

$$
\{j\}=\gamma_{j}[j]
$$

In the limit of infinitely dilute systems, the activity coefficient becomes 1 :

$$
\text { ideal solution: } \quad \gamma_{\mathrm{j}}=1 \Rightarrow\{\mathrm{j}\}=[\mathrm{j}]
$$

Since $\gamma_{j}$ corrects for electrostatic shielding by other ions, $\gamma_{j}$ depends on the ionic strength:

$$
I=\frac{1}{2} \sum_{j} z_{j}^{2}[j]
$$

The sum is taken of all ions in the solution. Due to the square of charge $z_{j}$, multivalent ions contribute particularly strongly to the ionic strength.

\section{Appendix B.2. Activity Corrections}

For the calculation of the activity correction $\gamma$ or $\lg \gamma$, several semi-empirical approaches are available (each with its own validity range defined by the ionic strength):

$$
\begin{aligned}
& \text { Debye-Huckel }(\mathrm{DH}): \lg \gamma_{\mathrm{j}}=-\mathrm{Az}_{\mathrm{j}}^{2} \sqrt{\mathrm{I}} \quad\left(\text { for } \mathrm{I}<10^{-2.3} \mathrm{M}\right) \\
& \text { Extended DH : } \quad \lg \gamma_{j}=-A z_{j}^{2}\left(\frac{\sqrt{\mathrm{I}}}{1+\mathrm{B} \alpha_{\mathrm{j}} \sqrt{\mathrm{I}}}\right) \\
& \text { Davies : } \\
& \lg \gamma_{\mathrm{j}}=-\mathrm{A} z_{\mathrm{j}}^{2}\left(\frac{\sqrt{\mathrm{I}}}{1+\sqrt{\mathrm{I}}}-0.3 \cdot \mathrm{I}\right) \quad(\text { for } \mathrm{I} \leq 0.5 \mathrm{M}) \\
& \text { Truesdell-Jones : } \quad \lg \gamma_{\mathrm{j}}=-\mathrm{A} z_{\mathrm{j}}^{2}\left(\frac{\sqrt{\mathrm{I}}}{1+\mathrm{B} \alpha_{\mathrm{j}}^{0} \sqrt{\mathrm{I}}}-\mathrm{b}_{\mathrm{j}} \mathrm{I}\right) \quad(\text { for } \mathrm{I} \leq 0.5 \mathrm{M})
\end{aligned}
$$

All quantities carrying the subscript $j$ are ion-specific parameters $\left(\alpha_{j}, \alpha_{j}{ }^{0}\right.$, and $\left.b_{j}\right)$. The parameters $\mathrm{A}$ and $\mathrm{B}$ depend on temperature $\mathrm{T}$ and the dielectric constant $\varepsilon$. For water at $25^{\circ} \mathrm{C}$, we have (with $\varepsilon=\varepsilon_{\mathrm{r}} \varepsilon_{0}=78.54 \cdot 8.854 \cdot 10^{-12} \mathrm{~J}^{-1} \mathrm{C}^{2} \mathrm{~m}^{-1}$ ):

$$
\mathrm{A}=1.82 \cdot 10^{6}(\varepsilon \mathrm{T})^{-3 / 2}=0.5085 \mathrm{M}^{-1 / 2} \quad \text { and } \quad \mathrm{B}=3.29 \mathrm{~nm}^{-1} \mathrm{M}^{-1 / 2}
$$




\section{Appendix C. Mathematical Relationships}

Appendix C.1. Index Transformations and Special Values for EPs

Concerning the equivalence points, there are two sorts of indices, $j$ and $n$, which originate from two different fields. The integer $j$ is the index that labels all acid-relevant quantities (in the 1-component system): the acid species [j], the acidity constants $\mathrm{pK}_{\mathrm{j}}$, and the ionization fractions $a_{j}$. In contrast, the index $n$ is a parameter of the 3-component system that confines the equivalent fraction $n=C_{B} / C_{T}$ to integer and half-integer values. The transformation rule between both index types is simple:

$$
n=j \text { for EPs and } n=j-\frac{1}{2} \text { for semi-EPs }
$$

Table A1 lists some useful relations between equivalence points, acidity constants $\mathrm{pK}_{\mathrm{j}}$, ionization fractions $a_{j}$, and moments $Y_{L}$.

Table A1. Special values of $a_{j}$ and $Y_{L}$ at equivalence points.

\begin{tabular}{ll}
\hline $\begin{array}{l}\text { semi-EP } \\
\text { for Half-Integer } \mathbf{n}\left(\mathbf{j}=\mathbf{n}+\frac{1}{2}\right)\end{array}$ & $\begin{array}{l}\mathrm{EP}_{\mathbf{n}} \\
\text { for Integer } \mathbf{n}(\mathbf{j}=\mathbf{n})\end{array}$ \\
\hline $\mathrm{pH}_{\mathrm{n}}=\mathrm{pK}_{\mathrm{j}}$ & $\mathrm{pH}_{\mathrm{n}}=\mathrm{pH}_{\mathrm{j}} \equiv \frac{1}{2}\left(\mathrm{pK}_{\mathrm{j}}+\mathrm{pK}_{\mathrm{j}+1}\right)$ \\
$\mathrm{a}_{\mathrm{j}}=\mathrm{a}_{\mathrm{j}-1} \approx \frac{1}{2}$ & $\mathrm{a}_{\mathrm{j}}=1-2 \mathrm{a}_{\mathrm{j}-1}(\approx 1)$ \\
$\mathrm{Y}_{\mathrm{L}}=\frac{1}{2}\left\{(\mathrm{j}-1)^{\mathrm{L}}+\mathrm{j}^{\mathrm{L}}\right\}$ & $\mathrm{Y}_{\mathrm{L}} \approx \mathrm{j}^{\mathrm{L}}$ \\
$\mathrm{Y}_{\mathrm{L}}\left(\mathrm{pK}_{1}\right)=\frac{1}{2}$ & $\mathrm{Y}_{\mathrm{L}}\left(\mathrm{pH}_{1}\right)=1$ \\
$\mathrm{Y}_{\mathrm{L}}\left(\mathrm{pK}_{2}\right)=\frac{1}{2}\left(1+2^{\mathrm{L}}\right)$ & $\mathrm{Y}_{\mathrm{L}}\left(\mathrm{pH}_{2}\right)=2^{\mathrm{L}}$ \\
$\mathrm{Y}_{\mathrm{L}}\left(\mathrm{pK}_{3}\right)=\frac{1}{2}\left(2^{\mathrm{L}}+3^{\mathrm{L}}\right)$ & $\mathrm{Y}_{\mathrm{L}}\left(\mathrm{pH}_{3}\right)=3^{\mathrm{L}}$ \\
$\mathrm{Y}_{1}\left(\mathrm{pK}_{\mathrm{j}}\right)=\mathrm{j}-\frac{1}{2}$ & $\mathrm{Y}_{1}\left(\mathrm{pH}_{\mathrm{j}}\right)=\mathrm{j}$ \\
$\mathrm{Y}_{2}\left(\mathrm{pK}_{\mathrm{j}}\right)=\mathrm{j}(\mathrm{j}-1)+\frac{1}{2}$ & $\mathrm{Y}_{2}\left(\mathrm{pH}_{\mathrm{j}}\right)=\mathrm{j}^{2}$ \\
\hline
\end{tabular}

\section{Appendix C.2. pH Derivatives}

The following list contains a set of important $\mathrm{pH}$ derivations:

$$
\begin{aligned}
& \frac{\mathrm{dx}}{\mathrm{dpH}}=(-\ln 10) \mathrm{x} \\
& \frac{\mathrm{d}^{\mathrm{k}} \mathrm{x}}{\mathrm{d} \mathrm{pH}^{\mathrm{k}}}=(-\ln 10)^{\mathrm{k}} \mathrm{x} \\
& \frac{\mathrm{df}(\mathrm{x})}{\mathrm{d} \mathrm{pH}}=(-\ln 10) \frac{\mathrm{df}(\mathrm{x})}{\mathrm{dx}} \\
& \frac{\mathrm{d} \mathrm{w}(\mathrm{x})}{\mathrm{dpH}}=(\ln 10)(\mathrm{w}+2 \mathrm{x}) \\
& \frac{\mathrm{d}^{\mathrm{k}} \mathrm{w}(\mathrm{x})}{\mathrm{dp \textrm {H } ^ { \mathrm { k } }}}=(\ln 10)^{\mathrm{k}}\left\{\begin{array}{cc}
\mathrm{w}+2 \mathrm{x} & \text { for k odd } \\
\mathrm{w} & \text { for k even }
\end{array}\right. \\
& \frac{\mathrm{da}_{0}(\mathrm{x})}{\mathrm{d} \mathrm{pH}}=(-\ln 10) \mathrm{Y}_{1} \mathrm{a}_{0} \\
& \frac{d a_{j}(x)}{d p H}=(-\ln 10)\left(Y_{1}-j\right) a_{j} \\
& \frac{\mathrm{d} \ln \mathrm{a}_{\mathrm{j}}}{\mathrm{d} \ln \mathrm{x}}=\mathrm{Y}_{1}-\mathrm{j} \\
& \frac{d^{2} a_{j}(x)}{d \mathrm{pH}^{2}}=(-\ln 10)^{2}\left\{\left(Y_{1}^{2}-Y_{2}\right)+\left(Y_{1}-j\right)^{2}\right\} a_{j} \\
& \frac{\mathrm{dY}_{1}(\mathrm{x})}{\mathrm{dpH}}=(-\ln 10)\left(\mathrm{Y}_{1}^{2}-\mathrm{Y}_{2}\right) \\
& \frac{\mathrm{d}^{2} \mathrm{Y}_{1}(\mathrm{x})}{\mathrm{d} \mathrm{pH}^{2}}=(-\ln 10)^{2}\left(2 \mathrm{Y}_{1}{ }^{3}-3 \mathrm{Y}_{1} \mathrm{Y}_{2}+\mathrm{Y}_{3}\right) \\
& \frac{d^{3} Y_{1}(x)}{d \mathrm{pH}^{3}}=(-\ln 10)^{3}\left(6 \mathrm{Y}_{1}^{4}-12 \mathrm{Y}_{2} \mathrm{Y}_{1}^{2}+4 \mathrm{Y}_{3} \mathrm{Y}_{1}+3 \mathrm{Y}_{2}{ }^{2}-\mathrm{Y}_{4}\right) \\
& \frac{\mathrm{dY}_{\mathrm{L}}(\mathrm{x})}{\mathrm{d} \mathrm{pH}}=(-\ln 10)\left(\mathrm{Y}_{1} \mathrm{Y}_{\mathrm{L}}-\mathrm{Y}_{\mathrm{L}+1}\right)
\end{aligned}
$$




\section{References}

1. Stumm, W.; Morgan, J.J. Aquatic Chemistry, 3rd ed.; John Wiley \& Sons: New York, NY, USA, 1996; ISBN 978-0-471-51185-4.

2. Morel, F.M.M.; Hering, J.G. Principles and Applications of Aquatic Chemistry; Wiley: New York, NY, USA, 1993; ISBN 978-0-47154896-6.

3. Appelo, C.; Postma, D. Geochemistry, Groundwater and Pollution, 2nd ed.; Routledge: Boca Raton, FL, USA, 2010; ISBN 978-0-41536428-7.

4. Butler, J.N. Ionic Equilibrium: Solubility and pH Calculations, Rev; Wiley: New York, NY, USA, 1998 ; ISBN 0471585262.

5. Harris, D.C. Quantitative Chemical Analysis, 8th ed.; Freeman Custom Publishing: New York, NY, USA, $2010 ;$ ISBN 1429264845.

6. Hunter, K.A. Acid-Base Chemistry of Aquatic Systems: An Introduction to the Chemistry of Acid-Base Equilibria with Emphasis on the Carbon Dioxide System in Natural Waters; Department of Chemistry, University of Otago: Dunedin, New Zealand, 1998.

7. Kahlert, H.; Scholz, F. Acid-Base Diagrams; Springer: Berlin/Heidelberg, Germany, 2013; ISBN 978-3-642-37901-7.

8. Pardue, H.L.; Odeh, I.N.; Tesfai, T.M. Unified Approximations: A New Approach for Monoprotic Weak Acid-Base Equilibria. J. Chem. Educ. 2004, 81, 1367. [CrossRef]

9. Casado-Riobó, A. A More Rational Treatment of the Acid-Base Equilibria Applying the Proton Condition in Equilibrium. How the Protons in Equilibria are Additive: Dissolutions of Acids. Crit. Rev. Anal. Chem. 2005, 35, 289-299. [CrossRef]

10. Hofmann, A.F.; Soetaert, K.; Middelburg, J.J.; Meysman, F.J.R. AquaEnv: An Aquatic Acid-Base Modelling Environment in R. Aquat Geochem. 2010, 16, 507-546. [CrossRef]

11. Parkhust, D.L.; Appelo, C. Description of Input and Examples for PHREEQC Version 3: A Computer Program for Speciation, BatchReaction, One-Dimensional Transport, and Inverse Geochemical Calculations; US Geological Survey: Denver, CO, USA, 2013.

12. Kulik, D.A.; Wagner, T.; Dmytrieva, S.V.; Kosakowski, G.; Hingerl, F.F.; Chudnenko, K.V.; Berner, U.R. GEM-Selektor geochemical modeling package: Revised algorithm and GEMS3K numerical kernel for coupled simulation codes. Comput. Geosci. 2012. [CrossRef]

13. Koukkari, P.; Pajarre, R. A Gibbs energy minimization method for constrained and partial equilibria. Pure Appl. Chem. 2011, 83, 1243-1254. [CrossRef]

14. King, D.W.; Kester, D.R. A general approach for calculating polyprotic acid speciation and buffer capacity. J. Chem. Educ. 1990, 67, 932. [CrossRef]

15. Weltin, E. Calculating Equilibrium Concentrations for Stepwise Binding of Ligands and Polyprotic Acid-Base Systems: A General Numerical Method to Solve Multistep Equilibrium Problems. J. Chem. Educ. 1993, 70, 568. [CrossRef]

16. Rodriguez, J.L.; Loparo, K.A. Modeling and identification of $\mathrm{pH}$ processes. In Proceedings of the 2004 American Control Conference, Boston, MA, USA, 30 June-2 July 2004; IEEE: Piscataway, NJ, USA, 2004; Volume 6, pp. 5483-5488, ISBN 0-7803-8335-4.

17. Hurek, J.; Nackiewicz, J. A Simple Method for the Consecutive Determination of Protonation Constants through Evaluation of Formation Curves. J. Chem. Educ. 2013, 90, 604-608. [CrossRef]

18. Mioni, R.; Mioni, G. A Mathematical Model of pH, Based on the Total Stoichiometric Concentration of Acids, Bases and Ampholytes Dissolved in Water. Scand. J. Clin. Lab. Investig. 2015, 75, 452-469. [CrossRef]

19. Gambi, A.; Toniolo, R. Acid-Base Logarithmic Diagrams with Computer Algebra Systems. ChemTexts 2016, 2, 9. [CrossRef]

20. Simms, H.S. Dissociation of Polyvalent Substances II. Relation of Constants to Chemical Structure. J. Am. Chem. Soc. 1926, 48 , 1251-1261. [CrossRef]

21. Pehrsson, L. Acid-base titrations by stepwise addition of equal volumes of titrant with special reference to automatic titrations-II Theory of titration of mixtures of acids, polyprotic acids, acids in mixture with weak bases, and ampholytes. Talanta 1976, 23, 781-788. [CrossRef]

22. de Levie, R. The Formalism of Titration Theory. Chem. Educator 2001, 6, 272-276. [CrossRef]

23. Jano, I.; Hardcastle, J.; Jano, L.A.; Bates, K.R.; McCreary, H.E. General Equation for Determining the Dissociation Constants of Polyprotic Acids and Bases from Additive Properties: Part III. Calculation of Errors. Anal. Chim. Acta 2001, 428, 309-321. [CrossRef]

24. Khan, A. A simple method for analysis of titration curves of polyprotic acids. Nucleus 2015, 51, 448-454.

25. Asuero, A.G. Buffer Capacity of a Polyprotic Acid: First Derivative of the Buffer Capacity and pKa Values of Single and Overlapping Equilibria. Crit. Rev. Anal. Chem. 2007, 37, 269-301. [CrossRef]

26. Asuero, A.G.; Michałowski, T. Comprehensive Formulation of Titration Curves for Complex Acid-Base Systems and Its Analytical Implications. Crit. Rev. Anal. Chem. 2011, 41, 151-187. [CrossRef]

27. Michałowski, T.; Asuero, A.G. New Approaches in Modeling Carbonate Alkalinity and Total Alkalinity. Crit. Rev. Anal. Chem. 2012, 42, 220-244. [CrossRef]

28. Michałowska-Kaczmarczyk, A.M.; Michałowski, T. Dynamic Buffer Capacity in Acid-Base Systems. J. Solut. Chem. 2015, 44, 1256-1266. [CrossRef] [PubMed]

29. Kaczmarczyk, A.M.M.; Kucab, A.S.; Asuero, A.G.; Michalowski, T. The Simms Constants as Parameters in Hyperbolic Functions Related to Acid-Base Titration Curves. J. Chem. Appl. Chem. Eng. 2018, 2. [CrossRef]

30. Michalowska-Kaczmarczyk, A.M.; Michalowski, T. Dynamic buffer capacity versus alkalinity. Formulation in terms of Simms constants idea. Biomed. Sci. Eng. 2020, 6, 1-9. [CrossRef]

31. Schellman, J.A. Macromolecular binding. Biopolymers 1975, 14, 999-1018. [CrossRef] 
32. Wyman, J.; Gill, S.J. Binding and Linkage: Functionnal Chemistry of Biological Molecules; University Science Books: Mill Valley, CA, USA, 1990; ISBN 9780935702569.

33. Onufriev, A.; Case, D.A.; Ullmann, G.M. A novel view of pH titration in biomolecules. Biochemistry 2001, 40, 3413-3419. [CrossRef] [PubMed]

34. Ullmann, G.M. Relations between Protonation Constants and Titration Curves in Polyprotic Acids: A Critical View. J. Phys. Chem. B 2003, 107, 1263-1271. [CrossRef]

35. Allison, J.D.; Brown, D.S.; Novo-Gradac, K.J. MINTEQA2/PRODEFA2, A Geochemical Assessment Model for Environmental Systems: User Manual Supplement for Version 4.0; EPA: Washington, DC, USA, 1998.

36. Ball, J.W.; Nordstrom, D.K. WATEQ4F-User's Manual with Revised Thermodynamic Data Base and Test Cases for Calculating Speciation of Major, Trace and Redox Elements in Natural Waters; US Geological Survey: Denver, CO, USA, 1991.

37. Reif, F. Fundamentals of Statistical and Thermal Physics; McGraw-Hill: Boston, MA, USA, 1965; ISBN 978-0-07-051800-1.

38. Kittel, C. Introduction to Solid State Physics, 4th ed.; John Wiley \& Sons Ltd.: Hoboken, NJ, USA, 1971; ISBN 978-0-471-14286-7.

39. Millero, F.J. Thermodynamics of the Carbon Dioxide System in the Oceans. Geochim. Cosmochim. Acta 1995, 59, 661-677. [CrossRef]

40. RES ${ }^{3}$ T- Rossendorf Expert System for Surface and Sorption Thermodynamics. Available online: https://www.hzdr.de/db/res3t. login (accessed on 15 August 2019). 